Universidad de Lima

Facultad de Derecho

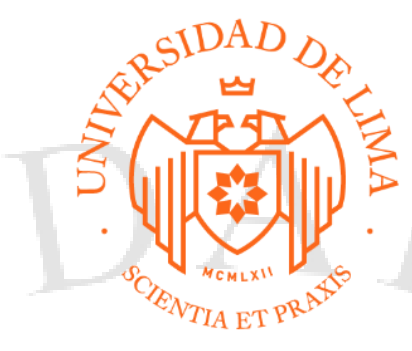

\title{
"LA PARTICIPACIÓN DEL SECTOR PRIVADO PARA LA REMEDIACIÓN DE LOS PASIVOS AMBIENTALES MINEROS BAJO ADMINISTRACIÓN DEL ESTADO"
}

\author{
Tesis para optar el Título Profesional de Abogado \\ Jimena De Las Casas Carcovich \\ Código: 20120410 \\ Asesor
}

Carlos Andaluz Westreicher

Lima-Perú

Abril 2019 


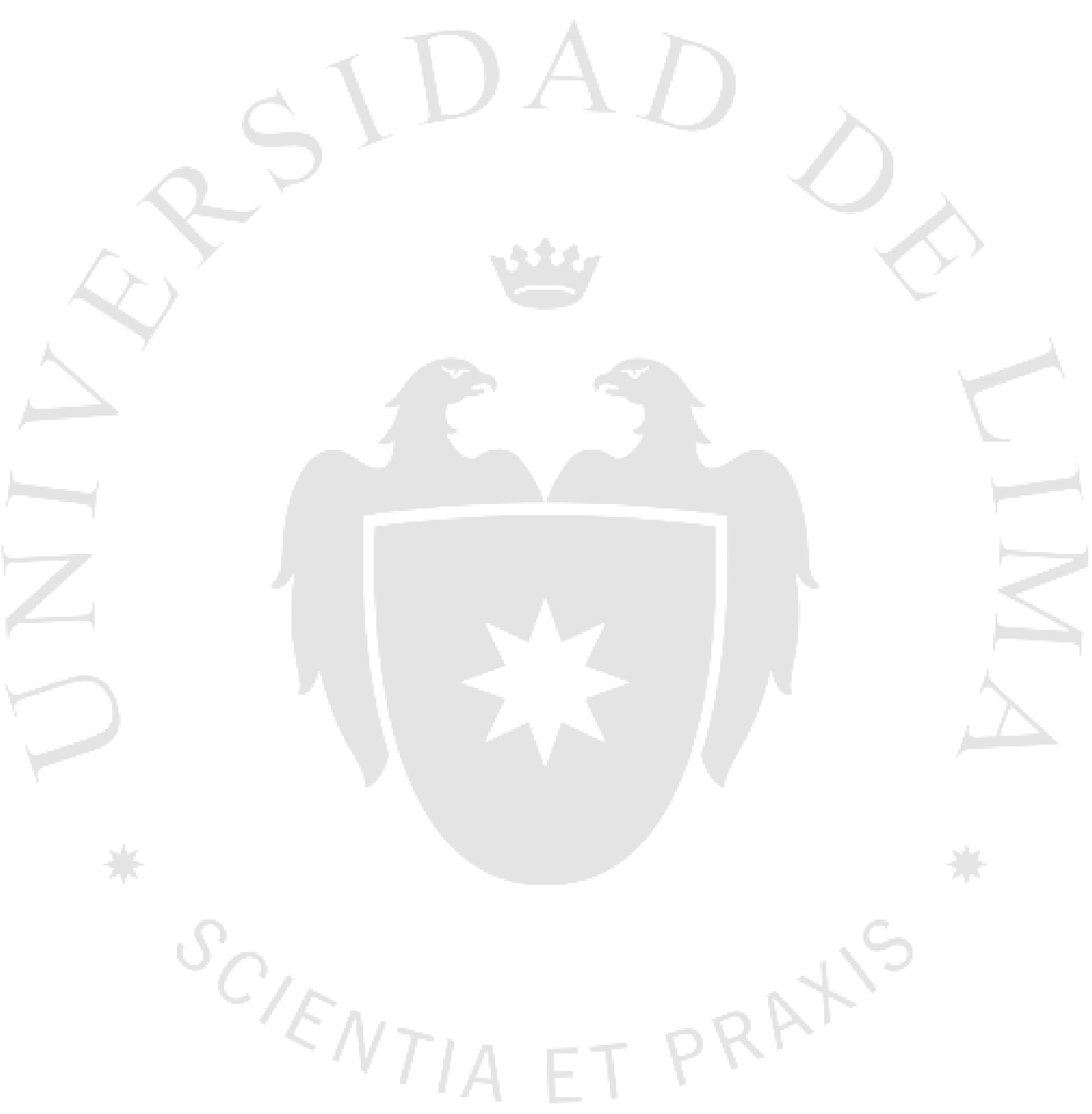




\section{"LA PARTICIPACIÓN DEL SECTOR}

\section{PRIVADO PARA LA REMEDIACIÓN DE LOS}

PASIVOS AMBIENTALES MINEROS BAJO

ADMINISTRACIÓN DEL ESTADO" 


\section{TABLA DE CONTENIDO}

$\begin{array}{ll}\text { TABLA DE ACRÓNIMOS Y SIGLAS } & 7\end{array}$

INTRODUCCIÓN

CAPÍTULO 1.- DELIMITACIÓN TEMÁTICA

CAPÍTULO 2.- LA EFICIENCIA DE LA GOBERNANZA ACTUAL DE 13

LOS PASIVOS AMBIENTALES MINEROS BAJO ADMINISTRACIÓN DEL ESTADO

2.1. Presentación de los Pasivos Ambientales Mineros (PAM) $\mathbf{1 3}$

2.2. Los derechos fundamentales afectados por los PAM, y los principios $\mathbf{1 5}$ ambientales aplicables en su gestión

2.2.1. Derechos fundamentales afectados $\quad \mathbf{1 5}$

2.2.2. Principios ambientales aplicables 19

2.3. Regulación de los PAM en el Perú: Introducción del marco legal 20 aplicable

2.3.1. Identificación de Responsables $\quad \mathbf{2 1}$

2.3.2. Remediación del PAM $\quad \mathbf{2 3}$

2.3.3. Controles Posteriores $\quad 26$

2.4. Presentación de la empresa pública de derecho privado, Activos $\mathbf{2 8}$ Mineros S.A.C y análisis de su gestión

2.4.1. Creación de Activos Mineros S.A.C. 28

2.4.2. Financiamiento de Activos Mineros S.A.C. 32

2.4.3. Eficiencia de la gestión de Activos Mineros S.A.C. 34

2.5. Eficiencia del marco normativo aplicable para el manejo de Pasivos $\mathbf{3 8}$ Ambientales Mineros bajo administración del estado en el Perú

2.5.1. Financiamiento $\mathbf{3 8}$

2.5.2. Institucionalidad $\quad 39$

2.5.3. Dificultades para la Participación del sector privado $\quad \mathbf{4 0}$ 
2.6. Conclusiones Preliminares

CAPÍTULO 3.- LEGISLACIÓN COMPARADA EN LA GESTIÓN DE

PAM Y EN LA SIMPLIFICACIÓN ADMINISTRATIVA

3.1. Tratamiento de los PAM en la experiencia internacional 47

3.1.1. Estados Unidos

3.1.2. Canadá

3.1.3. Australia 58

3.2. Ejemplos de simplificación administrativa en los países de la organización para la cooperación y el desarrollo económico

3.2.1. Australia 66

3.2.2. Francia 68

3.2.3. México 69

3.3. Conclusiones Preliminares

CAPÍTULO 4.- MODIFICACIONES A LA REGULACIÓN ACTUAL

DE LOS PAM BAJO ADMINISTRACIÓN DEL ESTADO

4.1. La Inversión Privada en la remediación de los PAM bajo

74 administración del Estado

4.1.1. La Privatización

4.1.2. Las Asociaciones Público Privadas

4.1.3. El mecanismo de Obras por Impuesto

4.2. La simplificación administrativa de los procedimientos

87 administrativos vinculados a la gestión de los PAM

4.2.1. La restricción de las entidades públicas involucradas

4.2.2. La evaluación de resultados por un órgano independiente

4.3. El rol del Estado en la remediación de los PAM

4.3.1. La redistribución tributaria para el financiamiento de los PAM bajo administración del Estado

4.3.2. El papel de las multas por infracciones ambientales 


\section{ÍNDICE DE TABLAS}

Tabla 1. PAM asumidos por el Estado

Tabla 2. Gestión Pasivos Ambientales en Perú y Estados Unidos $\quad 50$

Tabla 3. Definiciones de Mina Huérfana y Abandona en las distintas provincias $\mathbf{5 3}$ canadienses

Tabla 4. Canadá: Programas y Costos para la Remediación de Sitios 57 Contaminados

Tabla 5. Comparación de las modificatorias propuestas en los Proyectos de Ley $\mathrm{N}^{\mathrm{o}} 2045 / 2017-\mathrm{CR}$ y No $2484 / 2017-\mathrm{CR}$

Tabla 6. Pasos a seguir para la remediación voluntaria de PAM

Tabla 7. Propuesta de mejoras al marco normativo vigente 


\section{ÍNDICE DE GRÁFICOS}

Gráfico 1. PAM bajo administración de AMSAC con Plan de Cierre

aprobado

Gráfico 2. Balance del Fondo Superfund entre los Años Fiscales 1994 y 2009

50

Gráfico 3. Minas Abandonadas en Australia

Gráfico 4. Títulos Habilitantes a integrarse en la Certificación Ambiental

Global

Gráfico 5. Evaluación de anteproyectos regulatorios por parte de la COFEMER

Gráfico 6. Distribución del canon minero 


\section{TABLA DE ACRÓNIMOS Y SIGLAS}

Activos Mineros S.A.C.

AMSAC

Agencia de Protección Ambiental de Estados Unidos EPA

Asociaciones Públicas Privadas

APP

Certificados de Inversión Pública Regional y Local o Nacional

CIPRL

Comisión de Simplificación Administrativa

COSA

Comisión Económica para América Latina y el Caribe

CEPAL

Comisión Federal de Mejora Regulatoria

Dirección General de Asuntos Ambientales Mineros

Dirección General de Minería

COFEMER

DGAAM

DGM

Direcciones Regionales de Energía y Minas

DREM

Empresa Minera del Centro del Perú S.A.

CENTROMIN

EFA

Entidades de Fiscalización Ambiental

FONAM

Fondo Nacional del Ambiente

AMWG

Grupo de Trabajo para Minas Abandonadas

HRS

Hazard Ranking System

NAOMI

Iniciativa Nacional de Minas Huérfanas/Abandonadas

INGEMMET

Instituto Geológico, Minero y Metalúrgico

LGA

Ley General del Ambiente

LEY

Ley de Responsabilidad, Compensación y Recuperación

Ambiental

CERCLA

Marco Estratégico para Minas Abandonadas en la Industria Minera

Ministerio de Energía y Minas

MEM

National Priorities List

NPL 
Obras por Impuesto

OXI

Organismo de Evaluación y Fiscalización Ambiental

OEFA

Organismo Supervisor de la Inversión en Energía y Minería

OSINERGMIN

Organización para la Cooperación y Desarrollo Económico

OCDE

Pasivos Ambientales Mineros

PAM

Plan de Cierre Pasivos Ambientales Mineros

PCPAM

Producto Interno Bruto

PIB

Programa de Adecuación y Manejo Ambiental

PAMA

Reglamento de Pasivos Ambientales de la Actividad Minera

Servicio de Investigación del Congreso

RPAM

CRS

Servicio Nacional de Certificación Ambiental para las SENACE

Inversiones Sostenibles

Sitios Mineros Abandonados

AML

Textos Únicos de Procedimientos Administrativos

TUPA

Volcan Compañía Minera S.A.

VOLCAN 


\section{INTRODUCCIÓN}

Las prácticas mineras de alto impacto que datan desde la época colonial y que se realizaban sin mayores exigencies ambientales han generado en el Perú un alto número de Pasivos Ambientales Mineros (PAM), los cuales vendrían a ser todo impacto negativo generado por operaciones mineras abandonadas, con o sin dueño u operador identificable. Estos PAM significan un riesgo para la salud pública, la calidad de las aguas y para la flora y fauna. Incluso, han llevado a declaratorias de Emergencia Ambiental de diversas localidades afectadas, tal como sucedió en el distrito de Simón Bolivar en la provincia y departamento de Pasco.

De acuerdo con la Comisión Económica para América Latina y el Caribe (CEPAL), el Perú fue el primer país en América Latina que estableció un marco jurídico específico para la regulación de los PAM, buscando la remediación de los mismos y la mitigación de los impactos negativos a la salud de la población y al ecosistema circundante.

Desde el 2004 (año en el cual se aprobó la Ley N 28271, Ley que regula los pasivos ambientales de la actividad minera), el Perú ha logrado avances importantes en la gestión de los pasivos ambientales mineros. Sin embargo, aún queda mucho por recorrer. De acuerdo con el Inventario de PAM actualizado al año 2016 de la Dirección General de Minería del Ministerio de Energía y Minas, existían a lo largo del territorio nacional 8,854 pasivos de actividades mineras pasadas. De estos, 683 habían sido encargados al Estado para su remediación, pero al 2016 contaban con Plan de Cierre aprobado únicamente 12 de ellos, lo cual no necesariamente significa la ejecución del instrumento.

El objetivo de esta investigación es contribuir a las condiciones de gobernabilidad de los PAM que se encuentran bajo administración del Estado, aportando mejoras al marco normativo focalizadas en la promoción de la participación del sector privado en la remediación de los PAM y en la simplificación administrativa de los procesos vinculados en su gestión. 
Los PAM que se encuentran bajo administración del Estado son gestionados por la empresa estatal de derecho privado Activos Mineros S.A.C. (AMSAC), la cual no cuenta con el financiamiento suficiente ni las capacidades técnicas necesarias para llevar a cabo esta importante tarea. Incluso, gran parte de los recursos provienen de donaciones de la cooperación internacional al Estado para la remediación de los PAM, la cual es una fuente inestable y variable.

El segundo capítulo de la presente investigación, identifica la regulación existente vinculada a la remediación de los PAM bajo administración del Estado, analizando la eficiencia del marco normativo actual así como el rol que ocupa Activos Mineros S.A.C. en esta tarea, llegando finalmente a conclusiones sobre la extensión del cumplimiento de sus funciones.

A fin de identificar las mejores propuestas normativas, el tercer capítulo revisa la legislación comparada vinculada no solo a la gestión de los PAM, sino también la relacionada a los procedimientos de simplificación administrativa seguidos por los países integrantes de la Organización para la Cooperación y Desarrollo Económico (OCDE).

Finalmente, el cuarto capítulo de esta investigación propone cambios a la regulación existente, aplicando las modalidades de inversión privada en la gestión de los PAM bajo administración del Estado y planteando reformas jurídicas vinculadas a la simplificación administrativa, que beneficiarían el desarrollo sostenible del sector minero. Por último, hace un análisis del rol del Estado en la remediación de los PAM y de las fuentes de financiamiento que se encuentran a su disposición, y que podrían redireccionarse para esta importante tarea. 


\section{CAPÍTULO UNO: DELIMITACIÓN TEMÁTICA}

\subsection{Objetivo General}

El objetivo general de la presente investigación es el de identificar distintas maneras en las cuales la participación del sector privado favorecería la remediación de los pasivos ambientales mineros bajo administración del Estado, proponiendo modificaciones al marco regulatorio existente.

\subsection{Objetivos Específicos}

La presente investigación considera su desarrollo temático en torno a los siguientes objetivos específicos:

i. Identificar las fallas existentes en el tratamiento legal actual de la remediación de pasivos ambientales mineros bajo administración del Estado.

ii. Identificar el tratamiento de los pasivos ambientales mineros en la legislación comparada.

iii. Presentar modalidades de inversión privada en la remediación los pasivos ambientales mineros.

iv. Proponer la simplificación de los procedimientos administrativos vinculados a la gestión de los pasivos ambientales mineros, a fin de promover la participación del sector privado.

v. Proponer mejoras al financiamiento de la remediación los pasivos ambientales mineros.

vi. Demostrar los beneficios de una participación limitada por parte del Estado en la remediación de los pasivos ambientales mineros.

\subsection{Hipótesis de Investigación}


Habiéndose planteado los objetivos generales y específicos de la presente investigación, se presenta la siguiente hipótesis: "La participación del sector privado en la gestión de los Pasivos Ambientales Mineros bajo administración del Estado, aumentaría las actividades de remediación de los mismos."

La hipótesis de la investigación en cuestión califica como una hipótesis ex ante ya que, al sustentarla, la investigación se basará en un hecho que aún no ha sucedido; el aumento de las actividades de remediación de los PAM bajo administración del Estado. Sin embargo, se presume que ello sucederá como consecuencia de un hecho empírico: el aumento en la Inversión Privada.

Esta investigación es de importancia al ofrecer no únicamente un análisis de la regulación actual, sino también propone cambios a la misma aplicando modalidades de inversión privada en la gestión de los PAM bajo administración del Estado y planteando reformas jurídicas que beneficiarían el desarrollo sostenible del sector minero.

\subsection{Metodología}

La presente investigación utilizará el método sintético, por el cual se reconstruye un todo, a partir de los elementos distinguidos o desmembrados por el análisis. Se identificarán y analizarán como elementos distinguidos:

El concepto de PAM y su regulación.

- El tratamiento y financiamiento actual de los pasivos que se encuentran bajo administración del Estado.

- El tratamiento y financiamiento de los PAM en otros países con alta dependencia económica de las actividades mineras, y la manera cómo se fomenta la participación del sector privado.

- Ejemplos de simplificación administrativa en la legislación comparada que podrían utilizarse procedimientos administrados vinculados a la gestión de los pasivos ambientales mineros.

Finalmente, se unen los conceptos y, en atención a la hipótesis, se demostrará la conveniencia de la participación del sector privado en la remediación de los pasivos ambientales mineros. 


\section{CAPÍTULO DOS: LA EFICIENCIA DE LA \\ GOBERNANZA ACTUAL DE LOS PASIVOS \\ AMBIENTALES MINEROS BAJO ADMINISTRACIÓN \\ DEL ESTADO}

\subsection{Presentación de los Pasivos Ambientales Mineros (PAM)}

Cinco años después de iniciada la conquista del Perú, comenzaron las primeras explotaciones mineras españolas. La minería se volvió una de las actividades económicas más importante para la recaudación en el Virreinato peruano durante el siglo XVII, y siguió en crecimiento durante el último cuarto del siglo XVI. (Díaz, Arana, Torres, Patrucco, 2016, p 129)

Sin embargo, hacia 1700 , la producción minera pasó por altibajos, finalizando en un franco declive. En ese sentido, durante la Colonia algunas minas debieron ser abandonadas, por agotamiento del yacimiento, costos o por limitaciones tecnológicas, y para fines de esta etapa de la historia del Perú; se encontraban detenidas 1124 minas de plata y 57 minas de oro, lo cual tuvo impactos severos en la contaminación ambiental del aire, suelo y aguas del área de influencia de los proyectos. Posteriormente, en los primeros años de la República (1750-1850) la minería se encontraba en crisis, y se tomaron medidas para su reactivación como la creación de la Dirección General de Minería en 1821, y la licitación de minas abandonadas. (Díaz, et al., 2016, p 130-132)

Con la importancia de esta actividad para la economía y la capacidad productiva del Perú, la legislación minera en la época de la colonia y en los primeros años de la República no contemplaba disposiciones de protección del medio ambiente, dándole prioridad a la minería frente a otras actividades más compatibles con el mismo. Por ejemplo, las Ordenanzas de Minas del Virrey Toledo del año 1574, otorgaban derecho de uso preferente sobre bosques y fuentes de agua para el abastecimiento de las operaciones mineras. En la época de la República, se mantuvo la legislación minera colonial, protegiendo únicamente el derecho de libertad de las personas. En las primeras décadas 
de dicha época, la legislación ambiental era escaza y se centraba básicamente en la prestación de servicios de limpieza pública y gestión de aguas residuales. Asimismo, la capacidad de respuesta a los problemas ambientales era insuficiente dada la debilidad política de las entidades responsables y los escasos recursos con los que se contaba. Es recién a partir de los años noventa que se instituye un ordenamiento legal que promueve la protección del medio ambiente. El primer hito fue la promulgación del Código del Medio Ambiente y Los Recursos Naturales, mediante el Decreto Legislativo $N^{\circ} 613$ del 07 de septiembre del año 1990. (Díaz, et al., 2016, p 150- 151).

Asimismo, fue recién en la Constitución Política del Perú de 1979 que se estableció como patrimonio de la nación a los recursos naturales, renovables y no renovables; y en la de 1993 que se exige una ley orgánica para su regulación, lo cual expresa la importancia asignada en estas normas fundamentales a este componente de la naturaleza, en relación con el desarrollo sostenible del país.

En este contexto, mediante el Decreto Supremo No 016-93-EM, publicado el 15 de mayo de 1993, se aprobó el Reglamento para la Protección Ambiental en las Actividades Minero Metalúrgicas y el 14 de octubre de 2003, se aprobó la Ley $\mathrm{N}^{\circ}$ 28090, Ley que regula el Cierre de Minas.

La existencia de prácticas mineras de alto impacto que datan desde la época colonial, y que se realizaban sin normas precisas que regulen el cierre de sus minas, así como el manejo de sus residuos; ha llevado a la generación de Pasivos Ambientales Mineros (PAM), los cuales vendrían a ser todo impacto negativo generado por operaciones mineras abandonadas, con o sin dueño u operador identificable. El impacto de los PAM en el medio ambiente y la salud pública es significativo, al degradar la flora y fauna, generar riesgo a la salud pública, afectar la calidad de aguas superficiales y subterráneas y limitar el uso del suelo.

De acuerdo con la Comisión Económica para América Latina y el Caribe (CEPAL), el Perú fue el primer país en América Latina que estableció un marco jurídico específico para la regulación de los PAM. Esto, de acuerdo con la referida institución, fue 
consecuencia de la fuerte resistencia de la sociedad civil ante nuevos proyectos mineros, y a la negativa percepción pública hacia la actividad. (Oblasser y Chaparro, 2008, p 7).

Respondiendo a esta realidad, el 06 de julio del año 2004 se público la Ley $\mathrm{N}^{\circ}$ 28271, Ley que regula los pasivos ambientales de la actividad minera, que define a los PAM de la siguiente manera:

\section{“Artículo 2.- Definición de los Pasivos Ambientales}

Son considerados pasivos ambientales aquellas instalaciones, efluentes, emisiones, restos o depósitos de residuos producidos por operaciones mineras, en la actualidad abandonadas o inactivas y que constituyen un riesgo permanente y potencial para la salud de la población, el ecosistema circundante y la propiedad."

\subsection{Los derechos fundamentales afectados por los PAM y los principios ambientales aplicables en su gestión}

\subsubsection{Derechos fundamentales afectados}

Un PAM emblemático en el Perú es el depósito de plata ubicado en Cerro de Pasco, denominado Quiulacocha-Excélsior, de 55 metros de altura y de 200 millones de toneladas acumuladas durante un siglo de explotación minera (El basural de plata más codiciado del mundo está en el Perú, 2016). Es de destacar que este PAM, a la vez de constituir una amenaza a los derechos fundamentales a la salud, ambiente equilibrado y patrimonio, es también una oportunidad de aprovechamiento económico mediante la extracción del mineral que contiene, mediante el uso de las nuevas técnicas para ello.

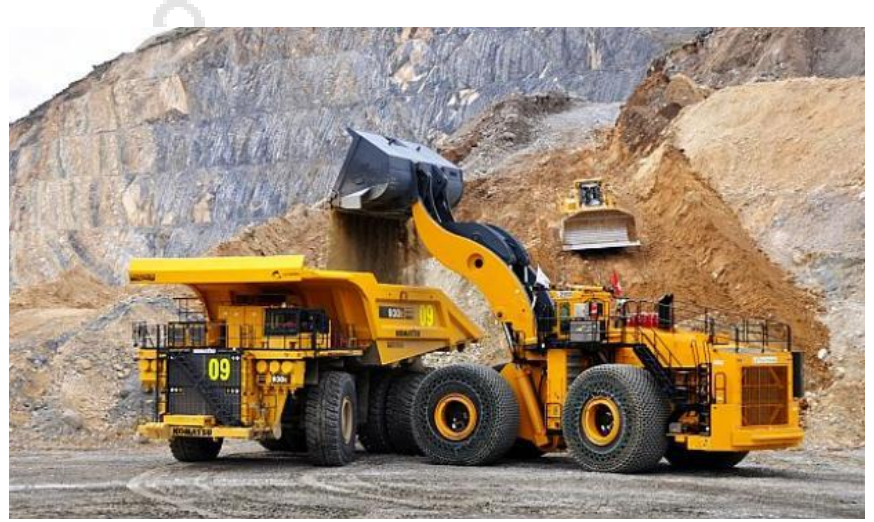

Fuente: El Comercio 
Esta amenaza a los derechos en mención quedan evidenciados, por ejemplo, del texto de la Resolución Ministerial N 177-2012-MINAM, mediante la cual el Ministerio del Ambiente declaró la Emergencia Ambiental a diversas localidades situadas en el distrito de Simón Bolívar, provincia y departamento Pasco, por un plazo de noventa (90) días.

En los considerandos de la referida Resolución se detalló que por Oficio $\mathrm{N}^{\circ} 61$ 2012-ALCALDIA-MDSB/PASCO, el Alcalde de la Municipalidad Distrital de Simón Bolivar solicitó al Ministerio del Ambiente la declaratoria de emergencia ambiental de centros poblados dentro de su jurisdicción, debido a los significativos impactos ambientales negativos producidos por los PAM de relaveras y desmontes.

De otro lado, la Resolución estableció que la Declaratoria de Emergencia Ambiental era necesaria debido a los elevados niveles de concentración de plomo en la sangre en un porcentaje significativo de la población, los cuales estarían asociados al impacto ambiental causado por la actividad minera. Dicha información había sido reportada por el Centro Nacional de Salud Ocupacional y Protección del Ambiente para la Salud.

Adicionalmente a ello, el artículo $2^{\circ}$ de la Resolución Ministerial N ${ }^{\circ}$ 177-2012MINAM aprobó el Plan de Acción Inmediato y de Corto Plazo para la atención de la Emergencia Ambiental de las localidades señaladas. Su ejecución estaba a cargo de las entidades públicas y privadas involucradas, en coordinación con el Gobierno Regional de Pasco y debía darse en un plazo de 90 días.

Entra las actividades a desarrollarse que contemplaba el Plan de Acción, estaban las siguientes:

1. OEFA, debía de desarrollar supervisiones especiales a las actividades mineras de la zona para verificar el cumplimiento de los compromisos asumidos, realizar la evaluación ambiental en ámbito de influencia de las localidades afectadas por actividad minera, e identificar las áreas críticas con presencia de aguas ácidas no tratadas así como las no consideradas en los planes de cierre que sean sometidos a evaluación. 
2. Activos Mineros S.A.C. debía llevar a cabo la neutralización de las Aguas ácidas de la relavera de Quiulacocha y de las filtraciones, la reforestación y forestación de las zonas críticas, la presentación y aprobación de un Plan de Cierre de Pasivos Ambientales de la desmontera excelsior, así como el inicio de las actividades señaladas, y finalmente la implementación de acciones de mitigación

3. El Ministerio de Salud debía desarrollar e implementar un Plan de Promoción de la Salud y un Plan de Intervención Nutricional, que serían dirigidos a la población ubicada en la zona de riesgo, desarrollar planes de vigilancia epidemiológica, de abastecimiento de agua potable, y llevar a cabo el fortalecimiento de los servicios de salud de la zona.

A marzo del 2013, se concluyó con gran parte de las acciones programadas, incluyendo la construcción de canales de captación de aguas ácidas, la forestación de áreas afectadas, la construcción de un cero perimétrico para evitar el acceso a residuos mineros, la pavimentación de vías, se realizaron consultas médicas gratuitas y capacitaciones, proyectos de agua potable y alcantarillado, entre otros. (2013, MINAM) Asimismo, el MEM contribuyó con la aprobación el Plan de Cierre de la Desmontera Excelsior.

Sin embargo, no se culminó el proyecto de cierre o Reaprovechamiento de la relavera, lo que originó la emergencia ambiental en un primer momento.

Ejemplos como el anteriormente descrito evidencian la severa afectación de los PAM a los diversos derechos fundamentales reconocidos en la Constitución Política del Perú, como por ejemplo:

- $\quad$ El derecho a la vida, reconocido en el artículo $2^{\circ}$, inciso 1.

- El derecho a gozar de un ambiente equilibrado y adecuado para el desarrollo de la vida, reconocido en el artículo $2^{\circ}$, inciso 22 .

- El derecho a la protección de la propia salud, la del medio familiar, y la de la comunidad, reconocido en el artículo $7^{\circ}$.

Cabe mencionar que el derecho a gozar de un ambiente equilibrado se complementa con el deber del Estado de "promover el uso sostenible de los recursos naturales" reconocido en el artículo $67^{\circ}$ de la Constitución Política del Perú. 
Entre las afectaciones ambientales más relevantes de los PAM está el daño a las fuentes de agua, por ello la Ley $\mathrm{N}^{\circ}$ 30588, publicada el 22 de junio de 2017, incorporó el artículo $7^{\circ}$-A a la Carta Magna, el cual establece la obligación del Estado de promover "el manejo sostenible del agua, el cual se reconoce como un recurso natural esencial y como tal, constituye un bien público y patrimonio de la Nación". No podemos perder de vista que la calidad de los recursos hídricos- vertebrador de la vida y las actividades económicas- no pueden ser afectados por los PAM sin que el Estado tome las medidas necesarias.

Finalmente, aún cuando el artículo $59^{\circ}$ de la Constitución Política del Perú establece que el Estado garantiza la libertad empresarial, de comercio e industria; también señala, en el mismo artículo, que el "ejercicio de estas libertades no debe ser lesivo a la moral, ni a la salud, ni a la seguridad pública”.

Al respecto, y en relación con el derecho a un medio ambiente sano, el Tribunal Constitucional, en el sexto fundamento de la Sentencia del Expediente 2071-2002AA/TC, ha señalado lo siguiente:

"Debe tenerse presente que, si bien en el ordenamiento constitucional coexisten diversos derechos constitucionales, hay circunstancias que legitiman la restricción de unos derechos en salvaguarda de otros, atendiendo a finalidades superiores del mismo ordenamiento constitucional. Bajo esta perspectiva, si el respeto a los derechos invocados en la demanda (libertad de empresa) supone menoscabar los derechos a la salud y a un medio ambiente sano de los vecinos, convirtiéndolos en irreparables, es evidente que deben prevalecer estos últimos, por estar vinculados al principio de protección al ser humano, contenido en el artículo $1^{\circ}$ de la Constitución Política del Perú, en virtud del cual la defensa de la persona humana y el respeto de su dignidad son el fin supremo de la sociedad y del Estado, y sin cuya vigencia carecerían de sentido todos los demás derechos constitucionales. Es evidente, también, que el interés individual no puede primar sobre el interés colectivo". (Sentencia del Tribunal Constitucional del Expediente $N^{o}$ 2071-2002-AA/TC, 2003) (EI subrayado es agregado propio) 


\subsubsection{Principios ambientales aplicables}

En el año 2005, se aprobó la Ley $\mathrm{N}^{\circ}$ 28611, Ley General del Ambiente (LGA), la cual en su Título Preliminar estableció los principios ambientales que orientan la política, el derecho ambiental y los actos de administración pública. En consecuencia, dichos principios deberán ser tomados en cuenta en la gestión de los PAM.

El Artículo VI de la referida norma introdujo el principio de prevención, de la siguiente manera:

\section{“Artículo VI.- Del principio de prevención}

La gestión ambiental tiene como objetivos prioritarios prevenir, vigilar y evitar la degradación ambiental. Cuando no sea posible eliminar las causas que la generan, se adoptan las medidas de mitigación, recuperación, restauración o eventual compensación, que correspondan.”

Adicionalmente, de acuerdo con el principio precautorio recogido en el artículo VII de la LGA, modificado por la Ley $\mathrm{N}^{\circ} 29050$ (24 de junio de 2007), estas acciones no deben ser tomadas únicamente cuando la existencia daño cuente con certeza científica absoluta, sino que también, ante una hipótesis con base científica que contemple la posibilidad de riesgo de daño grave o irreversible para el ambiente o la salud, deberán adoptarse medidas para conjurarlo; conforme es de verse del siguiente texto:

\section{“Artículo VII.- Del principio precautorio}

Cuando haya indicios razonables de peligro de daño grave o irreversible al ambiente o, a través de éste, a la salud, la ausencia de certeza científica no debe utilizarse como razón para no adoptar o postergar la ejecución de medidas eficaces y eficientes destinadas a evitar o reducir dicho peligro."

En el caso de los PAM, por lo general, la degradación ambiental ya ha ocurrido o está latente, toda vez que son resultados de prácticas mineras pasadas que se realizaron sin que se tome en cuenta este principio. En ese sentido, las medidas a adoptarse deben estar dirigidas a la restauración y mitigación del mismo. 
Bien podría ser que se reputen como inocuos ciertos PAM, hasta que se formula una hipótesis, sobre base científica, que desvirtúe este aserto y establezca su vinculación con un riesgo grave o irreversible para la salud o el ambiente; en cuyo caso la adopción de medidas para conjurarlo, en aplicación del principio precautorio, es indispensable.

En todo caso, las acciones que tome el Estado para la restauración de los PAM extendidos a lo largo del territorio peruano no deben esperar a la comprobación ineludible- con certeza científica- de que ellos implican un peligro grave para el ambiente o la salud. Basta la potencialidad de que se genere este tipo de daños, para que el Estado tome las medidas necesarias para su remediación.

Adicionalmente, en atención a los principios de internalización de costos y de responsabilidad ambiental, recogidos en los artículos VIII y IX de la LGA, respectivamente, quien asuma la remediación del PAM deberá ser, en teoría, el causante del mismo. Según el principio de internalización de costos del mencionado artículo, "toda persona natural o jurídica, pública o privada, debe asumir el costo de los riesgos o daños que genere sobre el ambiente”. Asimismo, según el principio de responsabilidad ambiental "el causante de la degradación del ambiente y de sus componentes, sea una persona natural o jurídica, pública o privada, está obligado a adoptar inexcusablemente las medidas para su restauración”.

En la práctica, estos últimos dos principios no siempre son aplicables, pues dada la antigüedad de los PAM existentes, el responsable no siempre será identificado o no contará con los medios necesarios para asumir las obligaciones de remediación del pasivo.

En dichos casos, el Estado debe priorizar el derecho irrenunciable de toda persona a vivir en un ambiente saludable, equilibrado y adecuado para el pleno desarrollo de la vida; reconocido no solo en la Constitución Política del Perú y en el artículo I de la LGA; sino también en una frondosa legislación ambiental internacional, de la que el Perú es país parte.

\subsection{Regulación de los PAM en el Perú- Introducción al Marco Legal Aplicable}


Los PAM, en el Perú, son regulados principalmente por la Ley $\mathrm{N}^{\circ} 28271$, Ley que regula los pasivos ambientales de la actividad minera; y el Reglamento de Pasivos Ambientales de la Actividad Minera (RPAM), aprobado por Decreto Supremo No 059-2005-EM.

Mediante el Decreto Legislativo No 1042 del 25 de junio de 2008, se modificó la Ley $\mathrm{N}^{\mathrm{o}}$ 28271, introduciendo nuevas modalidades de participación de terceros en la remediación de los PAM. Asimismo, por Decreto Supremo Nº 003-2009-EM se modificó el RPAM, adecuándolo a las nuevas disposiciones de la Ley $\mathrm{N}^{\circ} 28271$.

Finalmente, el Decreto Legislativo $N^{\circ} 1100$, Decreto Legislativo que Regula la Interdicción de la Minería Ilegal en toda la República y establece Medidas Complementarias, del 18 de febrero de 2012, se impone la obligación al Estado de promover la remediación de los PAM causados por minería ilegal.

De una interpretación sistemática de las referidas normas, se evidencia el procedimiento que se menciona a continuación en la gestión de los PAM:

\subsubsection{Identificación de Responsables}

El Ministerio de Energía y Minas (MEM), por intermedio de la Dirección General de Minería (DGM) y en coordinación con la Dirección General de Asuntos Ambientales Mineros (DGAAM) y el Instituto Geológico, Minero y Metalúrgico (INGEMMET), es la entidad encargada de identificar a los responsables de las operaciones mineras que abandonaron depósitos de residuos, labores o instalaciones mineras, generando pasivos ambientales en sus diversas modalidades.

La DGM deberá llevar a cabo un inventario de los PAM existentes, el cual será aprobado por Resolución Ministerial y actualizado constantemente. Los titulares mineros con concesiones vigentes se encuentran obligados a brindar el acceso e información requerida para este fin. Los PAM podrán ser causados tanto por privados como por el propio Estado, a través de empresas de su propiedad. 
De acuerdo con el artículo 20 del RPAM, el Estado asumirá la remediación de los pasivos ambientales en los siguientes casos:

a) Cuando los responsables no han sido identificados

b) En caso una empresa de propiedad del Estado sea responsable en no menos de dos tercios del monto correspondiente a la remediación.

c) Excepcionalmente, en función a la debida tutela del interés público.

Respecto al último caso, el artículo $21^{\circ}$ del referido Reglamento establece lo siguiente:

“Artículo 21.- Criterios para la determinación de las situaciones de interés público

La determinación de las situaciones de interés público que sustenta las acciones de remediación de las áreas con pasivos ambientales mineros por el Estado, se basa en el análisis de riesgos a la salud y seguridad humana, así como al medio ambiente del área afectada por los pasivos ambientales mineros y sus zonas de influencia.

Cuando lo consideren necesario, los órganos competentes del Ministerio de Salud, Agricultura, del Ambiente y los gobiernos regionales y locales podrán solicitar al MEM la invocación del interés público antes mencionado, sustentando su pedido en los informes técnicos correspondientes.”

Asimismo, en mérito al artículo $11^{\circ}$ del Decreto Legislativo $\mathrm{N}^{\circ} 1100$, se impuso la obligación al Estado de promover la remediación de los PAM causados por minería ilegal.

Por lo tanto, son cuatro las circunstancias en las cuales el Estado debe intervenir en la remediación de los PAM:

- Cuando los responsables no han sido identificados

- En caso una empresa de propiedad del Estado sea responsable en no menos de dos tercios del monto correspondiente a la remediación

- En función a la debida tutela del interés público

- Ante PAM causados por minería ilegal. 
De lo establecido en la norma, es posible concluir que la responsabilidad por los PAM se basa en el principio 16 de la Declaración de Río sobre Medio Ambiente y Desarrollo, el cual establece lo siguiente:

"Las autoridades nacionales deberían procurar fomentar la internalización de los costos ambientales y el uso de instrumentos económicos, teniendo en cuenta el criterio de que el que contamina debe, en principio, cargar con los costos de la contaminación, teniendo debidamente en cuenta el interés público y sin distorsionar el comercio ni las inversiones internacionales. ”

Por lo tanto, la responsabilidad del PAM se atribuirá en un principio al causante del mismo, sea este el Estado o un privado. En un primer momento se considerará el factor objetivo de atribución de responsabilidad, no siendo necesario probar la culpa del causante, sino únicamente que la acción efectivamente causó el daño. (Comisión Europa, 2000, p 19)

Excepcionalmente, en caso el causante no sea identificado, por razones de interés público o frente a PAM causados por minería ilegal; no se tomará en cuenta la responsabilidad objetiva con la finalidad de asegurar la restauración del medio ambiente.

\subsubsection{Remediación del PAM}

La remediación, de acuerdo con el RPAM, podrá ser efectuada tanto por el responsable del pasivo o por un tercero que asuma voluntariamente la responsabilidad de remediar. $\mathrm{Al}$ respecto, el artículo 12 del referido reglamento establece lo siguiente:

\section{“Artículo 12.- Modalidades de Remediación voluntaria}

Cualquier persona o entidad, sea titular de concesiones mineras o no, podrá asumir la responsabilidad de remediar voluntariamente pasivos ambientales mineros, inventariados o no, que se encuentren ubicados en su propia concesión minera, de tercero o en áreas de libre denunciabilidad, (...)”

De este modo, el RPAM establece cuatro modalidades de remediación voluntaria; el Plan de Cierre de PAM, el Plan de Cierre de Minas, la re utilización y el re aprovechamiento. 


\section{a) Plan de Cierre de PAM}

El Plan de Cierre de PAM es la modalidad más antigua pues, antes de las modificatorias, se contemplaba en la Ley $\mathrm{N}^{\circ} 28271$ y su reglamento como la única forma de remediar los PAM. (Bailetti, 2008, p 113)

Este instrumento de gestión ambiental se presenta ante el MEM, acreditando la presentación previa de dicho plan ante la autoridad regional competente del área en la que se ubica el pasivo ambiental. Debe ser elaborado a nivel de factibilidad y buscar alcanzar los siguientes objetivos:

- $\quad$ Estabilidad física a largo plazo.

- $\quad$ Estabilidad química a largo plazo.

- $\quad$ Remediación de las áreas afectadas.

- Uso alternativo de áreas o instalaciones.

Determinación de las condiciones del posible uso futuro de dichas áreas o instalaciones.

Para el caso de los remediadores voluntarios, se permite la celebración de convenios de responsabilidad limitada, a fin de que estos se obliguen a determinados compromisos distintos a la presentación regular de un plan de cierre de pasivos. Las posibilidades de limitación son las siguientes:

- Evaluar el PAM, determinando los tipos de contaminantes que contienen, sus cantidades y sus características.

- Elaborar el estudio ambiental de remediación

- Ejecutar ciertas acciones u obras destinadas a la remediación ambiental de uno o varios PAM, o de sus impactos ambientales

- Presentar un Plan de Cierre de PAM señalando un monto máximo de dinero a ser invertido.

\section{b) Plan de Cierre de Minas}

Se permite, en cualquier etapa de las actividades mineras, incluir en el plan de cierre de minas o modificatorias la remediación de uno o varios PAM, siempre que se encuentren dentro del área de influencia del proyecto de dicho plan de cierre y sean objeto de la etapa de participación ciudadana. (Bailetti, 2008, p 114) 


\section{c) Re utilización}

Está dirigido a titulares de una concesión minera con PAM, quienes podrán re utilizar las áreas que los contienen señalándolo en el estudio ambiental correspondiente, y considerándolo en la presentación o modificatoria del plan de cierre de minas, otorgando especial prioridad a la adopción inmediata de medidas de mitigación de los impactos al ambiente producidos por el pasivo.

\section{d) Re aprovechamiento}

De acuerdo al numeral $10^{\circ}$ del artículo $4^{\circ}$ del RPAM, el re aprovechamiento "consiste en la extracción de minerales de pasivos ambientales tales como desmontes, relaves u otros que pudieran contener valor económico, determinando la obligación de su remediación ambiental".

El artículo $60^{\circ}$ del RPAM otorgó un derecho de exclusividad a toda persona que se considere generador o con derecho sobre un PAM para que, dentro de los 30 días siguientes a la entrada en vigencia del reglamento, pudiera solicitar su re aprovechamiento o remediación. Este plazo fue ampliado por 60 días para el concesionario, cesionario o cualquier otra persona con derecho de explotación de una concesión minera en que se encuentre ubicado un PAM.

El solicitante contaba con el plazo de un año desde su solicitud para presentar el instrumento de gestión ambiental que corresponda. Habiendo transcurrido el plazo del derecho de exclusividad; cualquier interesado puede solicitar el re aprovechamiento de los PAM, siempre y cuando no se encuentren recogidos en un instrumento de gestión ambiental o de remediación. Por lo tanto, a diferencia de la re utilización, será posible que un PAM sea aprovechado por un titular minero distinto al de la concesión minera.

\section{e) Áreas de Conservación Ambiental Minera}

Según el artículo $16^{\circ}$ del RPAM, el MEM y los gobiernos regionales podrán promover la constitución de Áreas de Conservación Ambiental Minera, a efectos de que las áreas donde se ubican los PAM sean remediadas voluntariamente por titulares distintos a los responsables, organizaciones no gubernamentales, entidades de conservación nacionales o extranjeras, u otras organizaciones de la sociedad civil, mediante la total ejecución del 
Plan de Cierre de Pasivos Ambientales Mineros correspondiente, incluidas las medidas de post cierre.

Posteriormente, las áreas rehabilitadas podrán ser utilizadas directamente por el titular del Área de Conservación Ambiental Minera o por terceros, para fines distintos que no pongan en riesgo la remediación ambiental realizada.

\section{f) Solicitud de Uso Alternativo}

En atención a lo establecido por el artículo $64^{\circ}$ del RPAM, las municipalidades distritales dentro de las cuales se ubiquen los PAM podrán solicitar a la DGAAM en cualquier momento su uso alternativo.

La DGAAM podrá autorizar la propuesta en tanto considere que el acondicionamiento del PAM eliminará el riesgo que éste significa al ambiente y a la salud humana, previa opinión técnica favorable del Ministerio de Salud a través de su Dirección General de Salud Ambiental - DIGESA y de las autoridades pertinentes. La propuesta de uso alternativo se evaluará conjuntamente con un plan de cierre de pasivos ambientales.

\section{g) Remediación para el cumplimiento de obligaciones de trabajo}

El artículo $66^{\circ}$ del RPAM permite que los gastos en los que incurran los titulares mineros para la remediación voluntaria de los PAM sean aplicados para el cumplimiento de un año de la obligación de trabajo de la concesión minera que dicho titular elija, en cualquier momento de la vigencia de dicha concesión. Para ello, la DGM emitirá un certificado otorgando dicho beneficio previa verificación del monto invertido. (Bailetti, 2008, p 116)

\subsubsection{Controles Posteriores}

De acuerdo con el artículo $47^{\circ}$ del RPAM, el Organismo Supervisor de la Inversión en Energía y Minería (OSINERGMIN), la autoridad regional competente o el Organismo de Evaluación y Fiscalización Ambiental (OEFA), tienen la responsabilidad de fiscalizar y controlar el cumplimiento de las obligaciones asumidas por los generadores y remediadores voluntarios, según su respectiva competencia. 
Sin embargo, en virtud de la Primera Disposición Complementaria Final de la Ley $\mathrm{N}^{\circ}$ 29325, Ley del Sistema Nacional de Evaluación y Fiscalización Ambiental, se estableció lo siguiente:

"Mediante Decreto Supremo refrendado por los sectores involucrados, se establecerán las entidades cuyas funciones de evaluación, supervisión, fiscalización, control y sanción en materia ambiental serán asumidas por el OEFA, así como el cronograma para la transferencia del respectivo acervo documentado, personal, bienes y recursos, de cada una de las entidades."

Es por ello que, mediante Resolución $\mathrm{N}^{\circ}$ 003-2010-OEFA/CD, el Consejo Directivo del OEFA aprobó los aspectos objeto de transferencia de las funciones de supervisión, fiscalización y sanción ambiental en materia de minería provenientes del OSINERGMIN, incluyendo las referidas a los PAM, asumiendo así facultades exclusivas en la materia.

De otro lado, en el artículo $52^{\circ}$ del RPAM se establecen como infracciones referidas al incumplimiento de obligaciones ambientales, pasibles de ser sancionadas, las siguientes:

No declarar pasivos ambientales mineros que se encuentren dentro del área de concesión, en el plazo establecido

No cumplir con presentar el Plan de Cierre de Pasivos Ambientales en el plazo establecido

- Incumplir el cronograma del instrumento de remediación aprobado o la ejecución de las medidas dispuestas por la autoridad.

- Haber incumplido con la adopción inmediata de medidas de mitigación o remediación ambiental y/o la ejecución de las medidas complementarias dispuestas.

- Haber incumplido con las medidas mantenimiento y monitoreo establecidas para la etapa de cierre y post cierre

- Haber incumplido con presentar los informes semestrales ante la autoridad competente, dando cuenta del avance de las labores de remediación señaladas en el Plan de Cierre aprobado y con información detallada respecto de la ejecución de las medidas comprometidas para el semestre inmediato siguiente. 
- No haber logrado la aprobación del Plan de Cierre de Pasivos Ambientales presentado por causas imputables, en caso de ser el generador del pasivo ambiental minero

- No haber presentado el Estudio de Impacto Ambiental para el re aprovechamiento de un pasivo ambiental, o la respectiva modificatoria dentro del plazo establecido.

- En caso de haber solicitado el Re aprovechamiento; incumplir con informar semestralmente a la autoridad a cargo de la fiscalización, los avances en el re aprovechamiento del PAM y el cumplimiento de las obligaciones ambientales relacionadas.

El mismo artículo establece que un trato diferenciado dependiendo de quién es el sujeto que incurre en las infracciones señaladas. En caso el responsable sea el generador del PAM, se podrá declarar adicionalmente: i) la suspensión de los permisos de operación o exploración otorgados, según corresponda y/o ii) la denegatoria del otorgamiento de concesión de beneficio, en cualquier operación minera del titular dentro del territorio nacional. De otro lado, para los remediadores voluntarios las multas máximas serán de hasta el $20 \%$ de lo que se indique para cada infracción.

\subsection{Presentación de la Empresa Pública de Derecho Privado, Activos Mineros} S.A.C. y análisis de su gestión

\subsubsection{Creación de Activos Mineros S.A.C.}

El 1 de enero de 1974 se creó la Empresa Minera del Centro del Perú S.A. (Centromin), sobre la base del negocio minero expropiado y posteriormente pagado por compensación a la Sucursal en el Perú de Cerro de Pasco Corporation.

Mediante Decreto Supremo N 019-82-EM/VM, de fecha 30 de junio de 1982, se aprobó el Estatuto Social de Centromin, en el cual es definida como una empresa estatal de derecho privado. Entre sus fines se encontraban la explotación de siete yacimientos mineros, las actividades propias de la industria minera definidas en la Ley General de Minería, así como todas las actividades en industrias afines que coadyuven y se requieran para el fin minero. (Herrera, Diez Canseco, Benites, Velásquez, Rey, 2003, p 3) 
En en el marco de los procesos de privatizaciones en el Perú de los años noventa, el Directorio de Centromin inició en 1992 un Plan de Reestructuración Empresarial, a fin de hacerla más atractiva a la inversión privada. En mérito al artículo 1 del Decreto Supremo Extraordinario $\mathrm{N}^{\circ}$ 118-93-PCM, publicado el 08 de septiembre de 1993, se aprobó el programa de reestructuración económica y financiera, que conllevó a la asunción de deudas y/o obligaciones a cargo de la empresa, vencidas o por vencerse, contraídas con el Gobierno Central, el Banco de la Nación, y con acreencias y acreedores externas. Asimismo, mediante Decreto de Urgencia N 02-94 se autorizó al Ministerio de Economía y Finanzas asumir la deuda externa de mediano y largo plazo de Centromin. Posteriormente, el artículo 5 de la Ley $\mathrm{N}^{\circ}$ 26438, publicada el 11 de enero de 1995 , aprobó la reestructuración legal y administrativa con la finalidad de regularizar las autorizaciones, permisos, títulos de propiedad y derechos en general de la empresa. (Herrera, et al, 2003, p 19-20).

Dado que la venta integral de Centromin no resultó exitosa, la Comisión Especial de Privatización dividió la empresa en unidades de negocio y realizó la venta fragmentada de la misma. Por ejemplo, la unidad de Cerro de Pasco se convirtió en la Empresa Minera Paraghsa S.A. Las unidades de San Cristóbal y Andaychagua formaron parte de la Empresa Minera Mahr Túnel, y la unidad minera Casapalca pasó a denominarse Empresa Minera Yauliyacu S.A. (Herrera, et al, 2003, p 23)

De acuerdo con la Comisión Investigadora del Congreso de la República del Perú, encargada de cumplir las conclusiones y recomendaciones a las que arribaron las cinco Comisiones Investigadoras respecto al periodo del ex presidente Alberto Fujimori Fujimori; la contaminación del medio ambiente en las zonas donde estaban ubicadas las operaciones no tuvo la importancia debida en los Contratos de Venta de las empresas privatizadas. (Herrera, et al, 2003, p 27)

Por ejemplo, en el caso de la unidad minera Paragsha, adquirida por Volcan Compañía Minera S.A. (Volcan); mediante Resolución Directoral N 120-99-EM/DGM se establecieron las responsabilidades para el cumplimiento del Programa de Adecuación y Manejo Ambiental (PAMA), haciendo responsable a Centromin por el $87.7 \%$ del 
mismo, mientras que a Volcan únicamente se responsabilizó por el 12.2\% restante. Evaluaciones posteriores demostraron que las cantidades presupuestadas para Volcan no fueron cumplidas y resultaron insuficientes para mitigar los PAM generados en la unidad minera por Centromin, así como los daños ambientales que generaría la empresa adquirente en sus operaciones. (Herrera, et al, 2003, p 35-38)

Finalmente, en sesión del Consejo Directivo de Pro Inversión de fecha 12 de Julio de 2006, se adoptó el Acuerdo $\mathrm{N}^{\circ}$ 146-02-2006, que aprobó la transferencia directa de inmuebles de Centromin a favor de la Empresa Minera Regional Grau Bayóvar S.A., cuya denominación social fue modificada a Activos Mineros S.A.C. (AMSAC). AMSAC es una empresa estatal de derecho privado, perteneciente al sector minero y a la Corporación Fondo Nacional de Financiamiento de la Actividad Empresarial del Estado (FONAFE), quien es titular del $100 \%$ de las acciones. Su principal objetivo es el de remediar los pasivos ambientales a cargo del Estado. (http://www.amsac.pe/index.php/nosotros/nuestra-empresa)

En ese sentido, mediante Decreto Supremo $N^{\circ}$ 058-2006-EM se dispuso que AMSAC asuma la conducción de proyectos de PAMA, planes de cierre, y de las obligaciones de remediación que le correspondían a Centromin (la cual desde el 2003 ya no contaba con operaciones mineras), así como de otras empresas estatales.

Posteriormente, se le ha encargado a AMSAC la remediación de PAM adicionales, como se hizo, por ejemplo, mediante Resolución Ministerial № 535-2016-MEM/DM, que actualizó el Inventario Inicial de PAM, aprobado por Resolución Ministerial N² 2902006-MEM/DM.

También figuran entre las actividades de AMSAC la administración y supervisión de los compromisos de post privatización asumidos por los inversionistas mineros, y el colaborar con la promoción de la inversión privada en las concesiones mineras del Estado. (http://www.amsac.pe/index.php/nosotros/nuestra-empresa) 
Por otro lado, el artículo $11^{\circ}$ del Decreto Legislativo $\mathrm{N}^{\circ} 1100$ impuso la obligación al Estado de promover la remediación de los PAM causados por minería ilegal, por intermedio de AMSAC.

En ese sentido, según lo establecido en el RPAM respecto de la responsabilidad del Estado en la remediación de los PAM, así como lo dispuesto por el artículo $11^{\circ}$ del Decreto Legislativo $N^{\circ} 1100$; son cuatro las circunstancias en las cuales el Estado debe intervenir en la remediación de los PAM y que correspondería a AMSAC:

- Cuando los responsables no han sido identificados

- En caso una empresa de propiedad del Estado sea responsable en no menos de dos tercios del monto correspondiente a la remediación

- En función a la debida tutela del interés público

- Ante PAM causados por minería ilegal.

Es importante recordar que, de acuerdo con el artículo $60^{\circ}$ de la Constitución Política del Perú, la actividad empresarial del Estado es subsidiaria, y se realiza por razón de alto interés público o de manifiesta conveniencia nacional. El Tribunal Constitucional ha definido la subsidiaridad, en la Sentencia recaída sobre el Expediente $\mathrm{N}^{\circ} 0008-2003-\mathrm{AI} / \mathrm{TC}$, de la siguiente manera:

"Las acciones del Estado deben estar vinculadas al fomento, estimulación, coordinación, complementación, integración o sustitución, en vía supletoria, complementaria o de reemplazo, de la libre iniciativa privada. La subsidiariedad se manifiesta como el acto accesorio o de perfeccionamiento en materia económica, que se justifica por la inacción o defección de la iniciativa privada.

Debe enfatizarse que "la intervención de las autoridades públicas en el campo económico, por dilatada y profunda que sea, no sólo no debe coartar la libre iniciativa de los particulares, sino que, por el contrario, ha de garantizar la expansión de esa libre iniciativa", y la de los derechos esenciales de la persona humana." (Sentencia del Tribunal Constitucional del Expediente $N^{o}$ 0008-2003-AI/TC, 2003) (El subrayado es agregado propio)

En atención a lo expuesto, la actividad empresarial del Estado vinculada a los pasivos ambientales no debe sustituir a la iniciativa privada, ni ser un obstáculo para ella. 


\subsubsection{Financiamiento de Activos Mineros S.A.C.}

Mediante la Ley $\mathrm{N}^{\circ} 27170$ se creó el FONAFE, definiendo al mismo en su artículo $1^{\circ}$ como una Empresa de Derecho Público adscrita al Sector Economía y Finanzas, encargada de normar y dirigir la actividad empresarial del Estado.

De acuerdo al artículo 3 de la referida Ley, algunas de las funciones con las que cuenta el FONAFE serían las siguientes:

“Artículo 3.- FONAFE: Funciones

(...) Son funciones del Directorio del FONAFE:

a) Aprobar el presupuesto consolidado de las empresas, en las que su participación accionaria es mayoritaria, en el marco de las normas presupuestales correspondientes;

b) Aprobar las normas de gestión de las empresas a las que se refiere el literal anterior;

c) Ejercer la titularidad de las acciones representativas del capital social de todas las empresas, creadas o por crearse, en las que participa el Estado y administrar los recursos derivados de dicha titularidad;

d) Designar a los representantes ante la junta de accionistas de las empresas en las que tiene participación accionaria; (...)”

Siendo el FONAFE titular del 100\% de las acciones de AMSAC, es el responsable de aprobar el presupuesto de esta última y las normas de gestión, administrar sus recursos, así como de designar a los representantes ante la junta de accionistas.

Por otro lado, mediante asignaciones presupuestales del Sector Público, el Ministerio de Energía y Mina puede destinar parte de sus recursos asignados a AMSAC. Así por ejemplo, en virtud de la Cuadragésima Segunda Disposición Complementaria Final de la Ley $\mathrm{N}^{\circ}$ 30518, Ley de Presupuesto del Sector Público Para el Año Fiscal 2017; se autorizó al Ministerio de Energía y Minas, con cargo a los recursos de su presupuesto institucional, efectuar transferencia financiera al Instituto Peruano de Energía Nuclear hasta por el monto de S/ 23832 020,00 de nuevos soles. Una parte de 
dicha transferencia debía de ser asignada a favor de la Empresa Activos Mineros SAC, para ser destinados a financiar estudios de pre inversión, ejecución de proyectos de inversión, post cierre, trabajos complementarios, de mantenimiento, reparaciones, entre otros, relacionados con la remediación de pasivos ambientales.

El RPAM define los siguientes mecanismos de financiamiento adicionales:

a) Fideicomisos para ejecución de la remediación ambiental a cargo del Estado. Celebrados por el Fondo Nacional del Ambiente (FONAM), institución de derecho privado creada por la Ley $\mathrm{N}^{\circ} 26793$ que tiene como objetivo financiar planes, programas, proyectos y actividades orientadas a la protección del ambiente, el uso sostenible de los de los recursos naturales y el patrimonio ambiental. (http://fonamperu.org.pe/) Los Fideicomisos también podrán ser establecidos por el Ministerio de Energía y Minas, a través de la Dirección General de Minería.

Un ejemplo sería el Convenio de cooperación interinstitucional entre el FONAM, el MEM y AMSAC para la Remediación Ambiental de los cinco depósitos de relaves de El Dorado", celebrado en el año 2007, y que estableció las siguientes obligaciones para las partes: (http://fonamperu.org.pe/proyectos-pasivos-ambientales/)

AMSAC: Culminar el Estudio del Plan de Cierre de Minas, realizar la convocatoria a la Licitación Pública para las obras del proyecto, ejecutar y contratar la supervisión de obras, enviar trimestralmente escritos sobre el avance del proyecto al MEM y al FONAM.

- $\quad$ FONAM: Entregar el estudio "Ingeniería en Detalle para el Cierre Ambiental de Cinco depósitos de Relaves de El Dorado" elaborado con los recursos del Convenio entre el FONAM/Empresas Mineras, financiar y entregar el estudio del Plan de Cierre del proyecto, así como financiar la ejecución del proyecto en si mismo.

- $\quad$ MEM: Facilitar el desarrollo y la viabilidad del convenio para permitir la ejecución del proyecto, sin perjuicio de supervisar los avances del mismo.

\section{b) Participación de PROINVERSIÓN}


Mediante acuerdo del Ministerio de Energía y Minas, el FONAM y PROINVERSIÓN, es posible celebrar convenios para la promoción de inversión privada en la remediación de áreas con PAM a cargo del Estado.

\section{c) Uso de monto presupuestal para la remediación.}

El Ministerio de Energía y Minas podrá destinar un monto presupuestal para remediar determinado pasivo ambiental a través de terceros especializados.

\section{d) Transferencia de ingresos por multas.}

Las multas que emita la DGM en aplicación de la legislación sobre pasivos ambientales, podrán servir para la remediación de las áreas con pasivos ambientales mineros que asuma o ejecute el Estado.

\section{e) Canjes de deuda.}

El estado puede celebrar acuerdos de canje de deuda por remediación de áreas con PAM.

\subsubsection{Eficiencia de la Gestión de Activos Mineros S.A.C.}

De acuerdo con el artículo $7^{\circ}$ del Reglamento de la Ley $N^{\circ} 28271$; es facultad de la DGM, en coordinación con la DGAAM y el INGEMMET; conducir las acciones para la identificación y elaboración del inventario de los pasivos ambientales mineros, considerando los riesgos inherentes a dichos pasivos, el cual deberá ser aprobado por Resolución Ministerial. Asimismo, la DGM deberá dar publicidad de dicho Inventario y sus actualizaciones en la página web del MEM.

La Resolución Ministerial N 535-2016-MEM/DM, publicada en el diario oficial El Peruano el día 22 de diciembre de 2016, aprobó la Actualización del Inventario Inicial de Pasivos Ambientales Mineros al 2016.

De acuerdo con el Inventario del 2016, a dicho año, existían a lo largo del territorio nacional 8,854 PAM. De estos, 683 habían sido encargados a AMSAC para su remediación. Sin embargo, contaban con Plan de Cierre aprobado únicamente 12 de estos, lo cual no necesariamente significa que se haya dado la ejecución del mismo. Por 
lo tanto, es factible deducir que AMSAC no ha sido capaz de cumplir con la remediación de la gran mayoría de los PAM bajo su administración.

Tabla 1. PAM asumidos por el Estado

\begin{tabular}{|c|c|}
\hline $\begin{array}{l}\text { PASIVOS AMBIENTALES ENCARGADOS PARA SU REMEDIACIÓN Y/O ASUMIDOS POR EL } \\
\text { ESTADO }\end{array}$ & Total PAMs \\
\hline R.M. N॰094-2013-MEM & 192 \\
\hline AZULMINA 1 & 2 \\
\hline AZULMINA 2 & 5 \\
\hline C.M. ACOMBAMBA S.A. & 17 \\
\hline C.M. GERMANIO & 17 \\
\hline C.M. SILVERIA & 17 \\
\hline C.M. VENTUROSA S.A. & 16 \\
\hline CARIDAD & 23 \\
\hline CAUDALOSA 1 & 5 \\
\hline CHUGUR (LLAUCANO) & 15 \\
\hline COLQUI & 10 \\
\hline DELTA UPAMAYO & 1 \\
\hline HUAMUYO & 10 \\
\hline HUANCHURINA (A) & 7 \\
\hline LICHICOCHA & 8 \\
\hline PLANTA SARAMARCA & 5 \\
\hline S.M. PACOCOCHA-CONC. HUAROCHIRI & 14 \\
\hline SANTA ROSA 2 & 19 \\
\hline SEDIMENTOS/RÍO SAN JUAN & 1 \\
\hline R.M. N`252-2016-MEM/DM & 14 \\
\hline ALADINO VI & 14 \\
\hline R.M. N 482-2012-MEM & 224 \\
\hline BARRAGAN (LLAUCANO) & 1 \\
\hline CARHUACAYAN & 20 \\
\hline CLEOPATRA & 14 \\
\hline EL DORADO (LLAUCANO) & 4 \\
\hline LA PASTORA (LLAUCANO) & 68 \\
\hline LOS NEGROS (LLAUCANO) & 33 \\
\hline PUSHAQUILCA & 25 \\
\hline SAN ANTONIO DE ESQUILACHE & 59 \\
\hline R.M.N044-2015-MEM/DM & 124 \\
\hline CANAURA & 3 \\
\hline CHULLUNCANE & 27 \\
\hline LAMPA MINING & 35 \\
\hline MARINADOS & 30 \\
\hline MARINA UNO & 29 \\
\hline R.M.N045-2015-MEM/DM & 129 \\
\hline C.M. HUAMPAR S.A. & 20 \\
\hline CECILIA & 49 \\
\hline EL TRIUNFO 1 & 3 \\
\hline KATANGA 1 & 12 \\
\hline NIVEL TRES & 11 \\
\hline PAREDONES & 29 \\
\hline SAN PEDRO NUEVO & 5 \\
\hline TOTAL GENERAL & 683 \\
\hline
\end{tabular}

Fuente: DGM

Gráfico 1. PAM bajo administración de AMSAC con Plan de Cierre aprobado

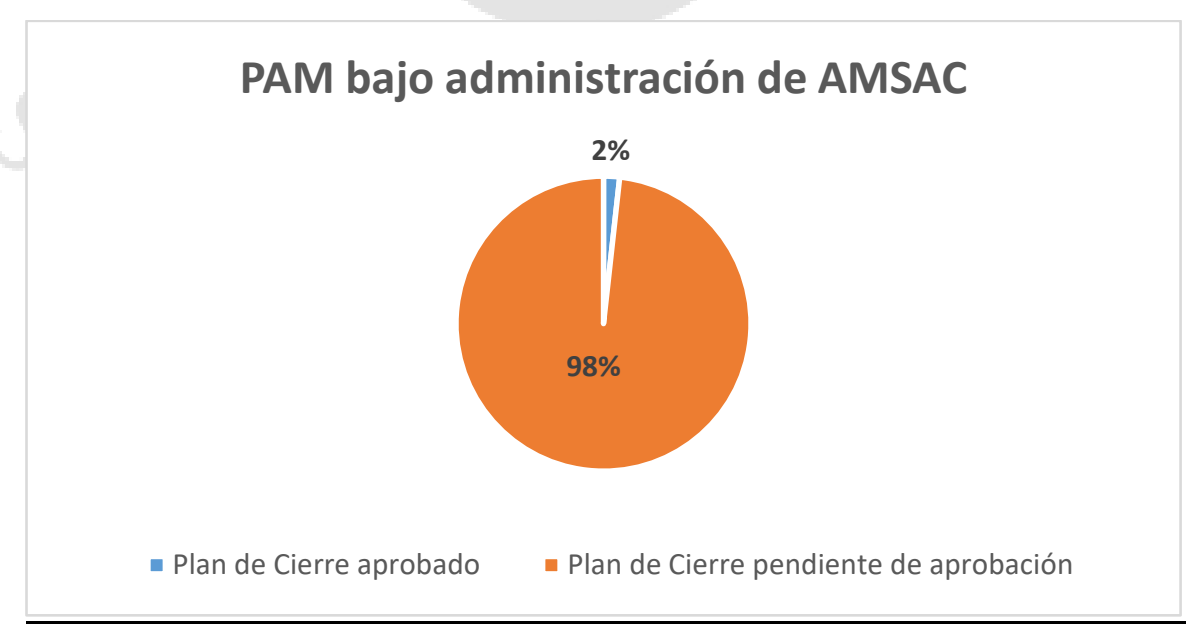

Fuente: Elaboración Propia 
Ejemplos de remediación de PAM realizados por AMSAC incluyen a los provenientes de la empresa minera Centromin, la remediación de cinco relaveras de la mina El Dorado del distrito Hualgayoc, y la remediación de pasivos de alto riesgo. Actualmente, existen únicamente 15 sitios remediados en los que se ha cumplido la obligación de 5 años de post monitoreo, incluyendo tanto a los PAM remediados por AMSAC o por privados. (Koica y Mireco, 2018, p. 3-38)

Un problema constantemente señalado por AMSAC es la escasez de trabajadores acreditados con los que cuenta. La consecuencia de ello es una falta de personal técnico profesional en el sistema general de gestión de PAM en el Perú, considerando que esta institución es la responsable la etapa de establecimiento y ejecución de diversos planes de cierre de PAM. PCPAM. (Koica y Mireco, 2018, p. 3-56) La empresa pública, incluso, realiza contratos de ejecución de obra con particulares, por los cuales les encarga obligaciones de remediación bajo su competencia a cambio de una remuneración, lo cual demuestra la falta de capacidades con las que cuenta para realizar las labores que le han sido encargadas.

Por ejemplo, mediante Contrato GL-C-O37-2016, AMSAC y HERTS SERVICIOS INTEGRALES S.A.C celebraron la Ejecución de la Obra "Mejoramiento y remediación de los suelos contaminados a través del mejoramiento de laderas con tratamiento paisajístico en la parte superior de los barrios de Santa Rosa, San Francisco, San Luis, Comandante Faura y Chanchamayo del sector de la Oroya Antigua, Yauli, Junín”. En virtud del mismo, AMSAC se comprometió al pago de S/.1,190,788.82 a HERTS SERVICIOS INTEGRALES S.A.C por la ejecución de la obra.

Por otro lado, AMSAC ha sido sancionado en múltiples ocasiones por el incumplimiento de las obligaciones ambientales en sus proyectos de remediación.

En el caso del Plan de Cierre de PAM de El Dorado (financiado por el Convenio de cooperación interinstitucional entre el FONAM, el MEM y AMSAC mencionado anteriormente), por Resolución $\mathrm{N}^{\circ}$ 13-2014-OEFA/TFA-SEM de fecha 29 de diciembre de 2014, la Sala Especializada en Minería del Tribunal de Fiscalización Ambiental del OEFA confirmó la Resolución Directoral N 520-2013-OEFA/DFSAI, en el extremo que 
halló responsable a AMSAC de lo siguiente (Resolución N 13-2014-OEFA/TFA-SEM, 2014):

- Haber incumplido las dos (2) medidas dispuestas por la Resolución de Gerencia de Fiscalización Minera del Osinergmin N 011-2009-OS/GFM, referidas a:

○ La implementación de un sistema de tratamiento de efluentes ácidos de los depósitos de relaves $\mathrm{N}^{\circ} 3,4$ y 5 .

- El retiro de inmediato de los relaves derramados en el río Hualgayoc y a los que se encuentran en la ladera del depósito de relaves $\mathrm{N}^{\circ} 3$.

- Haber incumplido los cuatro (4) mandatos ordenados por la Resolución de Gerencia de Fiscalización Minera del Osinergmin Nº11-2009-OS/GFM referidos a:

- La realización de un estudio de estabilización de la zona afectada, considerando las condiciones actuales de todos los relaves, conteniendo acciones y medidas para estabilizar los depósitos afectados $\mathrm{N}^{\circ} 3,4$ y 5 .

- La modificación del Plan de Cierre y presentación para aprobación ante el MEM.

○ La realización del monitoreo geotécnico de estabilidad física de todos los depósitos de relave.

- La construcción del sistema de tratamiento de los efluentes ácidos, que debía ser aprobado por la Autoridad Nacional del Agua.

No haber realizado la revegetación en las plataformas y taludes de los 5 depósitos de relaves, conforme al cronograma de ejecución de obra contenido en el Plan de Cierre del Proyecto.

- Haber excedido los límites máximos permisibles establecidos por el Anexo 1 de la Resolución Ministerial º 011-96- EMA/MM, para efluentes líquidos para las actividades minero-metalúrgicas,

Es interesante mencionar que, en sus descargos, AMSAC señaló que no tiene la condición de titular minero al ser una empresa del Estado a la cual se le encargó la administración y ejecución de la remediación ambiental de los 5 depósitos de relaves El Dorado, por lo que no ha asumido voluntariamente dicha remediación.

De igual modo, señaló que no realiza ninguna de las actividades comprendidas en el artículo VI del Título Preliminar del Decreto Supremo Nº 014-92-EM, siendo que su principal actividad es la remediación, por lo que no es una empresa constituida con fines 
de lucro. Por lo tanto, se habría vulnerado el principio de tipicidad al habérsele aplicado las normas sustantivas y tipificadoras que señalan como responsable al titular minero.

Al respecto, el OEFA señaló que el artículo $2^{\circ}$ del Decreto Supremo $N^{\circ} 058$ 2006-EM estableció que la conducción de la ejecución de los proyectos de remediación ambiental derivados de los PAMA y Planes de Cierre que estaban a cargo de Centromin o de otras empresas mineras del Estado serían asumidos directamente por AMSAC. Según el artículo $5^{\circ}$ de la misma norma, los proyectos derivados del PAMA, Planes de Cierre y remediación ambiental antes citados estarán sometidos a procesos regulares de fiscalización, realizados por los órganos competentes. En ese sentido, AMSAC no solo es responsable de asumir la remediación ambiental y de ejecutar las medidas establecidas en el Plan de Cierre El Dorado, sino también de cumplir con las normas ambientales del sector minero, estando por lo tanto sujeta a una sanción en el caso de verificarse que haya incurrido en incumplimiento de la legislación ambiental.

Lo cierto es que queda en evidencia la incapacidad de AMSAC para acometer por sí sola las tareas encargadas por el referido marco normativo sobre PAM.

\subsection{Eficiencia del marco normativo aplicable para el manejo de Pasivos Ambientales Mineros bajo administración del estado en el Perú}

\subsubsection{Financiamiento}

De acuerdo con el Banco Mundial, se presentan los siguientes problemas con los mecanismos de financiamiento mencionados: (Banco Mundial, 2005)

El FONAM carece de experiencia en la obtención de fondos para la remediación ambiental de los PAM bajo administración del Estado, por lo que necesitaría asociarse con agentes de probada experiencia técnica, así como recibir capacitación al respecto.

- Los PAM tienen baja prioridad en la percepción pública internacional, por lo que no existen muchos mecanismos financieros internacionales disponibles para un programa de rehabilitación sistemático.

- Es difícil pedir a los donantes extranjeros que vengan al rescate ofreciendo donaciones y contribuciones para resolver el problema de los legados huérfanos cuando el Estado se rehúsa a aportar un compromiso financiero significativo para tratar un problema de uno de los sectores más fuertes de la economía. 
Por otro lado, las transferencias presupuestarias que realiza el Estado a favor de AMSAC no siempre consideran los costos reales de los Planes de Cierre a ejecutar. Dicho análisis únicamente se ha llevado a cabo para las transferencias correspondientes al año 2019. (Directora General de Asuntos Ambientales Mineros, comunicación personal, 18 de diciembre de 2018)

En atención a lo expuesto, se evidencia que el financiamiento de AMSAC para la remediación de los PAM no es del todo adecuado, al depender en una gran parte de la cooperación internacional, la cual no solo es variable sino de difícil obtención, ya que hay resistencia a otorgar estos financiamientos para remediar los daños provocados al ambiente por un actor que se benefició de la actividad minera y no internalizó los costos de prevención.

\subsubsection{Institucionalidad}

Son varias las instituciones involucradas en la gestión de los PAM bajo administración del Estado.

La Dirección General de Minería, en coordinación con el INGEMMET y las Direcciones Regionales de Energía y Minas (DREM) de los Gobiernos Regionales, es la encargada de la identificación de los responsables de los PAM, así como de llevar el inventario de los PAM existentes. La DGAAM es la autoridad competente para la aprobación de los instrumentos de gestión ambiental relacionados a los PAM, así como las DREM para el caso de los pequeños productores mineros y productores mineros artesanales, y las facultades de fiscalización posterior son compartidas entre el OEFA y las autoridades regionales competentes.

Para el caso de los PAM bajo administración del Estado, AMSAC es la institución responsable de realizar los instrumentos de gestión ambiental necesarios, llevar a cabo las actividades de remediación, así como las medidas de post cierre, trabajos complementarios y de mantenimiento. Es preciso mencionar que previamente, el Ministerio de Energía y Minas, a través de Resolución Ministerial, deberá encargar a AMSAC los PAM que serán objeto de remediación por parte de esta entidad. 
La especialización de las entidades y las unidades coordinadoras fragmentadas generan una carga sobre el aparato burocrático, pues se amplían los procesos administrativos, demorando las decisiones respecto de la gestión de los PAM.

La cantidad de instituciones aumentan los costos transaccionales y lleva a un escaso intercambio de información, dificultando la actualización de los inventarios, así como la misma remediación de los PAM.

\subsubsection{Dificultades para la Participación del Sector Privado}

Como se mencionó anteriormente, el artículo $12^{\circ}$ del RPAM establece lo siguiente:

\section{“Artículo 12.- Modalidades de Remediación voluntaria}

Cualquier persona o entidad, sea titular de concesiones mineras o no, podrá asumir la responsabilidad de remediar voluntariamente pasivos ambientales mineros, inventariados o no, que se encuentren ubicados en su propia concesión minera, de tercero o en áreas de libre denunciabilidad, (...)”

Son modalidades de remediación voluntaria, aplicables tanto para los PAM bajo administración del Estado y del Sector Privado: el Plan de Cierre de PAM, el Plan de Cierre de Minas, la Re utilización y el Re aprovechamiento.

Para el caso de la remediación voluntaria por intermedio del plan de cierre de PAM; mediante Decreto Supremo N 003-2009-EM se incluyó la posibilidad de celebrar con la DGM los convenios de remediación voluntaria con responsabilidad limitada, por lo cual, según el artículo $15^{\circ}$ del RPAM, los interesados en asumir la remediación voluntaria podrán restringir su participación a los siguientes compromisos:

- $\quad$ Responsabilidad limitada a la evaluación del pasivo ambiental y/o preparación de determinado estudio ambiental de remediación.

- Responsabilidad limitada a la ejecución de ciertas acciones u obras destinadas a la remediación ambiental de uno o varios pasivos ambientales o de sus impactos ambientales.

- Responsabilidad limitada a la inversión de un monto máximo de dinero que se haya previsto como presupuesto de las acciones del plan de cierre.

- Limitación en la duración de la etapa de post cierre. 
Los mencionados convenios fomentan esta modalidad de remediación voluntaria al eliminar toda inseguridad respecto a la extensión de la responsabilidad del remediador, pudiéndosele exigir únicamente las obligaciones que este, libremente, ha asumido.

En la remediación voluntaria por Plan de Cierre de PAM, el beneficio se encuentra en la posibilidad de utilizar el área en la cual se encontraba el pasivo sin limitaciones cuando se localiza en una concesión bajo titularidad del remediador voluntario, sin tener que esperar el cierre del PAM por parte del causante. Cabe precisar que se mantiene la posibilidad de repetir contra el generador. Además, el remediador voluntario podrá aplicar los gastos en los que incurrió en la ejecución del Plan de Cierre del PAM para el cumplimiento de un año de la obligación de trabajo de la concesión minera.

De otro lado, en caso de incumplimiento de las obligaciones asumidas, el RPAM ha previsto en su artículo $52^{\circ}$ un criterio de gradualidad, señalando que las sanciones en el caso de un remediador voluntario son del $20 \%$ de las que corresponderían a los generadores del PAM, por el mismo incumplimiento en la remediación.

El RPAM también establece la modalidad de remediación voluntaria por re utilización y re aprovechamiento.

La re utilización, conforme se mencionó anteriormente y según lo dispuesto en el artículo $59^{\circ}$ del Reglamento, está dirigido a titulares de concesiones mineras, a fin de que hagan uso de las áreas que contienen los PAM. Como requisitos previos, deberán informar la existencia del PAM y la intención de re utilizarlo en el estudio ambiental correspondiente, así como considerarlo en el plan de cierre de minas. La re utilización es aplicable siempre y cuando el generador del PAM no hubiera asumido la responsabilidad del mismo a la fecha de vigencia del RPAM.

Como fue mencionado, a diferencia de la re utilización, en el caso del re aprovechamiento se aplica el siguiente orden de prioridad en los solicitantes, según el artículo $60^{\circ}$ de la norma citada: EI generador o cualquier otra persona o entidad que considere tener derecho respecto de un pasivo ambiental, quien contaba con treinta (30) días calendario desde la vigencia del referido artículo $60^{\circ}$ para comunicar a la DGM 
su responsabilidad como generador de dicho PAM o acreditar su derecho y solicitar su re aprovechamiento. Vencido el plazo, se perdía el derecho de exclusividad.

El titular de una concesión minera, cesionario u otra persona o entidad con derecho de explotar una concesión minera, en cuya concesión se encuentre ubicado algún PAM susceptible de re aprovechamiento, quien contaba con sesenta (60) días calendario para comunicar a la DGM su solicitud, los cuales se contaban a partir del vencimiento del plazo referido en el numeral precedente. Vencido el plazo, se perdía el derecho de exclusividad. Si luego del vencimiento último plazo no se presentaron solicitudes de re aprovechamiento por los sujetos mencionados en el numeral precedente; cualquier interesado se encontraría habilitado de comunicar a la DGM su decisión de re aprovechar el PAM.

Con el re aprovechamiento, el remediador voluntario puede re utilizar el PAM, presentando Estudio de Impacto Ambiental con cierre a nivel de factibilidad y liberándose, una vez aprobado el instrumento, de la presentación de un Plan de Cierre de Minas adicional.

Estas dos modalidades de remediación voluntaria significan un esfuerzo destacable por parte del Estado para promover la restauración del medio ambiente, otorgándoles incentivos y garantías para su participación. Incluso, el artículo $58^{\circ}$ del RPAM señala que Estado podrá re utilizar o re aprovechar PAM por intermedio de sus propias empresas, en caso sean autorizadas expresamente mediante la correspondiente norma legal.

Sin embargo, pese a que son permitidas, existe una restricción para la aplicación de estas modalidades de remediación voluntaria en el caso de los PAM que se encuentren bajo administración del Estado.

El artículo 12-A del RPAM estableció lo siguiente:

\section{"Artículo 12-A.- Prioridad en la remediación}

No se aceptará el inicio de alguna de las modalidades de remediación, en caso existan otras modalidades de remediación en proceso de evaluación o aprobadas. (...) 
Tampoco se admitirán estas modalidades respecto de pasivos ambientales que se encuentren comprendidos en el Decreto Supremo $N^{o}$ 013-2008-EM, en tanto no sean incluidos expresamente en el régimen regulado por el presente Reglamento mediante decreto supremo refrendado por el Ministro de Energía y Minas. (...)" (EI subrayado es agregado propio)

El Decreto Supremo $\mathbf{N}^{\mathbf{0}}$ 013-2008-EM ${ }^{1}$ es aplicable para los PAM a cargo de AMSAC que puedan ser aprovechados económicamente por inversionistas privados.

Según dicha norma, AMSAC deberá celebrar una subasta pública y un contrato para la transferencia de estos pasivos al sector privado. La subasta pública y el contrato, además, deberán cumplir con los siguientes requisitos establecidos en el artículo $2^{\circ}$ del referido Decreto Supremo:

"Artículo

2.1 A fin de cumplir con el objetivo descrito en el Artículo 1, Activos Mineros S.A.C. deberá realizar una Subasta Pública, observando las normas aplicables a las \begin{tabular}{l|ll} 
empresas del ámbito & de
\end{tabular} 2.2 Las bases de la Subasta Pública y el contrato respectivo incorporarán: 2.2.1 La obligación del inversionista de efectuar un aporte en efectivo directamente a un fideicomiso privado, estableciéndose los montos y cronogramas de aporte respectivos.

Los recursos del fideicomiso privado serán destinados para inversión en proyectos de infraestructura de transporte, electrificación, saneamiento, salud, educación y otras obras, proyectos y gastos relacionados al desarrollo sostenible y fortalecimiento de capacidades, en beneficio de las poblaciones del área de influencia del proyecto.

2.2.2 La obligación del inversionista y del operador si fuere el caso, de realizar sus actividades cumpliendo fielmente los compromisos establecidos en el Decreto Supremo $N^{o}$ 042-2003-EM, entre otros, el compromiso de operar con excelencia ambiental, establecer relaciones de diálogo y respeto con las poblaciones y autoridades de la zona. 2.2.3 Las bases incluirán dentro de los criterios de evaluación de los postores,

Dictan disposiciones para el aprovechamiento de residuos de los Proyectos de Cierre o Remediación Ambiental a cargo de la empresa del Estado Activos Mineros S.A.C. 
propuestas de programas de mitigación ambiental en la zona de influencia del proyecto." (El subrayado es agregado propio)

En ese sentido, a fin de que el privado pueda remediar voluntariamente un PAM bajo administración del Estado que sea re aprovechable económicamente, según lo establecido en el RPAM, es necesario que mediante un decreto supremo se libere al mismo del procedimiento reglado por el Decreto Supremo No 013-2008-EM.

La justificación de esta restricción es evitar que el MEM entre en conflicto con la normativa de AMSAC y que la empresa pública realice planes y esfuerzos para la remediación de un PAM que luego sea transferido, en cualquier momento, a un privado para su remediación voluntaria. Esto podría suceder, incluso, en el proceso de una subasta pública. En otras palabras, se quiso evitar el conflicto entre las entidades públicas respecto a la remediación de los PAM. (G. Bailetti Frayssinet, comunicación personal, 25 de octubre de 2018)

Para los casos en que el remediador voluntario quiera presentar un Plan de Cierre de este tipo de pasivo ambiental, es comprensible que el Estado priorice su re aprovechamiento y exija una norma que lo exceptúe de una subasta pública. Siendo los recursos naturales escasos, es deber del Estado promover el uso de los mismos de manera sostenible.

Sin embargo, para los casos en los que el remediador voluntario quiere re utilizar o re aprovechar este tipo de pasivos, lo exigido por la normativa, pese a que se encuentra debidamente justificado, ha demostrado ser en la realidad ineficiente. Según lo señalado por la empresa pública, de los PAM encargados a AMSAC, no hay ningún caso de pasivos transferidos al sector privado. (Activos Mineros S.A.C., comunicación personal, 19 de octubre de 2018)

Asimismo, de la revisión de la normativa del MEM, únicamente se han excluido 17 PAM del encargo de remediación efectuado a AMSAC. Dichos pasivos fueron separados de la empresa pública mediante Resolución Ministerial N N 420-2014MEM/DM, a fin de que sean transferidos a Minera Germania S.A. para su remediación voluntaria a través del re aprovechamiento. Sin embargo, al 2018 únicamente existían 
cinco casos en los que se ha presentado y aprobado los planes para el reúso de PAM, pero no existen casos en lo que se ha llevado a cabo el proyecto. (Koica y Mireco, 2018, p. 323)

Por otro lado, el MEM no ha emitido ningún decreto supremo de liberación de pasivos del procedimiento establecido en el Decreto Supremo No 013-2008-EM.

En ese sentido, lo señalado en el artículo 12-A del RPAM, pese a encontrarse válidamente justificado, implica un procedimiento administrativo más largo que el aplicable a los PAM que se encuentran bajo el sector privado y una restricción a la participación de los remediadores voluntarios, llevando a un manejo inadecuado de los recursos naturales. Además, se genera una asignación ineficiente del presupuesto público, pues el financiamiento de AMSAC mediante el Tesoro Público podría ser aliviado en caso se admitiesen las modalidades de remediación voluntaria sin restricción alguna.

Finalmente, es preciso mencionar que los convenios de remediación voluntaria que llegue a celebrar el MEM generalmente son incluidos en los instrumentos gestión ambiental de los titulares mineros, limitándose a los PAM que se encuentren próximos a las concesiones de los privados interesados. Actualmente, es tarea del privado decidir que PAM puede remediar o re aprovechar, ya que el MEM no ofrece ningún tipo de orientación al respecto. De hecho, el Inventario de PAM no promueve la participación del sector privado, al no especificar las condiciones de los pasivos ni señalar cuántos de ellos pueden ser re aprovechados. (Directora General de Asuntos Ambientales Mineros, comunicación personal, 18 de diciembre de 2018)

En conclusión, la participación del sector privado en la remediación de PAM bajo administración del Estado se daría de la siguiente manera:

1. Por medio de convenios específicos de promoción de inversión privada entre el MEM, el FONAM y PROINVERSIÓN, de acuerdo con el artículo 24 del RPAM.

2. Mediante licitaciones públicas, por las cuales AMSAC encarga los procesos de remediación. (Tenemos bolsa de S/70 millones para remediación ambiental, 2016)

3. Por subastas públicas y la celebración de contratos, mediante los cuales se transfiere un PAM re aprovechable económicamente a los inversionistas privados.

4. Mediante la admisión de las modalidades de remediación voluntaria 


\subsection{Conclusiones Preliminares}

En atención a lo demostrado en el presente capítulo, es posible concluir lo siguiente:

- Los PAM son resultado de actividades mineras que datan desde la época colonial y que se realizaban_sin normas que regulen las consecuencias ambientales del cierre de sus operaciones.

- Dada a la antigüedad de los PAM, no siempre será posible atribuir la responsabilidad al causante del mismo. Por lo tanto, en un primer momento y siempre que sea posible; se considerará el factor objetivo de atribución de responsabilidad. En caso el causante no sea identificado, por razones de interés público o frente a PAM causados por minería ilegal; el Estado asumirá la remediación con la finalidad de asegurar la restauración del medio ambiente.

La remediación de los PAM bajo administración de AMSAC ha sido ineficiente por los siguientes motivos:

- La cantidad de PAM que cuentan con plan de cierre aprobado y ejecutado es mínima.

- En el cumplimiento de sus obligaciones, AMSAC ha infringido la normativa ambiental en múltiples ocasiones.

- El financiamiento de AMSAC depende en una gran parte de la cooperación internacional, la cual es variable, y del Tesoro Público.

La cantidad de direcciones y entidades involucradas en el manejo de los PAM con facultades extremadamente especializadas genera demora en los procesos y, como consecuencia, en las decisiones respecto de la gestión de los PAM.

Las modalidades de remediación voluntaria y la posibilidad de celebrar este tipo convenios con responsabilidad limitada; promueven la restauración del medio ambiente por parte de la sociedad civil. Sin embargo, se restringe la re utilización y el re aprovechamiento cuando se trata de PAM que se encuentran bajo administración del Estado. 


\section{CAPÍTULO TRES: LEGISLACIÓN COMPARADA EN LA GESTIÓN DE PAM Y EN LA SIMPLIFICACIÓN ADMINISTRATIVA}

\subsection{Tratamiento de los PAM en la experiencia internacional}

A continuación, se presenta un estudio de legislación comparada sobre el tratamiento de los PAM en tres países mineros considerados líderes en esta temática: Estados Unidos, Canadá y Australia.

\subsubsection{Estados Unidos}

En el marco de la Ley de Responsabilidad, Compensación y Recuperación Ambiental (CERCLA), conocida también como la Ley Superfund, aprobada en el año 1980 por el Congreso Nacional de los Estados Unidos; se instaló el Programa Superfund, el cual es llevado a cabo por la Agencia de Protección Ambiental de Estados Unidos (EPA). (Oblasser y Chaparro, 2008, p 20)

La Ley CERCLA tiene como objetivo principal la identificación, investigación y restauración de sitios contaminados ubicados en territorio nacional que existen como consecuencia del manejo inadecuado, el desecho o la exposición de residuos peligrosos causados por instalaciones de fabricación, plantas procesadoras, botaderos o sitios mineros. Mediante la misma se facultó a la EPA a tomar las medidas adecuadas para la rehabilitación del medio ambiente y la limpieza de estos sitios contaminados. (https://www.epa.gov/superfund/what-superfund)

Los PAM, conocidos en Estados Unidos como Sitios Mineros Abandonados (AML- Abandoned Mine Lands), estarían bajo el ámbito del Superfund ${ }^{2}$. Dichos AML

En el caso de la minería de carbon, se aplican las disposiciones respect de minas abandonadas de la Ley de Minería Superficial, Control y Reclamación del año 1977. Por lo tanto, no formaría parte de la Ley CERCLA y, en consecuencia, no se comprenden dentro de las AML bajo el Programa Superfund. 
están definidos como toda tierra, agua o cuenca circundante donde ha ocurrido anteriormente la extracción, beneficio y/o procesamiento de minerales. Para el tratamiento de las AML y demás sitios contaminados bajo el Programa Superfund, la EPA podrá tomar cualquiera de estas tres acciones:

a) Respuesta de Emergencia: En caso el sitio contaminado requiera acción inmediata para la eliminación de los riesgos significativos hacia la salud y el medio ambiente.

b) Acción Temprana: Busca prevenir el contacto humano con los contaminantes, cuando estos generan un riesgo futuro. Estas acciones durarán hasta cinco (5) días y se centran, por ejemplo, en la provisión de agua potable a la comunidad, la prevención de la difusión de los contaminantes o el retiro de los materiales peligrosos.

c) Acción de Largo Plazo: En caso la remediación del sitio contaminado tome varios años o décadas. Usualmente se toman de la mano con las acciones tempranas. A fin de evaluar el riesgo de cada sitio contaminado hacia la salud de las personas, la flora y la fauna; la EPA utiliza una metodología de cálculo denominada Sistema de Clasificación de Peligros- Hazard Ranking System (HRS). Si luego de realizado el HRS, se considera que el riesgo es significativo; se incluirá al sitio contaminado en la Lista de Prioridades Nacionales- National Priorities List (NPL), permitiendo el financiamiento de las acciones de largo plazo a través del Superfund.

La Ley CERCLA define como responsables de los sitios contaminados a las siguientes personas: (https://www.epa.gov/enforcement/superfund-liability)

- $\quad$ Propietario u operador actual

- $\quad$ Propietario u operador del momento en el cual se produjo el residuo peligroso.

- Generador o responsable del traslado o disposición del contaminante.

- $\quad$ Transportador del residuo peligroso, que seleccionó el lugar al cual fue llevado.

A fin de liberarse de responsabilidad, dichos sujetos deberán probar la ruptura del nexo causal por hecho de fuerza mayor, acción u omisión de tercero, o por acto de guerra. Por otro lado, a las siguientes personas se les podrá limitar su responsabilidad:

- $\quad$ Las personas responsables por una pequeña cantidad de residuos.

- $\quad$ Las personas responsables de residuos de peligro limitado. 
- Las personas que tienen condición de municipalidad, propietario de vivienda, manipulador de residuos sólidos municipales o propietario de lo ubicado encima de los acuíferos contaminados.

- Quienes no cuentan con solvencia monetaria suficiente para pagar la remediación en su totalidad.

De acuerdo con lo señalado por la EPA, la remediación de más del 70\% de los sitios contaminados incluidos en el NPL es conducida por los responsables de su contaminación. En los casos en los que la remediación de los sitios contaminados es financiada por medio Superfund; la EPA se reserva el derecho de repetir contra los responsables, siempre y cuando hayan sido ubicados y cuenten con fondos suficientes.

Por otro lado, el financiamiento del Programa Superfund se realiza con cargo a un Fondo Fiduciario del Gobierno que cuenta con las siguiente fuentes de ingreso: (Ramseur y McCarthy, 2008, p 1-4)

a) Impuestos a la industria petrolera y química, e impuesto al ingreso corporativo: Se instaló un impuesto a la industria petrolera (9.7 centavos por barril) así como a la industria química, dependiendo del químico en cuestión. Bajo una interpretación del principio de "quien contamina paga", el impuesto se justificaba en el hecho de que la mayoría de las sustancias peligrosas que debían limpiarse provenían de estas industrias. Asimismo, cuando los ingresos de una compañía superaban los 2 millones de dólares, se cobraba un impuesto de $0.12 \%$ frente al exceso, bajo la suposición de que dichas compañías utilizaban o desechaban sustancias peligrosas. En el año 1995, se retiraron estos impuestos y, a la fecha, no se ha autorizado su reinstalación.

b) Recuperación de costos y multas de los responsables identificados: Se entiende por recuperación de costos al reembolso a la EPA de los gastos de limpieza y recuperación de sitios contaminados por parte de los sujetos potencialmente responsables. Varían de año a año y su proyección es difícil. De otro lado, de acuerdo con el Servicio de Investigación del Congreso (CRS) de Estado Unidos, las multas y penalidades contribuyen a una parte mínima de los ingresos del fondo.

c) Intereses y Beneficios de Inversiones del Estado 
De acuerdo a la CRS, entre los años fiscales 2002 y 2004, la limpieza de diversos sitios contaminados fue demorada por la insuficiencia de fondos para el Programa Superfund. La misma institución señala que ha habido una reducción en el Balance General del Fondo en los últimos años, conforme queda evidenciado en el siguiente gráfico: (Ramseur y McCarthy, 2008, p 4)

\section{Gráfico 2. Balance del Fondo Superfund entre los Años Fiscales 1994 y}

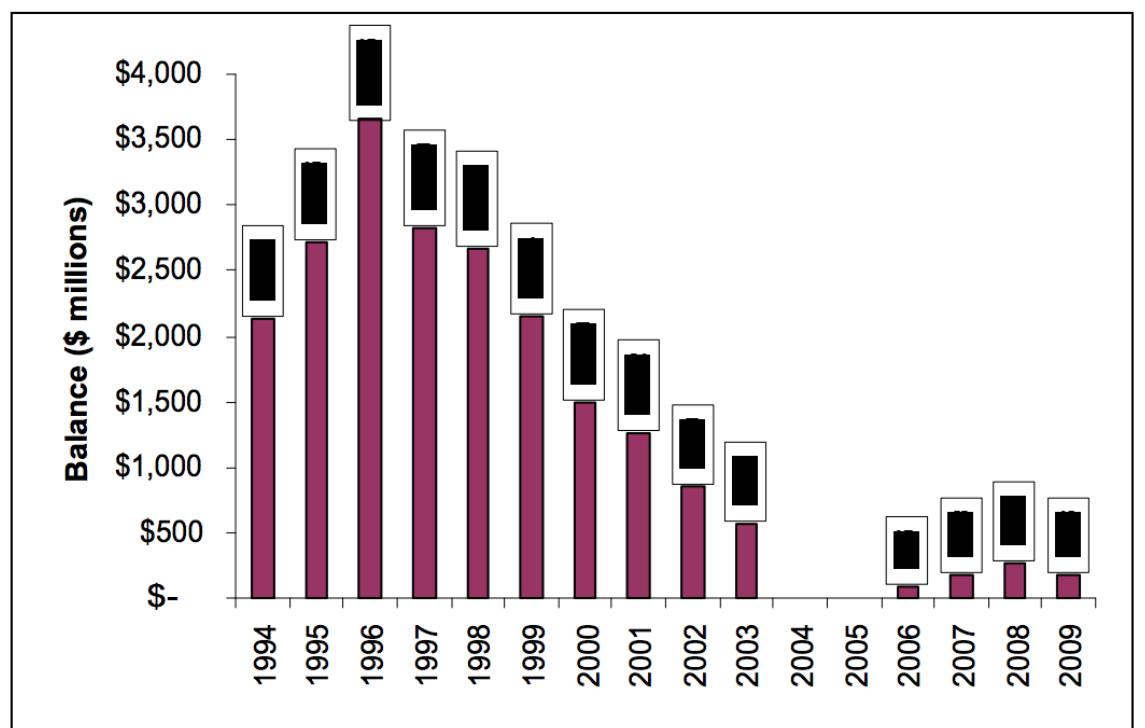

Fuente: CRS

Luego de haber realizado un análisis de la gestión de los PAM en Perú como en Estados Unidos (en donde se conocen como AML), se puede hacer la siguiente comparación:

Tabla 2. Gestión Pasivos Ambientales en Perú y Estados Unidos

\begin{tabular}{|c|c|c|}
\hline $\begin{array}{l}\text { Aspecto a } \\
\text { Comparar }\end{array}$ & Estados Unidos & Perú \\
\hline Instituciones & $\begin{array}{l}\text { Tanto las acciones de } \\
\text { identificación de responsables } \\
\text { como de remediación (en caso } \\
\text { no lo hagan los responsables } \\
\text { identificados) y priorización de } \\
\text { los sitios contaminados son } \\
\text { llevadas a capo por la EPA, a }\end{array}$ & 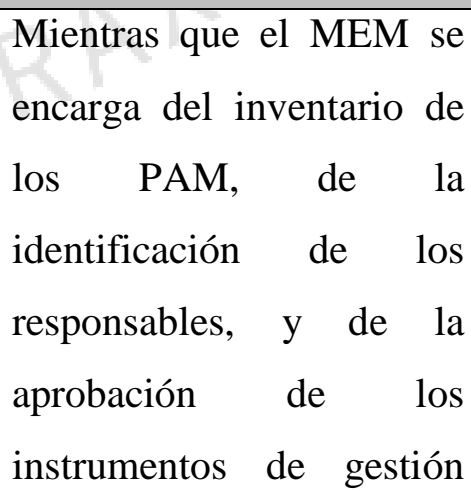 \\
\hline
\end{tabular}




\begin{tabular}{|c|c|c|}
\hline & $\begin{array}{l}\text { través de } \quad \text { sus } \text { unidades } \\
\text { operativas. No hay una } \\
\text { institución específica para la } \\
\text { remediación de los AML. }\end{array}$ & $\begin{array}{l}\text { ambiental necesarios, } \\
\text { AMSAC realiza las } \\
\text { actividades de remediación } \\
\text { necesarias. }\end{array}$ \\
\hline & $\begin{array}{l}\text { El financiamiento de las } \\
\text { actividades de remediación se } \\
\text { hace a través del Fondo } \\
\text { Fiduciario del Gobierno con las } \\
\text { siguientes fuentes de ingreso: } \\
\text { - Impuestos cobrados hasta } \\
1995 \text { a la industria petrolera } \\
\text { y química y al ingreso } \\
\text { corporativo } \\
\text { - Recuperación de costos y } \\
\text { multas de los responsables } \\
\text { identificados } \\
\text { Intereses y Beneficios de } \\
\text { Inversiones del Estado }\end{array}$ & $\begin{array}{l}\text { El financiamiento de la } \\
\text { remediación de los PAM } \\
\text { bajo administración del } \\
\text { Estado se realiza, en su } \\
\text { mayor parte, a través de } \\
\text { Asignaciones } \\
\text { Presupuestales Anuales del } \\
\text { Sector Público, la } \\
\text { Cooperación Internacional, } \\
\text { las transferencias del } \\
\text { FONAFE que recibe } \\
\text { AMSAC. } \\
\text { Asimismo, el RPAM } \\
\text { contempla la posibilidad de } \\
\text { utilizar ingresos } \\
\text { provenientes de multas } \\
\text { provenientes } \\
\text { incumplimiento } \\
\text { obligaciones referidas a los } \\
\text { PAM y de celebrar } \\
\text { convenios Con } \\
\text { ProInversión así como } \\
\text { acuerdos de canje de } \\
\text { deudas con el sector } \\
\text { privado. }\end{array}$ \\
\hline $\begin{array}{l}\text { Identificación } \\
\text { Responsables }\end{array}$ & $\begin{array}{lcc}\text { Estados Unidos no separa } & \text { en } \\
\text { momentos } & \text { distintos } & \text { la } \\
\text { identificación } & \text { de } & \text { los }\end{array}$ & $\begin{array}{l}\text { En el Perú, el Estado asume } \\
\text { la remediación del PAM en } \\
\text { caso no se haya }\end{array}$ \\
\hline
\end{tabular}




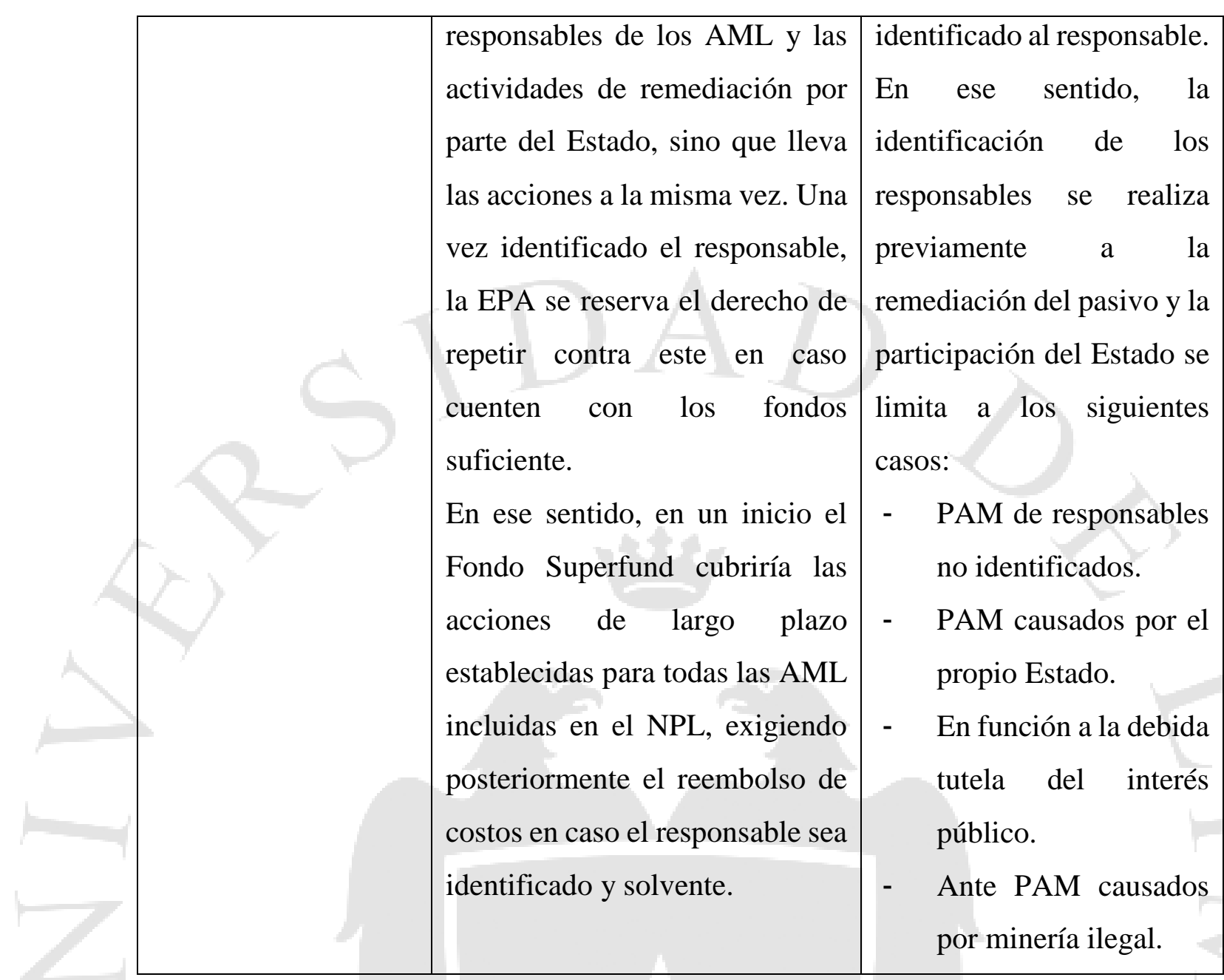

Fuente: Elaboración Propia

\subsubsection{Canadá}

La dependencia de la economía canadiense a la minería ha resultado en más de diez mil $(10,000)$ minas abandonas y huérfanas en distintas condiciones. Para abordar esta problemática, en el año 2002 se instaló la Iniciativa Nacional de Minas Huérfanas/Abandonadas (NAOMI, por sus siglas en ingles). NAOMI es un programa cooperativo canadiense que cuenta con un comité consultivo conformado por representantes de la industria minera, canadienses aborígenes, representantes de todos los niveles de gobierno, así como de las organizaciones no gubernamentales medio ambientales. La finalidad del Comité es analizar las cuestiones principales en las actividades de remediación de las minas abandonadas, así como postular recomendaciones respecto de cómo realizar dichas acciones de manera integrada y participativa, proponiendo asociaciones y alianzas. (Hogan y Tremblay, 2008, p 774) 
Uno de los principales objetivos de NAOMI era desarrollar las capacidades para la formulación de un inventario nacional de minas abandonas y huérfanas, que sea compatible con los inventarios propios de cada provincia y territorio. Sin embargo, las propias definiciones que cada jurisdicción maneja respecto de qué es una mina abandonada o huérfana representaba un obstáculo para la formulación del inventario nacional. (Hogan y Tremblay, 2008, p 777)

La siguiente tabla muestra las definiciones de minas huérfanas y abandonadas que algunas provincias manejan: (http://www.abandoned-mines.org/en/)

Tabla 3. Definiciones de Mina Huérfana y Abandona en las distintas provincias canadienses

\begin{tabular}{|c|c|c|}
\hline Provincia & Mina Abandonada & Mina Huérfana \\
\hline $\begin{array}{l}\text { Columbia } \\
\text { Británica }\end{array}$ & $\begin{array}{l}\text { Mina en la que se han satisfecho } \\
\text { todas las obligaciones derivadas de } \\
\text { autorizaciones y en la cual los } \\
\text { derechos mineros han sido } \\
\text { revertidos al Estado. }\end{array}$ & $\begin{array}{l}\text { No define a las minas huérfanas. } \\
\text { Sin embargo, define al sitio } \\
\text { minero histórico como aquel en el } \\
\text { que se han producido } \\
\text { perturbaciones mecánicas del } \\
\text { suelo o excavaciones para la } \\
\text { producción de minerales sin } \\
\text { autorizaciones derivadas de la Ley } \\
\text { de Actividades Mineras, } \\
\text { incluyendo a los sitios utilizados } \\
\text { para el procesamiento, } \\
\text { concentración y disposición de } \\
\text { residuos de minerales. }\end{array}$ \\
\hline Manitoba & \multicolumn{2}{|c|}{$\begin{array}{l}\text { No hace distinción entre minas huérfanas y abandonadas, y se refiere a } \\
\text { ambas como aquellas minas en las que el propietario no ha sido } \\
\text { identificado, no cuenta con los medios financieros o no está dispuesto a } \\
\text { realizar la rehabilitación del sitio minero. }\end{array}$} \\
\hline
\end{tabular}




\begin{tabular}{|c|l|l|}
\hline $\begin{array}{c}\text { Nuevo } \\
\text { Brunswick }\end{array}$ & $\begin{array}{l}\text { Mina o exploración minera inactiva } \\
\text { o sin derechos mineros vigentes, } \\
\text { que no cuenta con compañía minera } \\
\text { responsable o identificada. }\end{array}$ & \\
\hline Saskatchewan & $\begin{array}{l}\text { Sitio minero en el cual el operador } \\
\text { ha rechazado unilateralmente la } \\
\text { responsabilidad de la remediación, } \\
\text { voluntaria o involuntariamente (por } \\
\text { ejemplo, en caso haya sido } \\
\text { declarado en bancarrota). }\end{array}$ & Sitio minero abandonado sin \\
\hline
\end{tabular}

Fuente: NAOMI

Dada la diversidad de definiciones de sitios mineros abandonados y huérfanos, uno de los objetivos principales de NAOMI fue proponer un grupo de definiciones uniformizadas, que no colisionen con las específicas de cada jurisdicción, bajo las cuales pueda organizarse la información de las distintas provincias para así lograr inventariar las minas huérfanas y abandonadas en el territorio nacional. Como resultaron se dieron las siguientes definiciones: (http://www.noami.org/definitions_e.php)

a) Sitio Minero: Aquel lugar en el cual se han producido perturbaciones físicas como consecuencia de exploraciones y explotaciones mineras, así como por actividades de procesamiento de minerales.

b) Sitio Minero Abandonado o Huérfano (se utilizan como sinónimos): Sitio minero sin operador responsable identificado, el cual no ha sido remediado. En estos casos, la responsabilidad por la rehabilitación del sitio minero se revierte al Estado Federal o Provincial, dependiendo de la jurisdicción en la que se encuentre. Es preciso mencionar que, a diferencia del Perú, los sitios mineros abandonados pueden ser adoptados por una parte distinta al Estado, y volverse sitios mineros activos.

c) Legados Mineros: Sitios mineros desatendidos y no rehabilitado con responsable identificado. Es posible que el responsable no sea consciente de su propiedad.

Además, NAOMI propuso la siguiente clasificación de los sitios mineros, basada en sus características: 
a) Clase A: Sitio minero con potencial de causar afectaciones al medio ambiente, a la salud y seguridad pública.

b) Clase B: Sitio minero con potencial de causar afectaciones a la salud y seguridad pública, y con limitado potencial de causar afectaciones al medio ambiente.

c) Clase C: Sitio minero con potencial de causar afectaciones a la seguridad pública, y con poco o ningún potencial de causar afectaciones al medio ambiente y a la salud.

d) Clase D: Sitio minero sin ninguna afectación prevista hacia el medio ambiente, la salud y la seguridad pública.

e) Clase O: Sitio minero sin información disponible respecto de sus características.

Uno de los principales problemas para la rehabilitación de las minas abandonas en Canadá- al igual que para la remediación de los PAM en el Perú- es el financiamiento de estas acciones. En el año 2002, el comité consultivo de NAOMI instaló un grupo de trabajo con la responsabilidad de evaluar distintos enfoques de financiamiento y de documentar las opciones preferidas, que puedan adaptarse a las necesidades de cada jurisdicción. (Hogan y Tremblay, 2008, p 779)

Además, se elaboró el reporte denominado "Enfoques potenciales de financiamiento para las Minas Huérfanas/Abandonadas en Canadá" como herramienta para el grupo de Trabajo. A través de este documento se identificaron los siguientes enfoques de financiamiento: (Castrilli, 2003, p 9)

- Financiamiento del Estado a través de sus ingresos generales (recaudaciones tributarias)

- Constitución de un Fondo para la rehabilitación de las minas abandonadas/huérfanas, financiado por las contribuciones de la actual industria minera.

- Promoción de incentivos (deducciones tributarias, excepciones de responsabilidad, etc) por parte del Estado hacia las compañías mineras, a fin de que lleven a cabo las actividades de remediación en toda mina abandonada, o en sitios específicos.

- El Estado podría re direccionar una porción de los impuestos, subsidios e incentivos hacia la industria minera para la rehabilitación de las minas abandonadas.

- El Estado podría combinar los enfoques de financiamiento listados en los incisos precedentes. 
Asimismo, dicho documento recomendó que el régimen que se instaure para el financiamiento de la remediación de las minas abandonadas combine los siguientes mecanismos y enfoques: (Castrilli, 2003, p 94)

- Financiamiento del Estado a través de un solo nivel de gobierno, mediante sus ingresos generales.

- $\quad$ Impuestos a la producción de la industria minera.

- $\quad$ Asociaciones entre el Estado y la Industria.

- $\quad$ Re direccionamiento por parte del Estado de los impuestos existentes hacia la industria minera así como una reducción de incentivos, para que sean aplicados a la remediación de las minas abandonadas.

Utilización de intereses de fondos, multas y penalidades administrativas impuestas a la industria minera, donaciones individuales, etc.

Pese a que, por intermedio de NAOMI y de reportes como el presentado, se ha contribuido a la identificación de un financiamiento sostenible para la remediación de las minas abandonadas en Canadá; en la realidad, el financiamiento de dichas acciones proviene -en su mayoría- de compromisos estatales.

En el año 2003 el Gobierno Federal comprometió un presupuesto de 175 millones de dólares canadienses para la remediación por dos años de 57 sitios contaminados que se encontraban bajo su responsabilidad. Asimismo, en el año 2004 se aumentó el presupuesto a $\$ 3.5$ billones de dólares canadienses, los cuales debían de ser utilizados en acciones de rehabilitación de los sitios contaminados durante 10 años. (Hogan y Tremblay, 2008, p 783)

La siguiente tabla elaborada por la CEPAL sobre la base del "Mining Sector Performance Report 2012”, demuestra los compromisos para la remediación de los sitios contaminados asumidos por las distintas provincias canadienses: (Saade, 2014, p 23) 
Tabla 4. Canadá: Programas y Costos para la Remediación de Sitios

\section{Contaminados}

\begin{tabular}{|c|c|c|}
\hline Provincias & $\begin{array}{l}\text { Aplicación de Programas para la } \\
\text { Remediación de Sitios Contaminados. }\end{array}$ & Costos de remediación \\
\hline Columbia Británica & $\begin{array}{l}\text { En } 2003 \text { se estableció el Programa de } \\
\text { sitios contaminados de la Corona. Desde } \\
2003 \text { han sido remediados o estaban en } \\
\text { vías de hacerlo } 83 \text { sitios contaminados. }\end{array}$ & $\begin{array}{l}\text { Compromiso del gobierno en } \\
\text { gastos de remediación y manejo de } \\
\text { sitios contaminados por CAN\$276 } \\
\text { millones. A marzo del } 2013 \text { se } \\
\text { habían ejercido CAN\$161 millones. }\end{array}$ \\
\hline Manitoba & $\begin{array}{l}\text { En el } 2000 \text { se estableció el Programa de } \\
\text { Rehabilitación de Sitios Mineros } \\
\text { Huérfanos/Abandonados. Se identificaron } \\
149 \text { sitios contaminados que incluian } 5 \\
\text { sitios de alta prioridad (Lynn Lake, } \\
\text { Sherridon, Gods Lake, Snow Lake y } \\
\text { Baker Patton) y } 31 \text { sitios de alto riesgo. }\end{array}$ & $\begin{array}{l}\text { A diciembre del } 2012 \text {, la provincia } \\
\text { había gastado más de CAN\$100 } \\
\text { millones en la rehabilitación de } \\
\text { minas huérfanas y abandonadas. }\end{array}$ \\
\hline Terranova y Labrador & $\begin{array}{l}\text { Las minas huérfanas/abandonadas } \\
\text { preceden al Mining Act. }\end{array}$ & $\begin{array}{l}\text { Esta provincia ha gastado más de } \\
\text { CAN } \$ 30 \text { millones en los últimos } \\
\text { años en minas } \\
\text { huérfanas/abandonadas. }\end{array}$ \\
\hline Ontario & $\begin{array}{l}\text { En 1999, Ontario estableció un Fondo de } \\
\text { Rehabilitación de Minas Abandonadas. }\end{array}$ & $\begin{array}{l}\text { Entre septiembre de } 1999 \text { y marzo } \\
\text { del } 2013 \text { se han gastado CAN\$116 } \\
\text { millones en la rehabilitación de los } \\
\text { sitios de mayor prioridad. }\end{array}$ \\
\hline Quebec & $\begin{array}{l}\text { A marzo de } 2011 \text { el gobierno de Quebec } \\
\text { identificó } 679 \text { sitios mineros } \\
\text { contaminados que se estiman rehabilitar } \\
\text { en pocos años más. }\end{array}$ & $\begin{array}{l}\text { Los pasivos asociados a la } \\
\text { rehabilitación de las minas es del } \\
\text { orden de CAN } \$ 1,2 \text { billones. Hasta } \\
\text { ahora el gobierno ha asignado } \\
\text { CAN\$850 millones para la } \\
\text { rehabilitación de sitios } \\
\text { abandonados. }\end{array}$ \\
\hline
\end{tabular}

\section{Fuente: CEPAL}

Además de los compromisos estatales, es notable el compromiso de las empresas mineras por limpiar y rehabilitar los sitios mineros abandonados. En el año 2007 de instaló el "Fonds Restor-Action-Nunavik". Este fondo se constituyó por 30 compañías de exploración minera que operan en la provincia de Quebec, con el objetivo de remediar 18 sitios contaminados de alta prioridad en el territorio provincial, conjuntamente con el gobierno y la comunidad. De los 6 millones de dólares canadienses que maneja el Fondo; 4 millones de dólares provinieron de fondos del gobierno provincial de Quebec, y los dos millones restantes fueron contribuidos por la industria minera. Además de las contribuciones monetarias, las empresas comprometieron servicios, labores, equipos, acomodaciones, así como transporte aéreo y marítimo. Al 2017, se llevó a cabo la meta de rehabilitación de los 18 sitios contaminados, así como acciones de inspección final. (http://osiskogr.com/en/fonds-restor-action-nunavik-2/) 
Luego de haber realizado un análisis de la gestión de lo PAM en Perú como de las minas abandonadas y huérfanas en Canadá se puede comentar lo siguiente:

- Canadá ha comprometido un mayor monto del presupuesto público para la remediación de las minas abandonadas/huérfanas mientras que, en el Perú, el financiamiento para la remediación de los PAM depende de transferencias del sector público, así como de contribuciones y donaciones internacionales.

- $\quad$ A diferencia de Canadá, el Perú cuenta con una definición unitaria de PAM, así como un único Inventario Nacional.

- $\quad$ NAOMI es un ejemplo internacional de cómo mediante la colaboración entre distintos actores se puede enfrentar un problema de manera participativa, al proponer cambios y recomendaciones en la regulación de las minas abandonadas que consideren los intereses de todas las partes. De otro lado, el "Fonds RestorAction-Nunavik" demostró- con resultados tangibles- una colaboración eficiente entre el sector público y privado, al lograr el objetivo de remediación de 18 sitios contaminados de alta prioridad en un corto periodo.

En Canadá, existe la posibilidad de que una empresa minera pueda adoptar minas huérfanas y volverlas minas activas. Esto no sucede en Perú con los PAM, donde incluso no se permite irrestrictamente las modalidades de remediación voluntaria de los PAM bajo administración del Estado.

\subsubsection{Australia}

Anteriormente los estándares ambientales bajo los cuáles se realizaban las actividades mineras en Australia no eran igual de exigentes que los actuales. Como resultado, existen más de 50,000 minas abandonas alrededor del territorio australiano, de diferentes tamaños, características y complejidad, que representan riesgos a la salud y al medio ambiente. El siguiente mapa muestra la cantidad de minas abandonadas en cada jurisdicción, según la información disponible a Julio del 2011: (Unger, Lechner, Glenn, Edraki, Mulligan, 2012, p 262) 


\section{Gráfico 3. Minas Abandonadas en Australia}

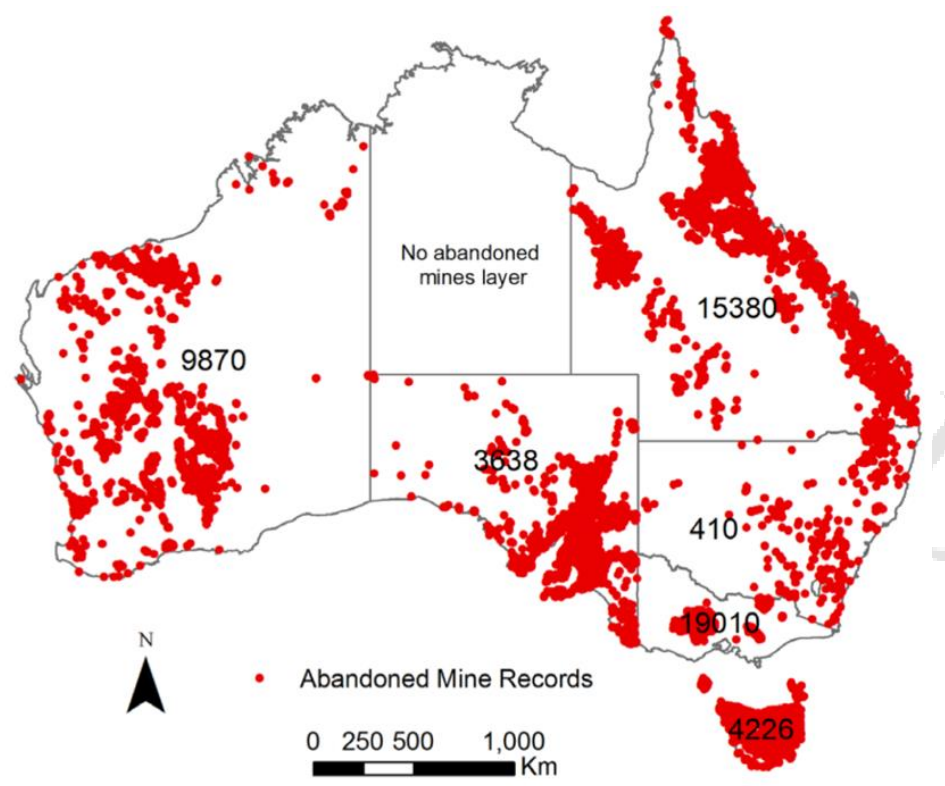

Fuente: (Unger, Lechner, Glenn, Edraki, Mulligan, 2012)

Las distintas jurisdicciones del territorio australiano tienen sus propias reglas y presupuestos para el manejo de las referidas minas. Incluso, solo 3 de las 7 jurisdicciones tienen programas formales de minas abandonadas: Queensland, Tasmania y Nueva Gales del Sur. Pocas cuentan con inventarios actualizados así como procesos de evaluación de riesgos y priorización de sitios contaminados. En este contexto, tomando como referencia la iniciativa canadiense de NAOMI, se llevó en el 2003 el Taller referente al "Manejo y la Remediación de Minas Abandonadas" el cual recomendó el desarrolló de una estrategia a nivel nacional para el manejo de las minas abandonadas. (Unger, Lechner, Glenn, Edraki, Mulligan, 2012, p 261-262)

Es así como, en el año 2010, el Grupo de Trabajo para Minas Abandonadas (AMWG, por sus siglas en inglés) publicó en el 2010 el "Marco Estratégico para Minas Abandonadas en la Industria Minera" (MEMAIM) con el fin objetivo principal de promover un enfoque estratégico para el manejo de las minas abandonadas, a fin de que los riesgos sean minimizados, los sitios manejados de manera eficiente y sostenible, con el reconocimiento de los valores de cada uno. Algunos de los asuntos abordados fueron: (MCMPR/MCA, 2010, p 7)

- $\quad$ El inventario de los sitios contaminados y el manejo de la información.

- La mejora de los conocimientos, relacionados a las minas abandonadas, respecto 
de responsabilidades y riesgos.

- $\quad$ La mejora del reporte de desempeños.

- La estandarización de procesos y metodologías.

- $\quad$ El compartimiento de conocimientos y habilidades entre jurisdicciones.

Al igual que NAOMI, el AMWG propuso una definición unitaria de minas abandonadas. Según el MEMAIN, estas vendrían a ser "aquellas minas donde los contratos o títulos mineros no siguen existiendo y la responsabilidad de rehabilitación no puede asignarse a un individuo, compañías u a organizaciones responsables por las actividades mineras originales.” (MCMPR/MCA, 2010, p 6)

Asimismo, a través del Capítulo 4 (Recursos y Oportunidades de Alianzas) del MEMAIN, el AMWG recomendó distintas asociaciones para los proyectos en minas abandonadas, entre las cuales se mencionó a las siguientes dos: (MCMPR/MCA, 2010, p 31)

a) Asociaciones entre Estado e Industria: Se señalan como posibles contribuciones por parte de la industria el ofrecimiento de servicios de gestión de proyectos, monitoreo ambiental, participación ciudadana, y consultoría en procedimientos y asuntos medio ambientales. Asimismo, se menciona la posibilidad de que las propias compañías rehabiliten las minas abandonadas a fin de ganar acceso a los recursos minerales.

b) Asociaciones con empresas privadas con intereses económicos en las minas: Según el MEMAIN, es posible que una empresa del sector privado se ofrezca a rehabilitar el sitio minero a fin de utilizarlo para otras actividades productivas. Pone como ejemplo la rehabilitación de minas abandonadas a fin de convertirlo en una instalación para la disposición de residuos.

Estas propuestas de alianzas son interesantes, ya que el costo de remediación de las minas abandonadas no puede ser asumido únicamente por el sector público o por el privado, toda vez que la rehabilitación de los sitios contaminados puede tomar años o décadas, y los compromisos monetarios son de largo plazo. 
En la actualidad, los mecanismos financieros utilizados en las distintas jurisdicciones de Australia para la limpieza de las minas abandonadas, son los siguientes: (Unger, Van Krieken, 2010, p 3 a 5)

a) Financiamiento Estatal: Los gobiernos estatales proveen fondos para la rehabilitación de las minas. Sin embargo, estos son limitados y dependen de un presupuesto volátil y la política del gobierno de turno. Como se mencionó anteriormente, son pocas las jurisdicciones con planes formales para el manejo de las minas abandonadas. (Saade, 2014, p 21-22)

\section{b) Impuestos a la producción minera}

c) Financiamiento público-privado: Es la opción más utilizada en Australia para financiar proyectos de infraestructura, y puede ser aplicada para la regeneración de las minas. Un ejemplo es el caso de la mina "Savage River", al noroeste de Tasmania. Del año 1966 al 1996, esta mina fue operada a tajo abierto, llevando a una severa contaminación del río ubicado dentro de la mina. Antes de la reapertura de esta mina en el año 1997, el gobierno de Tasmania implementó el Acuerdo de Goldamere, el cual estableció el programa de rehabilitación. El financiamiento para la remediación se realizó con los fondos establecidos por los propietarios anteriores existentes para el cierre de la mina, así como por el dinero proveniente de su compra por parte de los nuevos propietarios. Dado a que estos fondos aún eran insuficientes para la rehabilitación del sitio, el Gobierno de Tasmania conjuntamente con los nuevos propietarios implementaron un régimen de manejo y remediación; el Acuerdo de Goldamere permitía a los nuevos propietarios asumir contratos de remediación con el Estado, a fin de que pueda saldar con trabajo el precio de compra de la mina. Es preciso mencionar que el Acuerdo libraba de responsabilidad a los nuevos propietarios de la contaminación previa, existente o futura que sea causada por las operaciones anteriores, pero exigía a la nueva empresa su operación bajo las buenas prácticas ambientales existentes. Este acuerdo ha logrado que, desde el año 2000, se cumplan los objetivos de de calidad de agua propuestos para el río.

d) Fideicomisos: En el año 1995, a través del Mineral Resources Development Act, se constituyó en Tasmania un Fideicomiso para la remediación de las minas abandonadas. Asimismo, en el año 2013, se implementó en Australia Occidental el 
Fondo de Rehabilitación Minera, a utilizarse en caso los operadores mineros no cumplan con sus obligaciones de remediación.

Luego de haber realizado un análisis de la gestión de lo PAM en Perú como de las minas abandonadas en Australia se puede comentar lo siguiente:

- Tanto Perú como Australia entienden la importancia de un marco promotor de la inversión privada para la remediación de los PAM o las minas abandonadas.

- Por medio del MEMAIN, el AMWG ha hecho un mayor esfuerzo que Perú en la identificación de alianzas dinámicas entre el Estado y el Sector Privado, facilitando la re utilización de minerales por las empresas mineras y el uso del terreno para otras actividades productivas.

En Australia, solo 3 de las 7 jurisdicciones cuentan con un programa formal para el tratamiento de las minas abandonadas mientras que, en el Perú, la legislación específica de los PAM (Ley $\mathrm{N}^{\circ} 28271$, Ley que regula los pasivos ambientales de la actividad minera, y el RPAM) se aplica uniformemente a todos los departamentos. En Australia, existen impuestos a la producción minera recaudados para la remediación de las minas abandonadas. En el Perú, estos no han sido establecidos.

\subsection{Ejemplos de simplificación administrativa en los países de la Organización para la Cooperación y el Desarrollo Económico}

Con la simplificación administrativa se busca lograr procedimientos administrativos a costos razonables y sin trabas o complicaciones innecesarias, las cuales afectan no solo al ciudadano, sino también a la sociedad en su conjunto. Mayor cantidad de trámites implica mayores costos al mercado, y la consecuencia para el Estado es la dificultad para la captación de recursos de la inversión nacional y extranjera, así como una menor recaudación tributaria. (Maraví, 2000, pag 290)

Como bien señala Maraví, la simplificación administrativa en el Perú se ha reducido principalmente a la regulación de los Textos Únicos de Procedimientos Administrativos (TUPA) y no existe un control de la aplicación y cumplimiento de los principios y normas de simplificación administrativa. Incluso, de acuerdo con la Secretaría de Gestión Pública de la Presidencia del Consejo de Ministros, los principales 
avances han sido los siguientes: (http://sgp.pcm.gob.pe/simplificacion$\underline{\text { administrativa//) }}$

- $\quad$ Aprobación de TUPA modelos para las municipalidades distritales y provinciales, respecto de procedimientos específicos.

- Seguimiento por parte de la Secretaría de Gestión Pública a la actualización de los TUPA por parte de las entidades públicas, a fin de verificar su actualización a las nuevas metodologías.

- Asistencia técnica a los funcionarios y servidores encargados de la elaboración de los TUPA.

- Instalación de la "Mesa Nacional de Simplificación de Trámites", mesa de coordinación compuesta por la cooperación internacional, así como por entidades del sector público y privado, con la finalidad de que tiene como finalidad articular los esfuerzos en simplificación de trámites. Actualmente, la mesa se está concentrando en la simplificación de los trámites vinculados al sector turismo.

- Diseño de aplicativo informático para catalogar los trámites y servicios administrativos del Estado, a fin de estos se ubiquen en un solo portal de información para los usuarios.

De lo expuesto, queda demostrado que la mayoría de los esfuerzos de simplificación administrativa se han concentrado en la homogeneización y simplificación de trámites y de los TUPA, analizando si deben ser de aprobación automática o evaluación previa, los documentos a exigirse y la aplicación de los silencios administrativos. Por lo tanto, se ha perdido de vista el análisis de la finalidad y necesidad de la regulación, y de los beneficios y costos que conlleva para la ciudadanía y el sector privado.

Sin embargo, la creación del Servicio Nacional de Certificación Ambiental para las Inversiones Sostenibles (SENACE) es un ejemplo exitoso de reforma institucional que ha sido inspirada en los principios y normas que orientan la simplificación administrativa.

El SENACE fue creado en diciembre del 2012 a través de la Ley $\mathrm{N}^{\circ} 29968$ como un organismo público técnico especializado, adscrito al Ministerio del Ambiente. Su 
principal función es evaluar y aprobar los Estudios de Impacto Ambiental de mayor envergadura de los proyectos de inversión privada, pública o de capital mixto.

Al año 2021, se espera que la evaluación de los Estudios de Impacto Ambiental de todos los sectores sea transferida al SENACE, constituyéndose como la ventanilla única para la aprobación de la Certificación ambiental de los proyectos de inversión en el Perú. Por lo tanto, a través de esta institución se espera uniformizar los criterios de evaluación de los instrumentos de gestión ambiental, ofreciendo así un mejor servicio al ciudadano.

Asimismo, uno de los objetivos del SENACE es optimizar la evaluación ambiental, eliminando los procedimientos tediosos y burocráticos, en los cuales se debían presentar documentos de varias páginas con información poco relevante. Esta institución busca aprobar estudios eficientes, orientados únicamente a los temas ambientales relevantes del proyecto. (SENACE, 2018, p 4-5)

Un logro de simplificación administrativa llevado a cabo por esta entidad ha sido la aprobación de la Certificación Ambiental Global. Por su implementación, el Senace ganó el premio de "Buenas Prácticas en Gestión Pública 2017”, de la organización Ciudadanos al Día. El propósito de la Certificación Ambiental Global es el de lograr eficiencia en los procesos administrativos relacionados a la obtención de permisos ambientales, sin comprometer la protección del medio ambiente. (SENACE, 2018, p 4648)

Mediante la Certificación Ambiental Global se aprueba no únicamente el Estudio de Impacto Ambiental, sino que también se integran a este los títulos habilitantes que correspondan a la naturaleza del proyecto de inversión, y se encuentren relacionados a la certificación ambiental. Ejemplos de estos títulos habilitantes a integrarse se presentan en el siguiente gráfico: 


\section{Gráfico 4. Títulos Habilitantes a integrarse en la Certificación Ambiental Global}

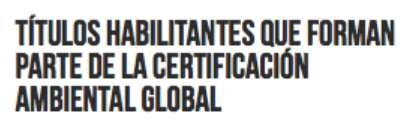

AMBIENTAL GLOBAL
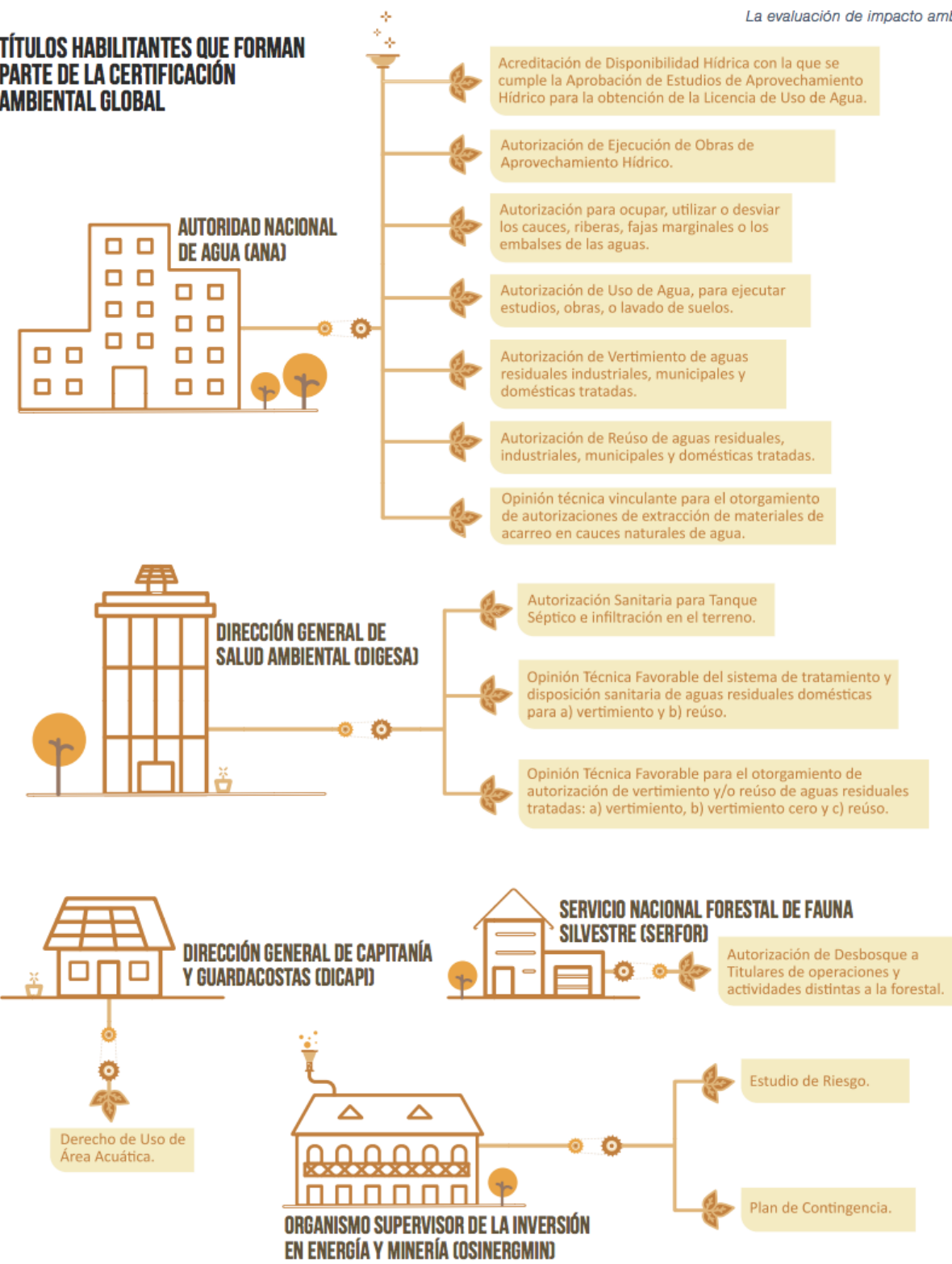

Fuente: (SENACE, 2018, p 47)

Los principales beneficios de este acto administrativo son las siguientes:

- $\quad$ Evita duplicidades en los procedimientos

- $\quad$ Evita contradicciones entre las distintas entidades evaluadoras.

- Reduce los costos transaccionales para los titulares de los proyectos de inversión.

- Garantiza trámites eficientes con plazos razonables, sin descuidar la calidad de la evaluación. 
En el caso de los PAM bajo administración del Estado, los costos para su remediación son excesivamente altos e implican compromisos monetarios de largo plazo para el aparato estatal. A fin de promover la participación del sector privado en su remediación, es necesario que los procedimientos administrativos a seguirse no impliquen costos y trámites innecesarios para quienes quieran involucrarse.

A continuación, se presentan distintos casos de simplificación administrativa que se han llevado en diferentes países pertenecientes a la Organización para la Cooperación y el Desarrollo Económico (OCDE), a la que el Perú aspira integrarse, y que pueden servir de ejemplo en los procedimientos relacionados a la remediación de los PAM bajo administración estatal:

\subsubsection{Australia}

Australia ha sido pionero en la instalación de Grupos de Trabajo para la evaluación de la regulación existente y la simplificación de procesos.

En Australia Occidental, por ejemplo, se instaló un panel para la revisión de regulación enfocado principalmente en la identificación de las prácticas regulatorias que impedían las operaciones en el mercado, con especial énfasis en las trabas para las pequeñas empresas. El Panel estaba conformado por representantes de las diferentes asociaciones industriales. (Organisation for Economic Co-operation and Development, 2003, p 76)

Por otro lado, a nivel federal, el Consejo de Gobiernos Australianos, instalado en 1994, ha impulsado reformas cooperativas entre los gobiernos, centralizadas en simplificación administrativa e iniciativas de reducción de carga administrativa. Asimismo, en la mayoría de las jurisdicciones se han establecido organismos especializados en reforma regulatoria. La función de estas instituciones es principalmente de supervisar los procesos de reforma regulatoria instaurados así como apoyar a las agencias responsables brindando recomendaciones independientes. Se busca lograr el cumplimiento de la finalidad de cada política pública o regulación instaurada con el menor impacto a los consumidores y al sector privado, asegurándose así la calidad de la misma. (Organisation for Economic Co-operation and Development, 2003, p 74- 75) 
Otro ejemplo interesante de organismo independiente enfocado en calidad regulatoria es el Grupo de Trabajo de Reducción de Burocracia de Queensland. Su propósito es el de ser un espacio de diálogo entre el sector privado y público, a fin de que el primero pueda proponer mejoras regulatorias relacionadas al sector empresarial. El Grupo de Trabajo reporta al Ministerio de Desarrollo Estatal, y está conformado por 10 miembros representantes del sector privado, y un representante del gobierno. Su principal propósito es el de identificar las principales cuestiones que impactan en el desarrollo de la regulación, y desarrollar estrategias integrales para enfrentarlas. Algunos de los asuntos abordados son: (Organisation for Economic Co-operation and Development, 2003, p 84-85)

- $\quad$ La evaluación inicial de la necesidad de la regulación

- $\quad$ La necesidad de eficiencia regulatoria

- La reducción de la carga de cumplimiento para el sector privado

- La promoción de un cambio cultural en el gobierno, a fin de que aumente el enfoque en políticas alternativas y medidas no regulatorias.

La gran contribución de estos Grupos de Trabajo es asegurar que el Estado tome en cuenta los intereses del sector privado y las áreas que le son más onerosas y gravosas, a la hora de formular políticas públicas, a fin de que se priorice la reducción de las principales trabas para las empresas como para los consumidores, y se identifiquen adecuadamente las necesidades del mercado.

Con relación a la simplificación administrativa; es notable la aprobación en 1997 por parte del Parlamento de Nueva Gales del Sur, de la Ley de Planificación y Evaluación Ambiental. Esta Ley significó una simplificación de los procesos para la obtención de permisos ambientales, instaurando ventanillas únicas para la tramitación de dichas autorizaciones. La aplicación de esta Ley ha resultado en la reducción de la duración de los procedimientos y costos de cumplimiento que debían asumir los empresarios, al instaurar un único punto de contacto para la obtención de las autorizaciones ambientales necesarias. (Organisation for Economic Co-operation and Development, 2003, p 95) 


\subsubsection{Francia}

Uno de los principales objetivos de la simplificación administrativa en Francia ha sido la modernización de las estructuras estatales y los modelos operativos.

En su mayoría, cada ministerio lleva a cabo la modernización de los procedimientos que tiene a su cargo y propone un programa anual de simplificación de formalidades administrativas y procedimientos, lo que contribuye a la elaboración de programa multianuales de modernización estatal.

Los planes que anualmente proponen los ministerios son presentados ante la Comisión de Simplificación Administrativa (COSA) para su evaluación. COSA luego los evalúa y hace entrega de las propuestas al Primer Ministro- quien es presidente de la comisión- para su revisión, junto con recomendaciones propias. El resultado es un esfuerzo coordinado de simplificación administrativa por parte del Estado, toda vez que las medidas de modernización que lleva a cabo cada ministerio contarán con la aprobación previa del Primer Ministro, y de un órgano externo. (Organisation for Economic Co-operation and Development, 2003, p 115-116)

Además de la evaluación de los procedimientos de cada ministerio, COSA es también responsable de lo siguiente: (Organisation for Economic Co-operation and Development, 2003, p 117)

a) Diseño de herramientas para la comprobación cuantitativa del impacto de las medidas adoptadas: Desarrollo de métodos para determinar ahorros en tiempo, número de procesos eliminados y ahorros económicos para los usuarios, como consecuencia de la simplificación administrativa.

b) Seguimiento a la implementación por parte de los ministerios de las medidas acordados.

c) Evaluación de Formatos: COSA desarrolla procesos para la evaluación cualitativa de formularios (físicos o electrónicos). Aspectos de los formularios a evaluar son el cumplimiento de la ley, la claridad para los usuarios, la necesidad o no de documentos adicionales, y la necesidad de visitas a las oficinas administrativas. Además, COSA provee un sello de calidad para los documentos que cuentan con los mejores diseños. 
De acuerdo con la OCDE, los esfuerzos de COSA, conjuntamente con las demás prácticas de simplificación administrativa llevadas en Francia, han resultado en la eliminación o simplificación de 25 millones de procedimientos, el ahorro de 10 millones de horas gastadas en los procedimientos y esperas en las oficinas administrativas, así como de un estimado de 91.5 millones de euros. (Organisation for Economic Cooperation and Development, 2003, p 126-127)

\subsubsection{México}

Entre 1989 y 1994, existía en México una falta de transparencia y apertura en la elaboración de las regulaciones sectoriales. Las autoridades actuaban de manera discrecional, sin métodos uniformizados y exigiendo el cumplimiento de una gran cantidad de formalidades a los usuarios de la administración pública. El Plan de Desarrollo Nacional de estos años señaló que la falta de métodos efectivos para combatir la democracia constituía un obstáculo al desarrollo económico. Desde ese entonces, ha existido en México una reducción en el tamaño del sector público, las formalidades en los procedimientos y de las legislaciones que imponían cargas innecesarias al sector privado. La simplificación administrativa ha sido uno de los mecanismos utilizados para ello. (Organisation for Economic Co-operation and Development, 2003, p 150)

De manera similar a la COSA en Francia, mediante la Ley Federal del Procedimiento Administrativo, se instaló en México en el año 2000, la Comisión Federal de Mejora Regulatoria (COFEMER). La COFEMER es un órgano administrativo desconcentrado, con autonomía técnica y operativa, adscrito a la Secretaría de Economía del Gobierno Federal de México. Su principal función es de impulsar la política de mejora regulatoria, a través de lo siguiente: (https://www.gob.mx/se/)

a) Revisión del marco regulatorio nacional: La COFEMER no solo diagnostica su aplicación, sino también formula propuestas legislativas y administrativas para la mejora del mismo en sectores específicos.

b) Análisis de las posibles regulaciones a emitirse por las dependencias del

Gobierno Federal: A fin de garantizar que los beneficios de la regulación sean mayores a sus costos, la COFEMER realiza un dictamen de las mismas. Las regulaciones propuestas deben ser presentadas a la COFEMER junto con un 
Análisis de Impacto Regulatorio. Si la regulación no es presentada conjuntamente con dicho análisis, se genera un incumplimiento a la Ley y, como consecuencia, la Contraloría General impondrá la correspondiente sanción a los oficiales responsables.

c) Administración del Registro Federal de Trámites y Servicios: Este registro es un inventario de los trámites existentes a nivel de la Administración Pública Federal. No se permite la aplicación de trámites que no pertenezcan a este registro así como su aplicación en forma distinta, lo que es considerado ilegal y por lo tanto, no sería exigible su cumplimiento a los usuarios de los servicios públicos.

d) Asesoramiento Técnico a Entidades Federativas y Municipios: La COFEMER brinda asesoramiento en mejora regulatoria, a fin de promover la eficiencia de la administración a un nivel local.

De acuerdo con el Informe Anual de Desempeño del 2016-2017 de la COFEMER ${ }^{3}$, en su Programa de Desarrollo Innovador 2013 - 2018, la Secretaría de Economía fijó el objetivo de reducir en un $25 \%$ la carga regulatoria para los ciudadanos y el sector privado. Se estimó que el costo de cumplimiento de los trámites y servicios federales equivalía al $4.25 \%$ del Producto Interno Bruto (PIB) del país, por lo que el cumplimiento de la meta significaba la reducción de dicho costo a un 3.15\% del PIB. A diciembre del 2017, los esfuerzo de la COFEMER lograron reducir dicho indicador a un $2.68 \%$ del PIB, superando la meta establecida por la Secretaría de Economía, entidad a la cual se encuentra adscrita la COFEMER. (COFEMER, 2017, p 10-11)

El siguiente gráfico muestra la cantidad de anteproyectos regulatorios evaluados por la COFEMER desde el año 2000, incluyendo a proyectos con o sin costos de cumplimiento presentados, reglas de operación y a las Solicitudes de Opinión sobre Tratados Internacionales (SOTI): (COFEMER, 2017, p 16)

\footnotetext{
${ }^{3}$ http://www.cofemer.gob.mx/docs-bin/dg/Informe_anual_2017.pdf
} 


\section{Gráfico 5. Evaluación de anteproyectos regulatorios por parte de la COFEMER}

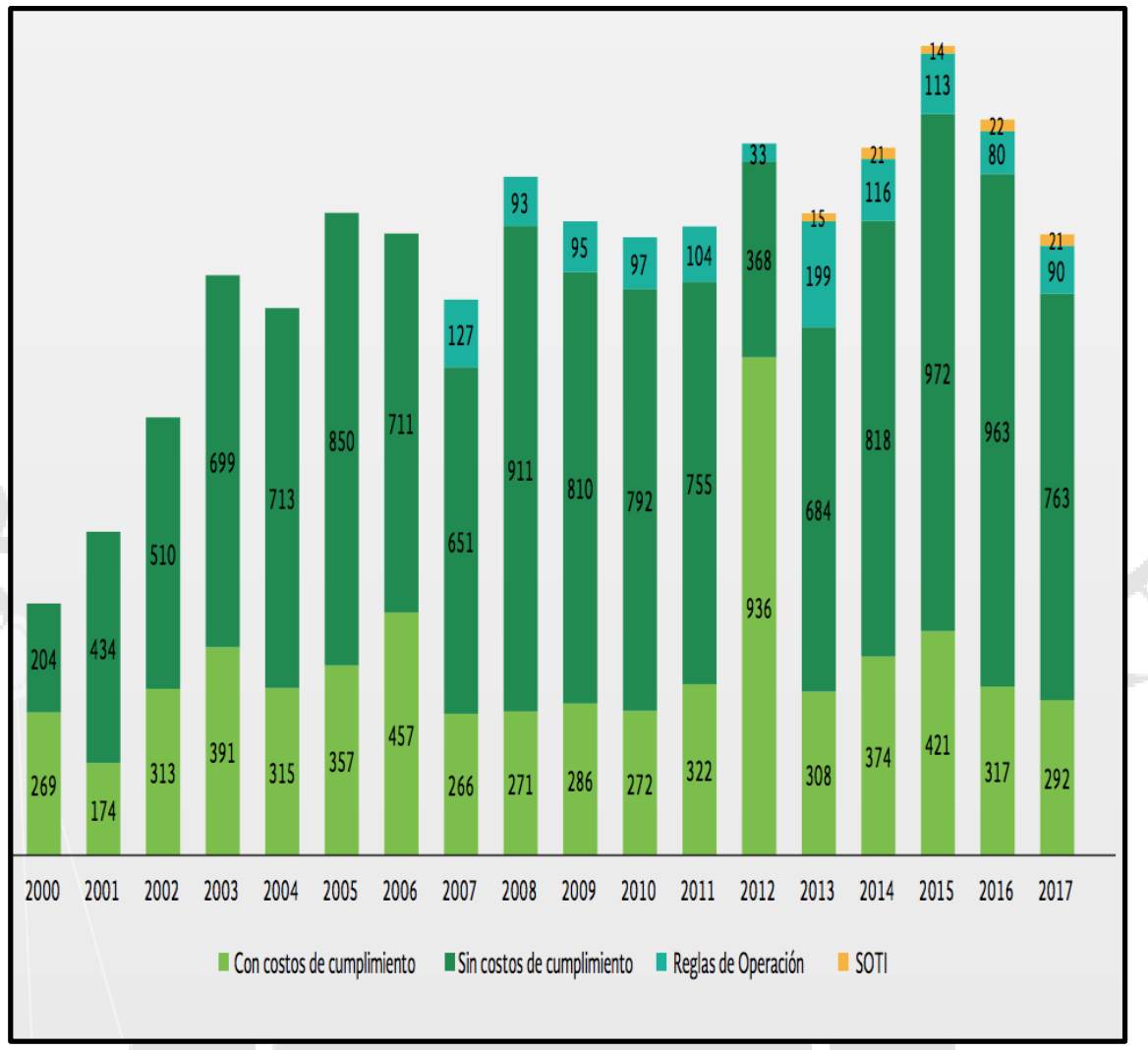

Fuente: (COFEMER, 2017)

\subsection{Conclusiones Preliminares}

En atención a lo expuesto respecto de la gestión de los PAM en Estados Unidos, Canadá y Australia; es posible concluir lo siguiente:

- Desde el retiro de los impuestos a la industria petrolera y química, y del impuesto al ingreso corporativo; la limpieza de los sitios contaminados en Estados Unidos ha sido demorada por la insuficiencia de fondos para el Programa Superfund. Esto demuestra que, incluso en países con gran poder económico, no resulta eficiente que los compromisos financieros de remediación de PAM sean asumidos únicamente por el Estado.

- $\quad$ En Estados Unidos, los procedimientos para la gestión de los PAM resultan más sencillos, toda vez que - a diferencia del Perú- la única institución involucrada es la EPA. Asimismo, no existen procesos de remediación distintos dependiendo de si el responsable es un privado o el Estado. 
- La instalación de NAOMI, en Canadá, es un ejemplo de colaboración del sector privado no solo en el financiamiento de la remediación de los PAM, sino también en su regulación- incluyendo a las formulación de definiciones unitarias- y en la identificación de enfoques de financiamiento que resulten adecuados a largo plazo.

- $\quad$ En Australia, las propuestas formuladas por el AMWG a través del MEMAIN como las medidas tomadas por las jurisdicciones han identificado la importancia de un financiamiento compartido entre el Estado y el Sector Privado, para la remediación de los PAM; sea por la facilitación de la re utilización de minerales por las empresas mineras, el uso del terreno para otras actividades productivas, la instauración de impuestos a la producción minera, o por el acuerdo de financiamientos mixtos específicos.

Finalmente, con relación a las iniciativas de simplificación administrativa tomadas en Australia, Francia y México, se concluye lo siguiente:

- Los Grupos de Trabajo y las Comisiones enfocadas en la simplificación administrativa instauradas en Australia, Francia y México tienen el beneficio de asegurar que, a la hora de formular políticas públicas, se priorice la reducción de las trabas que son más onerosas para el mercado y los usuarios de los servicios. En el Perú, podría instalarse una comisión específica inspirada en los ejemplos mencionados en el presente capítulo, para la revisión de los procedimientos vinculados a la gestión de los PAM.

Los beneficios de la simplificación administrativa se trasladan en la eliminación de trámites burocráticos innecesarios, el ahorro de horas gastadas en procedimientos y oficinas administrativas, y en la reducción de los costos monetarios vinculados al cumplimiento de trámites y servicios para los usuarios y el mercado. 


\section{CAPÍTULO CUATRO: MODIFICACIONES A LA REGULACIÓN ACTUAL DE LOS PAM BAJO ADMINISTRACIÓN DEL ESTADO}

En mayo del año 2018, el ministro de energía y minas, Francisco Ísmodes, declaró que su gestión propondría leyes que fomenten la remediación de los PAM, usando para ello el programa de obras por impuestos y añadió que, además, se gestionarían fuentes de financiamiento con la cooperación internacional. (MEM propondrá leyes que incentiven la remediación de pasivos ambientales por OxI, 2018)

Asimismo, en agosto del mismo año, el ministro precisó que, a dicha fecha, existían 9 mil PAM y sería necesaria una inversión aproximada de 7 mil millones de soles para la remediación de estos y de los 3 mil pasivos ambientales provenientes del sector hidrocarburos. (Ministerio de Energía y Minas, 2018)

Como ha sido expresado en el desarrollo del segundo capítulo de la presente investigación, depender fundamentalmente de mecanismos financieros internacionales para la remediación de los PAM no es adecuado, toda vez que estos tienen baja prioridad internacionalmente y los donantes extranjeros no se encuentran dispuestos a financiar un problema generado por el sector más fuerte de la economía peruana. Considerando además los ingentes recursos que demanda remediar la gran cantidad de PAM identificados.

De otro, la legislación comparada descrita en el tercer capítulo evidenció que los esfuerzos para la remediación de los PAM no pueden darse únicamente desde el Estado, sino que es necesario un trabajo conjunto con el sector privado. En ese sentido, la propuesta del ministro Ísmodes referida al manejo de los PAM mediante el mecanismo de obras por impuestos es adecuada. Sin embargo, la participación del sector privado no debe darse únicamente en este programa, toda vez que la inversión necesaria para cumplir con la remediación de todos los PAM existentes a la fecha (7 mil millones de soles) es 
extremadamente alta, y el programa de obras por impuesto cuenta con limitaciones de orden legal.

A lo largo de este capítulo -y en atención a lo desarrollado en los anteriores- se analizará la conveniencia de las distintas modalidades de inversión privada en la remediación los PAM bajo administración del Estado y se identificarán las distintas maneras en las cuales la participación del sector privado favorecería su remediación (más allá de los compromisos financieros) demostrando, además, los beneficios de una participación limitada por parte del Estado. Finalmente, se propondrán mejoras a los mecanismos existentes para el financiamiento de los PAM, con un enfoque en la redistribución de los ingresos estatales.

\subsection{La Inversión Privada en la remediación de los PAM bajo administración del}

\section{Estado}

El artículo 58 de la Constitución Política del Perú (1993) establece que el régimen económico del Perú se ejerce en una economía social de mercado:

"Artículo 58․- La iniciativa privada es libre. Se ejerce en una economía social de mercado. Bajo este régimen, el Estado orienta el desarrollo del país, y actúa principalmente en las áreas de promoción de empleo, salud, educación, seguridad, servicios públicos e infraestructura." (el subrayado es agregado propio)

Al respecto, el Tribunal Constitucional ha señalado lo siguiente:

"49. Tal como ha quedado dicho, uno de los principios rectores que informan al régimen económico de la Constitución es la función reguladora supletoria del Estado. Ello porque la economía social de mercado no puede ser confundida con los regímenes de economía mixta, planificada o interventora.

La labor del cuerpo político, en el contexto de un Estado social y democrático de derecho, no puede ser asociada a la idea de que tenga por regla incidir en la esfera de libertad de los agentes económicos. Su intervención, en lo que al funcionamiento de regular del mercado se refiere, debe configurarse como excepcional. Y es que toda regulación estatal debe justificarse por la presencia de una falla del mercado, es decir, por una situación en la que el libre juego de la oferta y la demanda y el régimen de libre competencia impidan alcanzar una asignación eficiente de recursos, lesionando 
intereses públicos." (Sentencia del Expediente $\mathrm{N}^{\circ}$ 0008-2003-AL/TC, 2003) (el subrayado es agregado propio)

En ese sentido, en atención a la economía social de mercado, la intervención del estado es excepcional y únicamente se dará en caso el mercado y la iniciativa privada no lleven a una la asignación eficiente de los recursos. Asimismo, conforme se mencionó anteriormente en la presente investigación, el rol subsidiario del Estado recogido en el artículo 60 de la Constitución Política del Perú establece que la actividad empresarial del Estado se realizará únicamente por razón de alto interés público o de manifiesta conveniencia nacional.

\subsubsection{La Privatización}

Un primer paso en el Perú para la aplicación de la economía social de mercado fue la privatización de las empresas públicas, por medio de la cual se transfieren los derechos de propiedad de las mismas a los privados. Usualmente, esta modalidad de inversión privada se da en los casos en los que es necesaria la apertura del mercado y la integración económica de un país, existen presiones de organismos internacionales, hay escasez de recursos estatales para financiar infraestructura, y/o el manejo del Estado de las empresas no ha llevado a resultados idóneos. En Latinoamérica, la crisis económica que se atravesó en varios países, así como la disponibilidad de inversionistas extranjeros, hizo de la privatización la solución a los problemas que sufrían los usuarios de los bienes y servicios que producían las empresas públicas. (Maraví et al. 2012, p 18-29).

Sin embargo, según Maraví (2012), la privatización no siempre es la solución adecuada y podrá utilizarse siempre que: pueda asegurarse la continuidad y sostenibilidad en la prestación de un servicio, cuando los riesgos involucrados en el negocio no sean muy altos, y en caso no haya un impacto político indeseable, toda vez que la privatización genera en la población una sensación de desprotección por parte del Estado (p 22-23).

Por lo tanto, para el caso de los PAM, no sería adecuado privatizar AMSAC a fin de que un privado ofrezca el servicio de remediación por lo siguiente:

- $\quad$ La inversión necesaria para la remediación de los PAM bajo administración del Estado es sumamente alta. 
- El privado estaría interesado en remediar los PAM siempre y cuando pueda lucrar de esta actividad, lo cual no siempre será el caso. En ese sentido, muchos PAM de alto riesgo no serían remediados por falta de interés del inversionista.

- $\quad$ El impacto político de una privatización de AMSAC sería muy alto, toda vez que la remediación de los PAM es una actividad sumamente sensible con un impacto en salud de las personas y en el derecho de estas a gozar de un medioambiente sano. En ese sentido, las poblaciones cercanas a los pasivos a remediarse exigirían la presencia de una entidad estatal.

\subsubsection{Las Asociaciones Público Privadas}

Posteriormente, surgieron en América Latina las Asociaciones Públicas Privadas (APP) como una herramienta para atender el déficit de infraestructura existente. Al incorporar al sector privado a la provisión de servicios e infraestructura, se generaban mayores posibilidades técnicas, financieras y gerenciales para el Estado. (Humberto Alva, 2017, p 33).

El Decreto Legislativo $\mathrm{N}^{\circ} 1224$, modificado por Decreto Legislativo $\mathrm{N}^{\circ} 1251$, define a las APP de la siguiente manera:

\section{“Artículo 11.- Definición}

11.1 Las Asociaciones Público Privadas son modalidades de participación de la inversión privada, en las que se incorpora experiencia, conocimientos, equipos, tecnología, y se distribuyen riesgos y recursos, preferentemente privados, con el objeto de crear, desarrollar, mejorar, operar o mantener infraestructura pública y/o proveer servicios públicos bajo los mecanismos contractuales permitidos por el marco legal vigente. Las Asociaciones Público Privadas se originan por iniciativa estatal o iniciativa privada.

11.2 Los contratos de Asociaciones Público Privadas son de largo plazo, en los cuales debe existir una adecuada distribución de riesgos entre las partes, de manera que los riesgos sean asignados a aquella parte con mayores capacidades para administrarlos, considerando el perfil de riesgos del proyecto. Asimismo, en todas las fases de desarrollo de las Asociaciones Público Privadas debe contemplarse el principio de valor por dinero, buscando la combinación óptima entre los costos y la calidad del servicio público ofrecido a los usuarios, a lo largo de la vida del proyecto. 
11.3 Puede desarrollarse un proyecto de Asociación Público Privada sobre la base de uno o más proyectos de inversión pública, siempre que estos últimos sean declarados viables en el marco del Sistema Nacional de Inversión Pública.

11.4 En una Asociación Público Privada participan el Estado, a través de alguna de las entidades públicas, y uno o más inversionistas privados."

De acuerdo con el European PPP Expertise Centre, las APP son contratos basados en la provisión de servicios por parte del privado que consideran el ciclo de vida completo del proyecto, bajo los cuales se le transfiere los riesgos del mismo y donde el pago al inversionista privado (a través de cobro de tarifas o pagos directos del Estado) esta directamente ligado al servicio prestado (como se citó en Humberto Alva, 2017, p. 33).

Maraví (2012), agrega que las APP “permiten esquemas de financiamiento y recuperación de equilibrio económico financiero que no necesariamente se verifican en la privatización. Por eso, para los inversionistas resulta preferible comprometerse en un esquema de APPs frente a uno de privatización". (p. 34)

Con base en lo expuesto, podemos concluir que, mediante las APP se busca la calidad de la infraestructura pública y/o servicios públicos, generándose así un beneficio para los consumidores. Al incorporar al sector privado, estos proyectos son gestionados con el financiamiento necesario, eficiencia y con una mayor capacidad técnica. El sector privado se beneficia con esta modalidad de contratación toda vez que mantiene el control del proyecto en todas sus etapas, a fin de asegurar su rentabilidad. Asimismo, se permiten esquemas de cofinanciamiento junto con el Estado lo cual alivia la inversión por parte del privado, sin que este pierda la posibilidad de gestionar el proyecto.

Según el Artículo 11 del Decreto Supremo No 410-2015-EF, que aprobó el Reglamento del Decreto Legislativo $N^{\circ}$ 1224; los tipos de proyecto que pueden desarrollarse a través de APP son de infraestructura pública en general, como redes viales, ferrocarriles, aeropuertos, puertos, infraestructura urbana, infraestructura penitenciaria, de salud y de educación, etc; así como servicios públicos, como los de telecomunicaciones, energía y alumbrado, agua y saneamiento, u otros de interés social relacionados con la educación, la salud y el ambiente, como el tratamiento y procesamiento de residuos, entre otros. En todos estos casos, como se mencionó 
anteriormente, el inversionista recupera su inversión mediante el cobro de tarifas a los usuarios o por transferencias directas del Estado.

Utilizar esta modalidad de inversión privada para los PAM bajo administración del Estado facilitaría la remediación de los mismos, toda vez que el sector privado cuenta con mayor presupuesto y experiencia técnica para llevar a cabo esta tarea, e implicaría una reducción de los trámites burocráticos involucrados. Sin embargo, no resultaría de interés para los inversionistas privados, por las siguientes razones:

- Los proyectos de APP son de largo plazo y el inversionista cuenta con el control del proyecto desde sus inicios, a fin de que pueda obtener los resultados necesarios para asegurar la inversión. En este caso, no es posible determinar con anticipación los costos involucrados, ni tampoco asegurar al inversionista el control del proyecto en su totalidad.

A diferencia de los servicios públicos de telecomunicaciones o alumbrado, la restauración de los PAM no implicaría el uso continuo de un servicio o infraestructura pública por parte de la sociedad, por lo que no se asegura una fuente de ingreso continúa para el privado ni una estructura explotable, no resultando atractivo para el inversionista.

Al momento de que el privado realice un análisis costo - beneficio del proyecto; el hecho de que la demanda del servicio no sea igual de alta como en el caso de la construcción de redes viales o puertos y que los riesgos a asumirse son altos, llevaría al inversionista a concluir que su inversión no aseguraría retornos atractivos.

En conclusión, pese a que las APP son socialmente rentables, no podrían ser utilizadas para la solución de este problema.

\subsubsection{El mecanismo de Obras por Impuesto}

Las Obras por Impuesto (OxI), en cambio, podrían ser utilizadas para la remediación de los PAM bajo administración del Estado.

El 20 de mayo 2008 se instauraron en el Perú las OxI mediante Ley $\mathbf{N}^{\mathbf{0}}$ 29230, Ley que Impulsa la Inversión Pública Regional y Local con Participación del Sector Privado. 
Por el mecanismo OxI se busca la ejecución de proyectos de inversión pública con participación del sector privado mediante la suscripción de convenios con todo nivel de Estado y/o Universidades Públicas, mediante los cuales las empresas se comprometen a ejecutar o financiar un proyecto de inversión pública- seleccionado en armonía con los planes de desarrollo de nacional, regional y local- con cargo a su impuesto a la renta de tercera categoría. A cambio, el Ministerio de Economía y Finanzas emite Certificados de Inversión Pública Regional y Local o Nacional (CIPRL) que se aplican contra el pago del Impuesto a la Renta resultante del privado. (Salinas Rivas, 2015, p 276).

Desde su instalación en el 2008, el marco normativo que regula las OxI se ha ido complementando. A continuación, se hace un listado de las modificaciones más importantes:

1) Decreto Supremo No 248-2009-EF: Aprueba el Texto Único Ordenado (TUO) del Reglamento de la Ley No 29230, el cual se encuentra derogado a la fecha.

2) Decreto Supremo No 220-2010-EF: Modifica el TUO del Reglamento de la Ley $\mathrm{N}^{\mathrm{o}} 29230$, estableciéndose la posibilidad de que se incorpore al monto total de la inversión reconocido en el CIPRL, las modificaciones que tenga el proyecto de inversión pública.

3) Decreto Supremo No 133-2012-EF: Aprueba el Nuevo Reglamento de la Ley No 29230 y establece la posibilidad de que los proyectos de inversión puedan incluir componentes como equipamiento, reingeniería de procesos, sistemas de información u otros. Asimismo, se incluye dentro de los alcances de las OxI a los proyectos intermunicipales o interregionales.

4) Ley $\mathbf{N}^{\mathbf{0}}$ 30056, Ley que modifica diversas leyes para facilitar la inversión, impulsar el desarrollo productivo y el crecimiento empresarial: Modifica la Ley $\mathrm{N}^{\circ} 29230$ y fortalece el mecanismo de OxI introduciendo la posibilidad de adjudicación directa de proyectos en casos específicos, la negociabilidad de los CIPRL, la extensión de la aplicación de las OxI a todo proyecto de inversión pública con declaración de viabilidad y la inclusión de las Universidades Públicas en el marco de la Ley de OxI.

5) Ley $\mathbf{N}^{\circ}$ 30138, Ley que dicta medidas complementarias para la ejecución de proyectos en el marco de la Ley $\mathbf{N}^{\circ}$ 29230: Incluye al mantenimiento del Proyecto de Inversión dentro del mecanismo de OxI. 
6) Decreto Supremo No 005-2014-EF: Aprueba el Nuevo Reglamento de la Ley No 29230 y se permite al sector privado proponer proyectos de inversión a financiarse por OxI.

7) Ley $\mathbf{N}^{\mathbf{0}}$ 30264, Ley que establece medidas para promover el crecimiento Económico: A través de su artículo $17^{\circ}$, incorpora a entidades del Gobierno Nacional en los alcances de la Ley $\mathrm{N}^{\circ} 29230$, a fin de que puedan ejecutar proyectos de inversión pública en salud, educación, turismo, agricultura y riego, orden público y seguridad, bajo el mecanismo OXI.

8) Decreto Legislativo $\mathbf{N}^{\mathbf{0}}$ 1250: Incorpora a los sectores electrificación rural, pesca, deporte, ambiente, habilitación urbana, protección social, desarrollo social, transportes, comunicaciones y justicia, en la aplicación de las OxI.

9) Decreto Supremo No 036-2017-EF: Aprueba el Nuevo Reglamento de la Ley No 29230.

Al 2015, mediante el mecanismo de OxI se habrían adjudicado a empresas privadas el estudio y ejecución de 159 proyectos de inversión pública, por más de S/. 1, 505 millones, beneficiando a un total de 9 millones de peruanos (ProInversión, 2015, p 5). En ese sentido, desde su instauración, el mecanismo de OxI ha resultado exitoso.

Para las empresas del sector privado, las OxI son una oportunidad de vincular su presupuesto de responsabilidad social a los proyectos priorizados, a fin de obtener el retorno de su inversión por intermedio de los CIPRL aplicables al Impuesto a la Renta.

El Tribunal Constitucional, mediante Pleno Jurisdiccional No 48-2004-PI-TC del 7 de abril 2005, estableció la siguiente relación entre el desarrollo sostenible y la responsabilidad social de las empresas que realizan actividades con impacto en el medio ambiente (como es el caso de las actividades extractivas):

"18. En cuanto al vínculo existente entre la producción económica y el derecho a un ambiente equilibrado y adecuado al desarrollo de la vida, se materializa en función a los principios siguientes: a) el principio de desarrollo sostenible o sustentable (...)

20. Al respecto, en 1987, la Comisión Mundial sobre el Medio Ambiente y Desarrollo de las Naciones Unidas, conocida también como la Comisión Brundtland, emitió su informe en el que definió el desarrollo sostenible como aquel proceso en donde se asegura la satisfacción de las necesidades humanas del presente sin que se ponga en peligro la 
capacidad de las generaciones futuras para atender sus propias necesidades y que, por ende, involucre la utilización de recursos, la dirección de las inversiones y la orientación de los cambios tecnológicos e institucionales que acrecienten el potencial actual y futuro de los recursos naturales en aras de atender las necesidades y aspiraciones humanas.

21. Por su parte, la Declaración de Río sobre el Medio Ambiente y el Desarrollo, del mes de junio de 1992, que recoge entre sus principales fines la integridad del sistema ambiental y de desarrollo mundial, proclama, entre otras cosas, una serie de principios, entre los que destacamos lo siguiente:

- Los seres humanos constituyen el centro de las preocupaciones relacionadas con el desarrollo sostenible. Tienen derecho a una vida saludable y productiva en armonía con la naturaleza.

- El derecho al desarrollo debe ejercerse en forma tal que responda equitativamente a las necesidades de desarrollo y ambientales de las generaciones presentes y futuras.

- Todos los Estados y todas las personas deberán cooperar en la tarea esencial de erradicar la pobreza como presupuesto indispensable para el desarrollo sostenible, a fin de reducir las disparidades en los niveles de vida y responder adecuadamente a las necesidades de la mayoría de los pueblos del mundo.

(...)

22. En atención a lo expuesto, el desarrollo sostenible o sustentable requiere de la responsabilidad social: ello implica la generación de actitudes y comportamientos de los agentes económicos y el establecimiento de políticas de promoción y el desarrollo de actividades que, en función del aprovechamiento o uso de los bienes ambientales, procuren el bien común y el bienestar general.

(...)

26. En el caso del medio ambiente, la responsabilidad social debe implicar el mantenimiento de un enfoque preventivo que favorezca su conservación; el fomento de iniciativas que promuevan una mayor responsabilidad ambiental; el fomento de inversiones en pro de las comunidades afincadas en el área de explotación; la búsqueda del desarrollo y la difusión de tecnologías compatibles con la conservación del ambiente, entre otras. " (Sentencia del Pleno Jurisdiccional No 48-2004-PI-TC, 2005) (El subrayado es agregado propio)

En ese sentido, para que la empresa minera lleve sus actividades de conformidad con el principio de desarrollo sostenible, necesariamente debe cumplir con estándares de responsabilidad social. 
Asimismo, la Ley No 27446, Ley del Sistema Nacional de Evaluación de Impacto Ambiental, establece en su artículo $34^{\circ}$ lo siguiente:

\section{"Artículo 34".- Impactos sociales en el ámbito del SEIA}

Entiéndase que toda referencia al impacto ambiental en el marco del SEIA comprende los impactos sociales que estuvieran relacionados, respecto de los cuales se deben considerar las medidas necesarias de acuerdo a cada proyecto de inversión, de modo que se asegure una gestión social adecuada, la transparencia de los procesos, la prevención de conflictos, así como la prevención, control, mitigación y eventual compensación e indemnización por los impactos sociales que se pudieran generar."

Por lo tanto, a fin de obtener la certificación ambiental (necesaria para el inicio de sus actividades), las empresas mineras deberán incurrir en los referidos gastos de responsabilidad social para la identificación de los impactos de la actividad y la implementación de las medidas de manejo necesarias.

Sin embargo, la Administración Tributaria usualmente cuestiona estos gastos de responsabilidad social. Según Zegarra (2009) "no se reconoce la necesidad de esta inversión social como vinculante con la generación de renta gravada. No se reconoce que estos gastos sí inciden directamente en el correcto desarrollo de las empresas. Por lo tanto, se asume que son donaciones, liberalidades que no cumplen con el principio de causalidad, y por lo tanto tienen un costo tributario adicional de $30 \%$ como gasto no deducible." (p. 15)

Las OxI, en cambio, permiten a las empresas mejorar la calidad de vida de las comunidades de su entorno sin que se cuestione la deducibilidad de estos gastos. Las empresas del sector extractivo podrían revisar sus programas de responsabilidad social y vincularlos a la lista de los proyectos priorizados de la zona de influencia, a fin de que sean ejecutados a través de este mecanismo, optimizando su impuesto a la renta con la aplicación de los CIPRL, los cuales incluso pueden negociarse y transferirse a terceros en casos de falta de liquidez. (De la Vega, 2017, p 37)

Según Jose Escaffi, gerente general de "AC Pública" de Apoyo Consultoría, las empresas que, actualmente, más aprovechan el mecanismo de OxI son las pertenecientes a los sectores de minería y finanzas, siendo responsables de más del $64 \%$ del total de 
proyectos ejecutados en OxI, a julio del 2018. En el caso de las mineras, el mecanismo de OxI permite actuar en beneficio de la población ubicada en la zona de influencia del proyecto, al tomar conocimiento de las necesidades existentes y haciendo uso efectivo de las contribuciones tributarias. (Obras por Impuestos: Mineras lideran ejecución de proyectos con S/ 1,256 millones, 2018)

Si las empresas mineras pudiesen financiar mediante OxI la remediación de los PAM inventariados, se les permitiría canalizar los gastos de responsabilidad social para la remediación de los sitios contaminados ubicados en la zona de influencia del proyecto, mejorando la salud y el medio ambiente de las poblaciones aledañas.

Por ejemplo, si las mineras que realizan actividades en el departamento de Pasco apoyaran en la remediación del depósito de plata Quiulacocha-Excélsior de 200 millones de toneladas, podrían mejorar la salud de la población ubicada cerca al mismo, como es el caso de los residentes del distrito de Simón Bolívar, que cuentan con niveles elevados de concentración de plomo en sangre como consecuencia de las operaciones mineras pasadas.

Incluso, cambiarían la percepción que tienen los locales respecto de las mineras como contaminadoras, lo que elimina la posibilidad de futuros conflictos sociales, los cuales pueden significar un costo de US\$ 20 millones a la semana para proyectos de entre US\$ 3,000 a US\$ 5,000 millones, según el Centre for Social Responsibility in Mining (CSRM) y el Harvard Kennedy School (como se citó en Conflictos sociales: ¿Cuánto pueden llegar a costar por semana a los grandes proyectos mineros?, 2016). A cambio, la empresa podrá recuperar su inversión mediante la emisión CIPRL, aplicables a su impuesto a la renta, sin que aplique ningún cuestionamiento sobre la deducibilidad del gasto.

A diferencia de las licitaciones que lleva a cabo AMSAC para remediación de los PAM bajo su administración, en las que los riesgos del proyecto los mantiene el Estado y que requieren de recursos públicos; en las OxI, la empresa asume el riesgo del proyecto y lo financia con recursos propios los cuales, posteriormente, recupera mediante deducciones tributarias. 
La legislación comparada analizada en el desarrollo de esta investigación también ha contemplado los beneficios de la participación del sector privado para la remediación de minas abandonadas, con modalidades similares a las OxI.

Como se mencionó en el capítulo anterior, el reporte denominado "Enfoques potenciales de financiamiento para las Minas Huérfanas/Abandonadas en Canadá" (Castrilli, 2003), elaborado como herramienta para NAOMI, recomendó como una modalidad de financiamiento la promoción de deducciones tributarias y excepciones de responsabilidad por parte del Estado, como incentivos para las compañías mineras, a fin de que lleven a cabo las actividades de remediación.

Asimismo, en el caso de Australia, para la remediación de la mina "Savage River", al noroeste de Tasmania; el gobernó implementó el Acuerdo de Goldamere antes de su reapertura, que permitía a los nuevos propietarios asumir contratos de remediación con el Estado, a fin de que puedan saldar con trabajo el precio de compra de la referida mina. Como resultado, desde el año 2000, se cumplieron los objetivos de calidad de agua propuestos para el río ubicado dentro de la mina, el cual se encontraba severamente contaminado, anteriormente.

En el Perú, cabe recordar que la Ley No 30264, Ley que establece medidas para promover el crecimiento Económico, incluyó a las entidades del Gobierno Nacional en los alcances de la Ley $\mathrm{N}^{\mathrm{o}} 29230$, a fin de que puedan ejecutar proyectos de inversión pública bajo el mecanismo OXI, y el Decreto Legislativo $\mathrm{N}^{\circ} 1250$ incorporó al sector ambiente a la referida Ley. En ese sentido, la utilización del mecanismo de OxI para la remediación de los PAM no sería facultad exclusiva del sector privado.

Esta iniciativa también ha sido materia de discusión en el Congreso de la República, habiéndose presentado los Proyectos de Ley N 2045/2017-CR, "Ley que modifica el artículo 17 de la Ley No 30264, Ley que Establece Medidas para Promover el Crecimiento Económico" y № 2484/2017-CR, "Ley que promueve la remediación de los Pasivos Ambientales a través de la Inversión Pública con la Participación del Sector Privado”. Ambos proponen la modificación del numeral 1 del artículo 17 de la Ley № 30264, conforme lo siguiente: 
Tabla 5. Comparación de las modificatorias propuestas en los Proyectos de Ley $N^{\circ} 2045 / 2017-C R$ y No 2484/2017-CR

\begin{tabular}{|c|c|}
\hline & Modificación Propuesta \\
\hline yecto de Ley $\mathbf{N}^{\circ}$ & 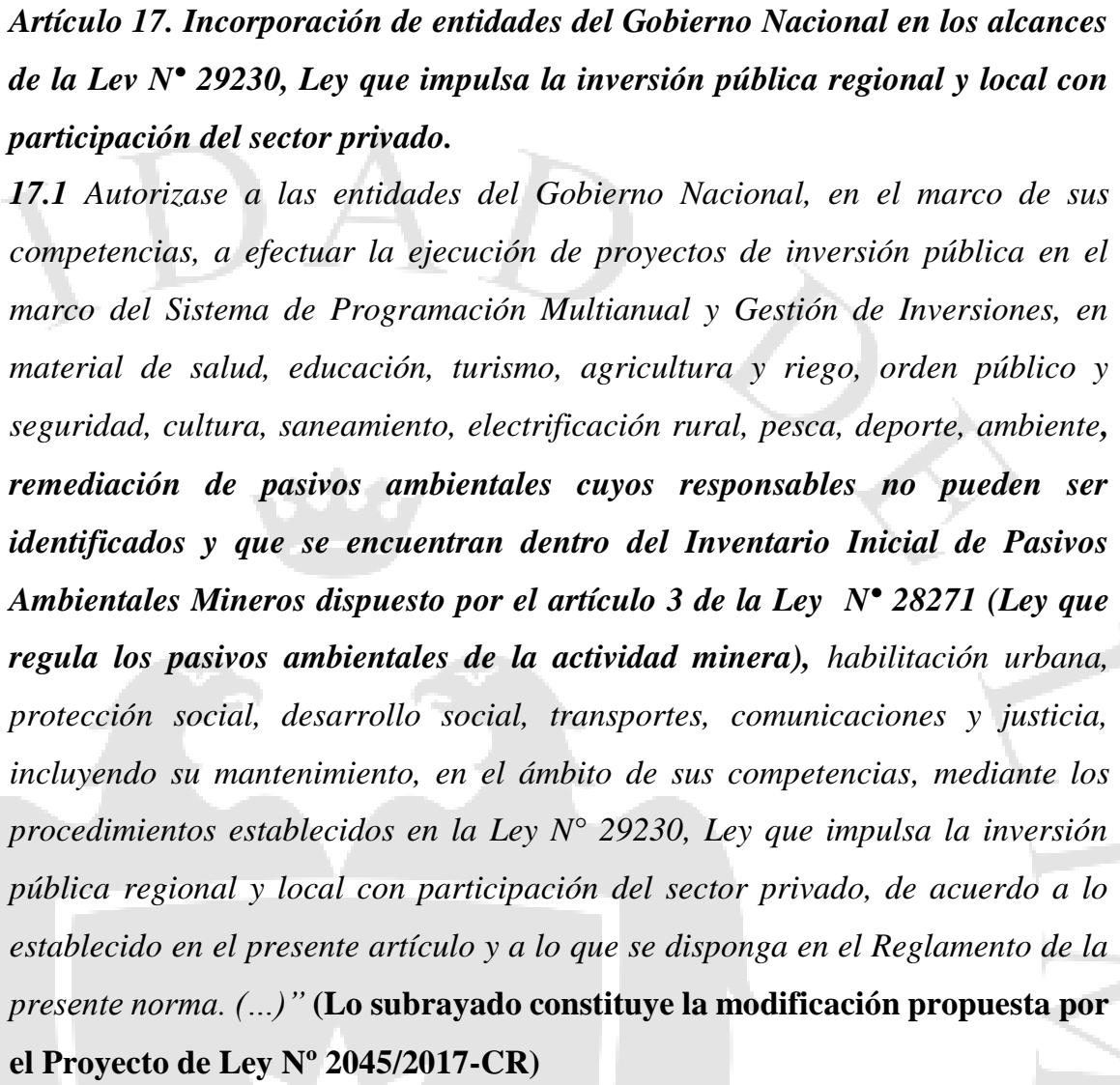 \\
\hline $\begin{array}{l}\text { Proyecto de Ley } \mathrm{N}^{\circ} \\
\text { 2484/2017-CR }\end{array}$ & $\begin{array}{l}\text { Artículo 17. Incorporación de entidades del Gobierno Nacional en los alcances } \\
\text { de la Ley } N^{\circ} 29230 \text {, Ley que impulsa la inversión pública regional y local con } \\
\text { participación del sector privado. } \\
\text { 17.1 Autorizase a las entidades del Gobierno Nacional, en el marco de sus } \\
\text { competencias, a efectuar la ejecución de proyectos de inversión pública en el } \\
\text { marco del Sistema de Programación Multianual y Gestión de Inversiones, en } \\
\text { material de salud, educación, turismo, agricultura y riego, orden público y } \\
\text { seguridad, cultura, saneamiento, electrificación rural, pesca, deporte, ambiente, } \\
\text { habilitación urbana, protección social, desarrollo social, transportes, } \\
\text { comunicaciones y justicia y remediación de los pasivos ambientales mineros e } \\
\text { hidrocarburíferos, cuyos responsables no hayan sido identificados, y que se } \\
\text { encuentren en el inventario de pasivos ambientales; incluyendo su } \\
\text { mantenimiento, en el ámbito de sus competencias, mediante los procedimientos } \\
\text { establecidos en la Ley } N^{\circ} 29230, \text { Ley que impulsa la inversión pública regional y } \\
\text { local con participación del sector privado, de acuerdo a lo establecido en el } \\
\text { presente artículo y a lo que se disponga en el Reglamento de la presente norma. }\end{array}$ \\
\hline
\end{tabular}




\begin{tabular}{|l|l|}
\hline & $\begin{array}{l}\text { (...)” (Lo subrayado constituye la modificación propuesta por el Proyecto de } \\
\left.\text { Ley } N^{\circ} \mathbf{2 4 8 4 / 2 0 1 7 - C R}\right)\end{array}$ \\
\hline
\end{tabular}

Pese a que estas iniciativas legislativas fueron presentados en el año 2017, únicamente cuenta con Dictamen el Proyecto de Ley No 2045/2017-CR, mientras que el Proyecto de Ley No 2484/2017-CR, desde marzo del 2018, se encuentra en discusión en las Comisiones de Energía y Minas, y de Pueblos Andinos, Amazónicos y Afroperuanos, Ambiente y Ecología. Sin embargo, a la fecha, estos proyectos de ley resultan obsoletos.

En atención a la comunicación efectuada por el ministro de Energía y Minas, referida a la remediación de pasivos ambientales mediante OxI, el 23 de julio del 2018 el Poder Ejecutivo publicó el Decreto Legislativo No 1361 , Decreto Legislativo que Impulsa el Financiamiento y Ejecución de Proyectos mediante el Mecanismo e Obras por Impuestos, el cual incorporó, entre otros, el siguiente artículo a la Ley $\mathbf{N}^{\mathbf{0}} \mathbf{2 9 2 3 0}$, Ley que impulsa la inversión pública regional y local con participación del sector privado:

“Artículo 2-B. Ejecución de proyectos de inversión de las entidades del Gobierno Nacional

Autorizase a las entidades del Gobierno Nacional, en el marco de sus competencias, a ejecutar proyectos de inversión en el marco del Sistema de Programación Multianual y Gestión de Inversiones, en materia de salud, educación, turismo, agricultura y riego, orden público y seguridad, cultura, saneamiento, electrificación rural, industria, turismo, pesca, deporte, ambiente, remediación de pasivos ambientales, habilitación urbana, protección social, desarrollo social, transportes, comunicaciones, justicia, acceso a servicios de atención al ciudadano, mercado de abastos, incluyendo su mantenimiento, en el ámbito de sus competencias, mediante los procedimientos establecidos en la presente Ley y en su Reglamento. (...)

Para dicho efecto, autorícese a la Dirección General de Endeudamiento y Tesoro Público (DGETP) a emitir los CIPGN, que tienen por finalidad la cancelación del monto que invierta la empresa privada que suscriba el convenio para financiar y/o ejecutar los proyectos de inversión a que se refiere el presente artículo. Esta modalidad de ejecución no constituye una operación oficial de crédito. 


\section{(...)” (El subrayado es agregado propio $)^{4}$}

Lo expuesto ha evidenciado el valor de las obras por impuesto, y los beneficios que traería su aplicación en el presente caso para la sociedad civil, el sector público y el sector privado. En ese sentido, se esperan resultados positivos en la aplicación de esta modificatoria, y corresponde a los Ministerios de Ambiente y al de Energía y Minas, conjuntamente con ProInversión, la difusión y promoción de las OxI en la remediación de pasivos ambientales.

\subsection{La simplificación administrativa de los procedimientos administrativos vinculados a la gestión de los PAM}

Crozier (1997) señala lo siguiente: "El sistema burocrático también se construyó sobre el paradigma de la especialización. Según este sistema, para resolver problemas es necesario desglosarlos en problemas más pequeños que puedan ser tratados en forma técnica por las unidades especializadas. No obstante, este modelo de coordinación fragmentada representará una carga sobre el aparato burocrático, presionando hasta lograr el crecimiento desmesurado de las oficinas centrales de gestión, donde predomina el "staff" en lugar de la línea, con la consiguiente pérdida de propósito de los empleados operativos." (p. 9)

Lo mencionado por el autor resulta aplicable a los gestión de los PAM en el Perú en donde -como ha sido expuesto en el desarrollo de la presente investigaciónintervienen diversas entidades públicas que deben coordinar entre sí, sobrecargando los procedimientos y dificultando la participación del sector privado en la remediación de los pasivos. En consecuencia, se pierde de vista el principal propósito; la restauración del medio ambiente.

A continuación, se presentarán propuestas de simplificación administrativa que buscan lograr procedimientos vinculados a la gestión de los PAM razonables, sin complicaciones innecesarias, que faciliten la participación del sector privado y la

Cabe mencionar que la modificatoria no se restringe únicamente a los pasivos ambientales de la actividad minera, siendo posible la utilización de las OxI para la remediación de los provenientes de actividades de otros sectores, como es el caso de los pasivos ambientales de hidrocarburos. 
captación de inversión para la restauración del medio ambiente. Estas propuestas transforman el sistema especializado existente en uno que responde a la complejidad del problema en cuestión con sencillez en sus estructuras y procesos.

\subsubsection{La restricción de las entidades públicas involucradas}

Como se mencionó anteriormente, las entidades públicas y direcciones involucradas en la gestión de los PAM bajo administración del Estado son múltiples.

La DGM, en coordinación con el INGEMMET y las DREM de identifica a los responsables de los PAM y lleva a cabo la actualización del inventario nacional de los mismos. La DGAAM, por otro lado, aprueba los instrumentos de gestión ambiental relacionados a los PAM. Finalmente, para el caso de los PAM bajo administración del Estado, AMSAC realiza y ejecuta los instrumentos de gestión ambiental necesarios, y lleva a cabo las actividades de remediación y control posterior.

En caso un privado quiere restaurar un PAM a través de las modalidades de remediación voluntaria, deberá seguir los siguientes pasos:

Tabla 6. Pasos a seguir para la remediación voluntaria de PAM

\begin{tabular}{|c|c|}
\hline $\begin{array}{c}\text { Para los casos de Re aprovechamiento y Re } \\
\text { utilización de PAM }\end{array}$ & $\begin{array}{c}\text { Para los casos de Plan de Cierre de PAM o de } \\
\text { inclusión de algún pasivo en el Plan de Cierre } \\
\text { de Minas }\end{array}$ \\
\hline $\begin{array}{l}\text { 1. Comunicar a la DGM la decisión de remediar } \\
\text { voluntariamente el PAM, precisando la } \\
\text { información que permita su identificación en } \\
\text { el inventario de pasivos. } \\
\text { 2. En caso el PAM solicitado no se encuentre } \\
\text { inventariado, la DGM deberá verificar la } \\
\text { existencia y condición del mismo, } \\
\text { incluyéndolo en el inventario en el plazo de } 60 \\
\text { días calendario de recibida la solicitud. } \\
\text { 3. Si dos o más personas alegan mejor derecho } \\
\text { para ejecutar cualquiera de las modalidades de } \\
\text { remediación voluntaria, la DGM deberá } \\
\text { declarar a quién corresponde la exclusividad }\end{array}$ & $\begin{array}{l}\text { 1. Presentar el Plan de Cierre de Minas o Plan de } \\
\text { Cierre de Pasivos Ambientales Mineros ante la } \\
\text { DGAAM. } \\
\text { 2. Para los casos de Plan de Cierre de Pasivos } \\
\text { Ambientales, el privado podrá celebrar un } \\
\text { convenio de remediación voluntaria con } \\
\text { responsabilidad limitada ante la DGM, a } \\
\text { través del establece restricciones en su } \\
\text { participación en la restauración del pasivo. }\end{array}$ \\
\hline
\end{tabular}




\begin{tabular}{|l|l|}
\hline para ello, considerando la prioridad en el \\
tiempo del inicio del procedimiento de \\
aprobación de cualquiera de las modalidades \\
de remediación \\
4. Por otro lado, deberá presentar el Estudio de \\
Impacto Ambiental correspondiente ante la \\
DGAAM.
\end{tabular}

Cabe precisar que para estos cuatro casos de remediación voluntaria; en caso el solicitante asuma la responsabilidad del íntegro de la remediación del pasivo, este podrá celebrar un convenio de remediación voluntaria con declaración de falta de responsabilidad ante la DGM, por el cual se acuerda que el solicitante no será identificado por esta dirección como el generador del pasivo que remedie voluntariamente.

De lo expuesto, se puede verificar que los procesos vinculados a la gestión de los PAM se encuentran fragmentados, y son llevados a cabo por distintas unidades coordinadoras y entidades, lo cual genera problemas como falta de vinculación en el trabajo. Por ejemplo, resulta difícil para la DGAAM conocer los resultados de las supervisiones que realice OEFA en relación al monitoreo de los PAM, lo que conduce a una ineficacia del trabajo, ya que la DGAAM realiza sus tareas con información insuficiente. (Koica y Mireco, 2018, p. 3-13)

Esta especialización genera una carga sobre el aparato burocrático, dificulta la participación del privado al aumentar costos transaccionales, y perjudica el intercambio así como la confiabilidad de la información de la administración pública. En el caso que estos PAM se encuentren bajo administración del Estado y hayan sido encargados a AMSAC; las coordinaciones entre entidades son incluso más extensas.

En Francia, como se señaló en el capítulo anterior, se priorizó la modernización de los procedimientos que tiene a su cargo cada ministerio, proponiéndose un programa anual de simplificación de formalidades administrativas y procedimientos, los cuales luego eran evaluados por COSA, un organismo independiente. El resultado de la simplificación administrativa en Francia ha sido la eliminación de 25 millones de procedimientos, el ahorro de 10 millones de horas gastadas y de un estimado de 91.5 millones de euros. 
En México, también se ha priorizado la reducción en tamaño del sector público, las formalidades en los procedimientos, y de las cargas innecesarias al sector privado. El Informe Anual de Desempeño del 2016-2017 de la COFEMER, estimó que el costo de cumplimiento de los trámites y servicios federales equivalía al $4.25 \%$ del Producto Interno Bruto (PIB) del país.

Por otro lado, en el Perú, el SENACE ha optimizado la evaluación ambiental, eliminando procedimientos tediosos e innecesarios. La implementación de la Certificación Ambiental Global por parte de esta institución ha logrado integrar en el Estudio de Impacto Ambiental títulos habilitantes que correspondan a la naturaleza del proyecto de inversión, evitando duplicidades en los procedimientos, contradicciones, reduciendo costos transaccionales y garantizando trámites con plazos razonables.

Con base en la experiencia internacional y nacional antes descrita, resultaría adecuado eliminar la especialización de las entidades y direcciones vinculadas a la gestión de los PAM. En ese sentido, se propone la concentración en la DGAAM de todas las facultades con las que cuenta el MEM, siendo esta la dirección más idónea para llevar a cabo las coordinaciones necesarias para la restauración de los pasivos. Esta dirección tendría a su cargo de las siguientes funciones:

La actualización del Inventario de PAM.

- La declaración sobre quién tiene mejor derecho para ejecutar cualquiera de las modalidades de remediación voluntaria, en caso este sea alegado por dos o más personas o instituciones.

- La realización de las coordinaciones con AMSAC, en caso un privado quiera remediar un PAM que se encuentra bajo administración de la empresa pública.

- La aprobación de las solicitudes de remediación voluntaria que presenten los privados.

- La celebración de los Convenios de Remediación Voluntaria con los privados

- $\quad$ La aprobación de los Instrumentos de gestión Ambiental vinculados a los PAM 
Las tres últimas funciones podrían darse en un único procedimiento administrativo, sin la necesidad de que el administrado presente distintas solicitudes generando múltiples procesos y contradicciones en la evaluación de los pedidos.

Por otro lado, con relación a los PAS que se encuentran bajo administración de AMSAC; a fin de facilitar la comunicación entre las diversas entidades y direcciones involucradas en su gestión (actualmente, DGM, DGAAM, INGEMMET y AMSAC) es necesaria una base compartida entre estas que cuente con información actualizada sobre el estado en el que se encuentra cada pasivo. Así, se pueden absolver fácilmente las dudas respecto de si el pasivo se encuentra identificado, con instrumento de gestión ambiental aprobado, en remediación o plan de remediación.

Con la implementación de esta base de información compartida, podría eliminarse la necesidad de un decreto supremo refrendado por el Ministro de Energía y Minas que libere al PAM que se encuentra bajo administración de AMSAC del procedimiento previsto en el Decreto Supremo No 013-2008-EM, que establece la necesidad de una subasta pública del pasivo re aprovechable.

En caso un privado quiera remediar un PAM que se encuentra previsto en el referido procedimiento, la DGAAM únicamente tendría que consultar esta base informativa a fin de verificar que el pasivo solicitado no se encuentra en proceso de ser subastado, transferido anteriormente al sector privado, o con plan de re aprovechamiento aprobado previamente por AMSAC. En caso este PAM no cuente con un plan de remediación; la DGAAM, previa comunicación a la empresa estatal, podría aprobar su remediación voluntaria por el privado a través de una Resolución Directoral.

A fin de que no existan contradicciones en la gestión de los PAM por las distintas instituciones, es necesario que esta base informativa se mantenga constantemente actualizada, bajo responsabilidad administrativa funcional ante la Contraloría General de la República del servidor o funcionario público responsable. ${ }^{5}$

La 9na disposición final de la Ley $N^{\circ}$ 27785, Ley Orgánica del Sistema Nacional de Control y de la Contraloría General de la República, define la responsabilidad administrativa funcional de la siguiente manera:

“Responsabilidad Administrativa Funcional.- Es aquella en la que incurren los servidores y funcionarios por haber contravenido el ordenamiento jurídico administrativo y las normas internas de la entidad a la que pertenecen, se encuentre vigente o extinguido el vínculo laboral o contractual al momento de su identificación durante el desarrollo de la acción de 


\subsubsection{La evaluación de resultados por un órgano independiente}

En la legislación comparada analizada previamente, se han instalado Grupos de Trabajo o Comisiones que tienen como finalidad la evaluación de la regulación existente y la simplificación de procesos.

En Australia Occidental, se instaló un panel conformado por representantes de asociaciones industriales para la revisión de regulación, enfocado en identificar prácticas regulatorias que innecesariamente impedían el desarrollo de las pequeñas empresas.

Por otro lado, el Grupo de Trabajo de Reducción de Burocracia de Queensland, conformado por 10 representantes del sector privado y un representante del gobierno, es un espacio de diálogo que tiene el objetivo de identificar las principales cuestiones que impactan en el desarrollo de la regulación, como la necesidad y eficiencia de la misma, y la carga de cumplimento que implica para el privado.

En Francia, la Comisión de Simplificación Administrativa evalúa estos planes los procedimientos administrativos de cada ministerio y formula recomendaciones para la mejora de los mismos. Entre sus principales funciones esta el diseño de herramientas para la comprobación del impacto de las medidas adoptadas, el seguimiento a la implementación por parte de los ministerios, y la evaluación de formatos.

El propósito de todas estas comisiones u organismos independientes es de revisar el marco regulatorio existente a fin de determinar la calidad del mismo, comprobando si el impacto a los consumidores y al sector privado es razonable en comparación con la finalidad de la política pública, priorizando la reducción de trabas e ineficiencias.

control.

Incurren también en responsabilidad administrativa funcional los servidores y funcionarios públicos que en el ejercicio de sus funciones, desarrollaron una gestión deficiente, para cuya configuración se requiere la existencia, previa a la asunción de la función pública que corresponda o durante el desempeño de la misma, de mecanismos objetivos o indicadores de medición de eficiencia."

Por otro lado, de acuerdo al artículo 45 de la referida Ley; la Contraloría General ejerce la potestad sancionadora, por cuanto determina la responsabilidad administrativa funcional e impone una sanción derivada de los informes de control emitidos por los órganos del Sistema. 
A diferencia de la gestión privada, en la administración pública no se tiene una percepción clara de los consecuencias de las políticas públicas, y las relaciones entre los programas y los resultados no son precisas. Las metas propuestas con frecuencia son retóricas, lo que lleva a la ampliación de los procedimientos y formalismos. (Crozier, 1997, p 10)

Sería útil contar un comité revisor de la normativa vinculada a la gestión de los PAM, en el cual participe el sector privado, a través de representantes de la empresa minera y de la Sociedad Nacional de Minería, Petróleo y Energía así como representantes de la Alta Dirección del Ministerio de Energía y Minas, y de la empresa pública AMSAC. Entre sus funciones podrían estar las siguientes:

Análisis de las principales trabas para los interesados en la remediación voluntaria de los PAM, incluyendo las obras por impuesto.

Evaluación de la efectividad de la remediación de los pasivos en los últimos años.

- Examen de la gestión de AMSAC y de las facilidades y/o dificultades para la participación del sector privado en la remediación de los PAM que le han sido encargados.

Estudio de las exigencias de los Instrumentos de Gestión Ambiental necesarios, y de la eficiencia en el proceso de evaluación de los mismos.

Planteamiento de propuestas de mejora, por parte de la sociedad civil y el sector privado.

Un ejemplo es este tipo de órgano consultivo en el Perú, es el Consejo Técnico Consultivo del SENACE. Según el artículo $16^{\circ}$ del Reglamento de Organización y Funciones de esta entidad, aprobado por Decreto Supremo No 009-2017-MINAM, el Consejo asesora al SENACE en temas especializados que sean sometidos a su consideración y esta integrado por cinco (5) especialistas en temas vinculados a proyectos de desarrollo e inversiones. Entre sus funciones está el análisis de propuestas generales y la formulación de recomendaciones para la mejora del Sistema Nacional de Evaluación de Impacto Ambiental.

Para finalizar, es preciso mencionar que los grupos de trabajo a los que se ha hecho mención, incluyendo el propuesto para los PAM, no solo ofrecen una evaluación de los 
resultados de programas anteriores. La evaluación influye en las decisiones de los funcionarios y servidores públicos, abriendo las puertas al cambio en la gestión pública, logrando normas y políticas públicas más eficientes.

\subsection{El rol del Estado en la remediación de los PAM}

El artículo $60^{\circ}$ de la Constitución Política del Perú, establece el principio de subsidiariedad en la actividad empresarial del Estado y dispone lo siguiente:

“(...) Sólo autorizado por ley expresa, el Estado puede realizar subsidiariamente actividad empresarial, directa o indirecta, por razón de alto interés público o de manifiesta conveniencia nacional. (...)”. (el subrayado es agregado propio)

De acuerdo con Kresalja, Baldo (2015), el principio de subsidiariedad tiene una fase negativa y otra positiva. La fase negativa representa el deber de abstención del Estado y de no involucrarse económicamente cuando la libertad de empresa es adecuada para lograr el bien común. La fase positiva demanda al Estado su intervención en caso la iniciativa privada no sea suficiente, siendo su participación socialmente indispensable. Adicionalmente, el autor señala que se vulnera el principio de subsidiariedad siempre que se promueve un intervencionismo estatal en la economía que busca sustituir la iniciativa privada, así como cuando se busca la abstención total del Estado en materia económica, obstruyendo la corrección las fallas del mercado e impidiendo que lleve adelante el Proyecto socioeconómico de la Constitución. (p. 28-31).

Landa (2007) señala que el rol subsidiario del Estado se consagra en el marco de una economía social de mercado, en la cual las reglas del mercado y la iniciativa privada deben cumplir una función social y apoyar al Estado en logro del bienestar general. Ello justifica a la Administración Pública a supervisar a las empresas, el trabajo y capital, la tecnología, la inversión, etc; a fin de no permanecer neutral ante las desigualdades económicas, sociales y culturales. (p 34-36)

En material administrativa, un ejemplo de aplicación del principio de subsidiariedad se da en la aplicación del Decreto Supremo No 034-2001-PCM, que estableció procedimientos mediante los cuales el FONAFE delimita y autoriza el 
desarrollo de actividades empresariales que con carácter subsidiario realiza el Estado. En su artículo $4^{\circ}$, el referido Decreto Supremo señala lo siguiente:

“En la delimitación del alcance de la actividad empresarial que con carácter subsidiario desarrolla el Estado, FONAFE deberá tomar en cuenta lo siguiente:

a) las condiciones de competencia en el mercado;

b) la situación de la oferta privada en la provisión y/o prestación de los bienes y/o servicios de que se trate;

c) la subsistencia de un alto interés público o manifiesta conveniencia nacional para el suministro de los bienes y/o servicios. Estas condiciones sólo se verifican con la existencia de la Ley que autoriza la(s) actividad(es) que desarrollan las empresas bajo el ámbito de FONAFE o con el desarrollo de actividades de servicio público y/o explotación de infraestructura pública.

FONAFE podrá solicitar un informe al INDECOPI y al titular del sector al que se encuentra adscrita la empresa de que se trate.

Dichas entidades, dentro del ámbito de sus funciones, deberán emitir un informe en un plazo no mayor de sesenta (60) días a partir de la fecha de presentación de la solicitud." (el subrayado es agregado propio)

En aplicación de este artículo, FONAFE encargó al INDECOPI la elaboración de informes sobre distintas empresas estatales a fin de que se defina caso por caso cuándo estarían realizando actividades consideradas subsidiarias, y en qué casos existiría una vulneración del mandato constitucional. (Kresalja Baldo, 2015, p 155-157)

Por otro lado, aplicando el principio de subsidiariedad a la gestión de los PAM; podemos concluir que el Estado (en este caso, por intermedio de AMSAC) debe encargarse de la remediación de los mismos únicamente cuando los privados no puedan o no estén interesados en realizar estas actividades.

Incluso, en los casos en los que algún PAM ya ha sido transferido a la empresa estatal para su remediación, y un privado se encuentra interesado en su re aprovechamiento o restauración; se debe priorizar la liberación del pasivo en cuestión del mandato de AMSAC, toda vez que si esto no sucediese, existiría una obstaculizan a la libertad de empresa. En este escenario no es necesaria la actividad subsidiaria por parte del Estado, toda vez la participación de la administración pública ya no resultaría 
socialmente indispensable. La iniciativa privada sería suficiente para lograr la finalidad pública de restauración del medio ambiente.

La Ley $\mathrm{N}^{\circ} 28271$, Ley que regula los pasivos ambientales de la actividad minera, así como su Reglamento, cumplen con promover la inversión privada en la gestión de los pasivos ambientales mineros. Sin embargo, como ha sido expuesto en el desarrollo de esta investigación, en la práctica se dificulta la palpitación del sector privado mediante un exceso de burocracia o limitando la transferencia de los PAM bajo gestión estatal. Como fue señalado por la empresa pública, ningún pasivo encargado a AMSAC ha sido transferido al sector privado. (Activos Mineros S.A.C., comunicación personal, 19 de octubre de 2018)

Actualmente, los esfuerzos de los funcionarios públicos se concentran en el aumento de los recursos de AMSAC para que lleve a cabo las tareas de remediación, y no en la solución al problema antes descrito. Al respecto, mediante la Resolución Ministerial $N^{\circ}$ 463-2018-MEM/DM, publicado en fecha 16 de noviembre de 2018, el MEM transfirió a AMSAC S/. 155000 000, 00 provenientes de recursos directamente recaudados (donaciones) a fin de que sean destinados a la ejecución de los proyectos de remediación de diversos PAM. Es más conveniente la promoción del re aprovechamiento o del uso del mecanismo de Obras por Impuestos para la restauración de estos pasivos, evitando una sobrecarga de los recursos estatales.

Finalmente, es preciso señalar que priorizar la actividad empresarial en la gestión de los PAM no implica que el financiamiento deba darse únicamente a través de inversiones por parte del sector privado. Lo que se busca es que la inversión provenga de la participación del mercado siempre que esta se encuentre disponible, y que el financiamiento por recursos estatales se de únicamente en los casos que sea indispensable para la restauración del pasivo y, con ello, del medio ambiente en general.

Como señaló Castrilli (2003) en el reporte preparado para la iniciativa NAOMI, a fin de lograr la limpieza de la mayor cantidad de minas abandonadas, es necesario que la legislación contemple una combinación de los distintos enfoques de financiamiento, incluyendo a los ingresos generales estatales, el re direccionamiento de impuestos 
aplicados a las empresas mineras, asociaciones entre el Estado y la Industria, así como el uso de multas y penalidad administrativas impuestas a la industria minera. (p. 94)

En el Perú, el financiamiento de las actividades de remediación que realiza AMSAC depende una gran parte de las donaciones realizadas por la cooperación internacional y de las transferencias del Tesoro Público.

Como se ha señalado previamente, la restauración de minas abandonadas tiene baja prioridad en la percepción internacional, por lo esta fuente es sumamente variable. Asimismo, las transferencias del Tesoro Público varían, dependiendo de las prioridades de cada gobierno de turno. En ese sentido, la combinación de distintos enfoque de ingreso propuesta por Castrilli podría resultar beneficiosa para la remediación de los PAM bajo administración del Estado.

A continuación, se proponen dos fuentes de ingreso adicionales para la remediación de los pasivos bajo administración del Estado.

\subsubsection{La redistribución tributaria para el financiamiento de los PAM bajo administración del Estado}

En Australia, se establecieron impuestos a la producción minera los cuales eran recaudados para la remediación de las minas abandonadas. Por otro lado, en Estado Unidos, se instaló un impuesto a la industria petrolera (9.7 centavos por barril) así como a la industria química y al ingreso corporativo para el financiamiento el Programa Superfund llevado a cabo por la EPA y encargado de la restauración de sitios contaminados.

En el caso de Estado Unidos, los impuestos instalados para la remediación de los sitios contaminados fueron retirados en el año 1995. Históricamente, estas contribuciones tributarias fueron responsables de la mayor parte del financiamiento del Programa Superfund, el cual en el año 1996 contaba con un fondo de 3.8 billones de dólares. Desde su retiro, los fondos del programa se han venido reduciendo generando inconvenientes para la restauración de los sitios contaminados. Incluso, al año 2004 el balance del Fondo 
era de cero dólares. Como consecuencia, actualmente los recursos provienen casi en su totalidad del Tesoro Público. (Ramseur, Reisch y McCarthy, 2008, p 4)

En el Perú, ningún impuesto ha sido establecido para la remediación de lo pasivos ambientales.

Sin embargo, es aplicable el canon minero, instalado por la Ley $\mathrm{N}^{\circ} 27506$, Ley de Canon, publicada el 10 de Julio de 2001. De acuerdo al Reglamento de la Ley No 27506, aprobado por Decreto Supremo $N^{\circ}$ 005-2002-EF, y a sus modificatorias; el canon minero, está constituido por el 50\% del Impuesto a la Renta que obtiene el Estado por las actividades de aprovechamiento de recursos minerales que realizan los titulares mineros, y es transferido en cuotas mensuales a los gobiernos regionales y locales. Los recursos provenientes del canon se distribuyen de la siguiente manera:

\section{Gráfico 6. Distribución del canon minero}

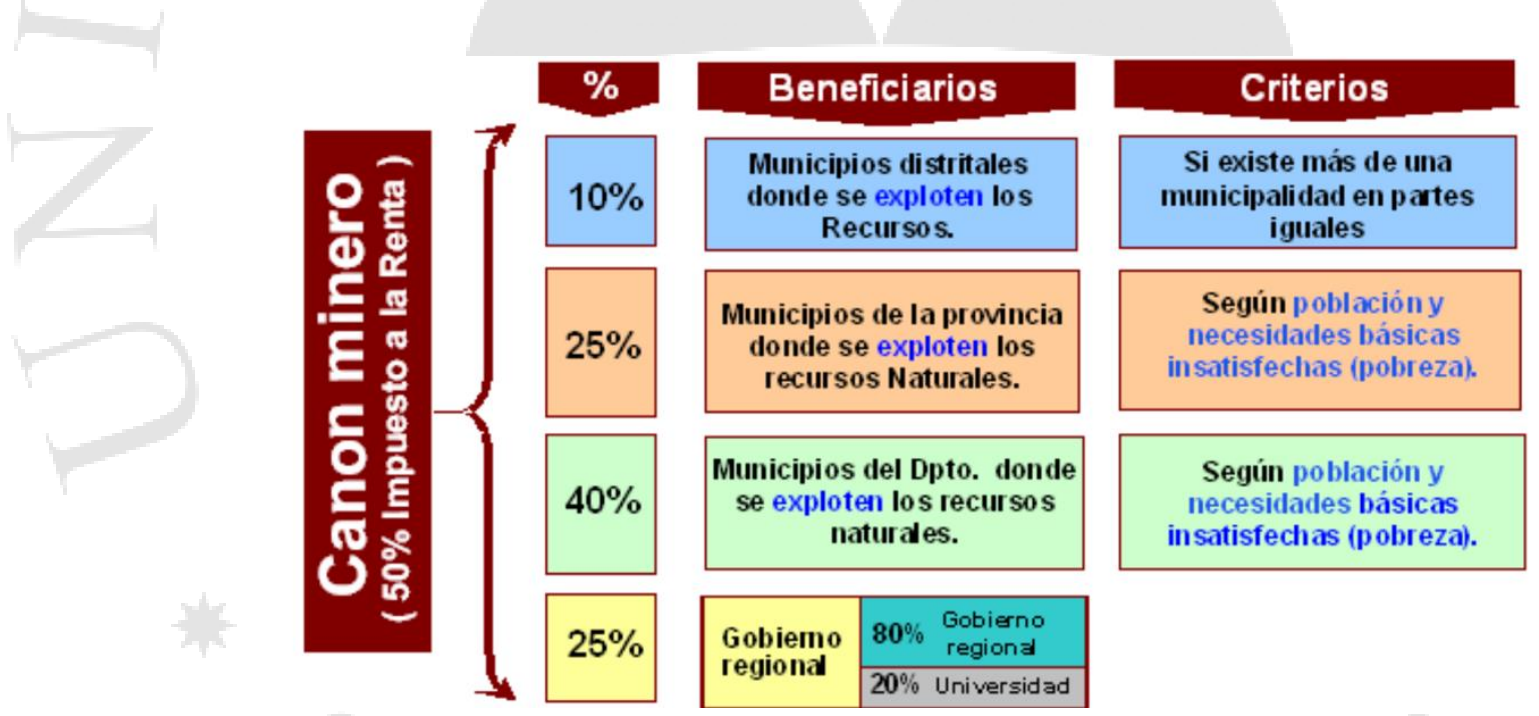

Fuente: Ministerio de Economía y Finanzas

Al estar vinculado al Impuesto a la Renta, el canon minero fluctúa según la rentabilidad del sector, la cotización de los minerales en bolsa, además de la productividad y eficiencia operativa de la mina. En los últimos años, el sector minero se ha mantenido rentable, y entre el 2001 y el 2004 los precios del oro y el cobre (principales minerales exportados por el Perú) subieron en $82 \%$ y $51 \%$, respectivamente. Por lo tanto, el canon minero crece sosteniblemente y con los fondos recaudados, los beneficiarios 
deben ejecutar proyectos de inversión en la zona de influencia. Sin embargo, los ciudadanos y las comunidades aledañas generalmente tienen la percepción de que las autoridades no están realizando obras, o que estas no contribuyen a la mejora de su calidad de vida. (Boza, 2006, p 17)

En el 2017 los consejeros de las regiones del sur manifestaron que las partidas provenientes del canon minero incrementaron la corrupción y los actos irregulares descomunalmente, a través de la instalación de mafias. El Presidente del Consejo Regional de Tacna agregó que se comparte una misma realidad en dichas regiones: presuntas obras sobrevaloradas y denuncias de irregularidades en las gestiones. (Dineros del canon minero atrajeron la corrupción en las regiones del sur, 2017)

Un ejemplo de una gestión ineficiente del canon minero se da en el distrito rural de Encañada de la provincia de Cajamarca. Los proyectos planificados por el municipio con los recursos del canon minero incluían la construcción de un "moderno palacio municipal" de seis pisos, así como de un hotel de diez pisos. Cabe señalar que población en dicha localidad es de menos de 30 mil habitantes, quienes disponen un promedio de S/. 185 mensuales. Adicionalmente, datos oficiales señalan que el 51.5\% de los cajamarquinos viven en un situación de pobreza extrema. (Boza, 2006, p 11)

Por otro lado, las operaciones mineras de Antamina iniciadas en el año 2001 en el distrito de San Marcos (provincia de Huari y departamento de Ancash) hicieron del municipio uno de los más ricos del país. De un presupuesto que no llegaba al millón de nuevos soles, el distrito pasó a disponer más de 250 millones. Por lo tanto, se excedieron las capacidades de gestión de las autoridades locales, lo que generó una percepción en la población de que la administración municipal es bastante deficiente. Pese a que un 55\% de los gastos municipales se han dado en la construcción de infraestructura pública, los vecinos de San Marcos consideran que no se han llevado a cabo obras importantes, como por ejemplo la provisión permanente de agua potable al pueblo. Asimismo, existen rumores de corrupción y sobrevaluación de obras, lo cual podría encontrarse relacionado con los signos de riqueza de algunas autoridades. (Salas Carreño, 2010, p 118)

El canon minero debe ser utilizado para el financiamiento de obras que generen beneficios en la calidad de vida de quienes habitan cerca o dentro del área de influencia 
del proyecto minero. Sin embargo, en muchos casos las inversiones que realizan las autoridades locales no cumplen con satisfacer las necesidades básicas de la población, sea por gestiones ineficientes o corruptas. Esto genera cuestionamientos sobre los beneficios que efectivamente genera en la población la distribución actual de este ingreso.

Vinculando la necesidad de una reformulación del esquema de este ingreso a la gestión de los PAM se propone que, en los casos en que existan pasivos ambientales por remediarse dentro del área de influencia directa o indirecta del proyecto minero; una parte del canon se destine a AMSAC, a fin de realice actividades de remediación de dichos pasivos.

De esta manera, se asegura la calidad en el gasto, toda vez que el canon minero se dirigiría a la mejora de la calidad de vida de la población mediante la restauración del medio ambiente, incluyéndose a los recursos hídricos afectados por los pasivos. Para el caso de los habitantes en el departamento de Pasco, quienes sufren de altos niveles de plomo en su sangre por los PAM ubicados en Cerro de Pasco, direccionar el canon minero a la limpieza de relaveras y desmontes traería beneficios reales en la salud de los pobladores.

Adicionalmente, habría una mayor rendición de cuentas y supervisión en el gasto de estos ingresos, reduciéndose así los niveles de corrupción y criminalidad. El hecho de que AMSAC cuenta con experiencia y capacitación en el manejo de presupuestos significativos llevaría a una gestión más eficiente- que el que actualmente llevan a cabo las autoridades locales- de los proyectos de inversión.

Por otro lado, el Principio 16 de la Declaración de Río sobre Medio Ambiente y Desarrollo establece lo siguiente:

"Las autoridades nacionales deberían procurar fomentar la internalización de los costos ambientales y el uso de instrumentos económicos, teniendo en cuenta el criterio de que el que contamina debe, en PRINCIPIO, cargar con los costos de la contaminación, teniendo debidamente en cuenta el interés público y sin distorsionar el comercio ni las inversiones internacionales. " 
En ese sentido, el principio contaminador pagador o de internalización de costos persigue la incorporación de los costos del bien o servicio en lo necesario para la prevención de los posibles daños que pueda generar la actividad económica, evitando así las externalidades. No obstante, de manera excepcional su aplicación puede incidir en la restauración del medio ambiente o la indemnización pecuniaria. Por lo tanto, la aplicación del principio puede adoptar forma de tributos, orientando lo recaudado para el financiamiento de acciones de recuperación del medioambiente. (Andaluz, 2016, p 645)

En Estados Unidos, una perspectiva amplia del principio contaminador- pagador justificó la instalación del impuesto a la industria petrolera y química, así como al ingreso corporativo, para el financiamiento el Programa Superfund.

En el Perú, la retribución de una parte del canon minero para la remediación de los PAM bajo gestión de AMSAC se sustentaría en este principio, toda vez que los titulares mineros asumirían, mediante el impuesto a la renta, los costos de restauración del medio ambiente ocasionados por las actividades históricas de la misma industria.

\subsubsection{El papel de las multas por infracciones ambientales}

En Estados Unidos, parte del financiamiento del Programa Superfund proviene de las multas impuestas a los responsables identificados. Sin embargo, su proyección es débil y solo contribuyen a una pequeña parte del fondo.

En el caso peruano, el RPAM autorizó el uso de las multas que emita la DGM en aplicación de la legislación sobre pasivos ambientales para la remediación de los PAM que asuma el Estado.

Sin embargo, la norma no autoriza el uso de las multas relacionadas con el incumplimiento de obligaciones ambientales, las cuales son impuestas por el OEFA en su calidad de autoridad competente. De hecho, la mayor parte de las infracciones detalladas en el artículo 52 $2^{\circ}$ del RPAM son de carácter ambiental, y lo recaudado por estos incumplimientos no podrá ser utilizado para el financiamiento de las actividades de remediación que lleve a cabo AMSAC. 
La Ley $N^{\circ}$ 29325, Ley del Sistema Nacional de Evaluación y Fiscalización Ambiental, establece en su artículo $27^{\circ}$ que constituyen recursos del OEFA los montos por concepto de multas que en el ejercicio de sus funciones, imponga dicha autoridad fiscalizadora.

Adicionalmente, la novena disposición complementaria final de dicha Ley, incorporada por el Artículo 3 del Decreto Legislativo $\mathrm{N}^{\circ}$ 1389, publicado el 05 septiembre 2018, señala que las multas coercitivas impuestas por las entidades de fiscalización ambiental ${ }^{6}$ (EFA) como consecuencia del incumplimiento de las medidas administrativas (preventivas, cautelares y correctivas) dictadas en el marco de la fiscalización ambiental, constituyen recursos directamente recaudados y son destinados a financiar las acciones de fiscalización ambiental de dichas EFA.

En el marco de sus competencias y funciones, el OEFA fiscaliza a los administrados en los sectores de minería, energía, pesquería, infraestructura de residuos sólidos, e industria. La fiscalización ambiental entendida de manera amplia, engloba acciones de evaluación, supervisión, control y de fiscalización en sentido estricto, que incluye la imposición de las sanciones correspondientes. ${ }^{7}$ Para el cumplimiento de sus funciones, OEFA debe llevar a cabo acciones de vigilancia, recepción de denuncias ambientales, monitoreos, seguimiento y verificación obligaciones ambientales a través de supervisiones de campo, entre otras.

Resulta entendible que las multas impuestas por la institución sean utilizadas para el financiamiento de las acciones de fiscalización que lleva a cabo, toda vez que presentan costos significativos. Sin embargo, es cuestionable el uso que se le da a los ingresos por multas en los casos en los que ellos exceden las necesidades de la entidad.

Por ejemplo, mediante la Resolución de Presidencia del Consejo Directivo No 1042015-OEFA/PCD, se autorizó la transferencia financiera de cinco millones de nuevos

Las Entidades de Fiscalización Ambiental (EFA) son entidades de ámbito nacional, local o regional, que forman parte del Sistema Nacional de Fiscalización Ambiental y que tienen atribuidas alguna o todas las funciones de fiscalización ambiental. El OEFA forma parte de las EFA y ejerce la rectoría, normando y supervisando a dichas entidades.

Mediante Resolución Ministerial No 247-2013-MINAM del 27 de agosto de 2013, se aprobó el Régimen Común de Fiscalización Ambiental, el cual establece en el numeral 2 del Artículo $2^{\circ}$ que "cuando en la presente norma se hace referencia a la fiscalización ambiental, esta deberá entenderse en sentido amplio". 
soles del OEFA a favor del SERNANP, para el financiamiento de actividades de gestión ambiental vinculadas a la protección de Áreas Naturales Protegidas. El artículo $2^{\circ}$ precisó que la transferencia financiera autorizada se realizaba con cargo a los recursos directamente recaudados, provenientes de las multas administrativas impuestas por el OEFA en el ejercicio de sus funciones. Prácticas como éstas no solo desnaturalizan el destino de las multas, sino que resultan cuestionables, toda vez que puede presentar arbitrariedades en la elección de las entidades beneficiarias.

Las sanciones administrativas tienen una finalidad eminentemente punitiva, derivada de la comisión de una conducta tipificada como infracción en las normas. Las multas impuestas por OEFA tienen también una función disuasoria para quienes actúan sin la diligencia debida en sus actividades económicas, o dolosamente deciden incumplir las obligaciones ambientales. Por otro lado, el principio de prevención -como ya ha sido señalado- establece que son objetivos prioritarios de la gestión ambiental prevenir, vigilar y evitar la degradación ambiental. Cuando ello no sea posible, corresponde adoptar las medidas necesarias para la eventual mitigación, recuperación, restauración o compensación del daño. En ese sentido, cuando los daños efectivamente se generen y corresponda aplicar la sanción administrativa, en atención al principio de prevención, sería óptimo que lo recaudado se destine a fines de restauración ambiental. (Andaluz, 2016, p 646 y 831)

Por lo tanto, lo más adecuado es destinar los excedentes de las multas a la restauración del medio ambiente. En ese sentido, se propone que un porcentaje de estos ingresos se destine a AMSAC para la remediación de los PAM, en vez de ser transferidos a otras entidades del sector. Ello haría que el uso de las multas que imponga OEFA se encuentre en mayor sintonía con el principio de prevención, antes citado. 


\section{CONCLUSIONES}

En atención a lo expuesto en el desarrollo de la presente investigación, se concluye lo siguiente:

- La remediación de los pasivos ambientales mineros implica una inversión sumamente alta (aproximadamente 7 mil millones de soles) y de largo plazo. Desde el año 2004, el Estado ha realizado esfuerzos importantes para la restauración de las zonas afectadas por estas operaciones mineras abandonadas. Incluso, ha asumido la restauración no solo de los pasivos causados por empresas públicas, sino también de los que son de alto interés público, que no cuentan con responsable identificado y los causados por la minería ilegal. Un gran avance para el Perú es el mantener un inventario actualizado de los PAM que existen a lo largo del territorio. Países más desarrollados, como por ejemplo Canadá, aún se encuentran en proceso de elaboración de un instrumento como este. Sin embargo, en la restauración de estos PAM, la magnitud del problema excede las capacidades de la administración pública.

Actualmente, el Estado no cuenta con el financiamiento necesario para llevar a cabo estas actividades. Las fuentes de las que depende resultan variables, como son las asignaciones presupuestales que se designen al sector energía y minas para este fin, así como las donaciones que realice la cooperación internacional. Además, AMSAC -empresa estatal encargada de la remediación de los PAM bajo gestión pública- no cuenta con las capacidades técnicas suficientes, por lo que procede a transferir las obligaciones de remediación a terceros a través de contrataciones públicas. A todo esto, se agrega exceso de burocracia y de instituciones vinculadas a la gestión de los PAM, lo que no solo demora la restauración sino que también dificulta la participación del sector privado. Como resultado, la cantidad de PAM bajo gestión de AMSAC con planes de cierre aprobados es mínima, y en el cumplimiento de sus obligaciones la empresa pública constantemente ha infringido la normativa ambiental. 
- La experiencia internacional permite comprobar que la diversidad en las fuentes de financiamiento y la apertura a la participación del sector privado resulta fundamental para la restauración de las minas abandonadas. En el caso de Estados Unidos, el retiro de los impuestos a la industria petrolera, química y al ingreso corporativo que se destinaban a la limpieza de los sitios contaminados, llevó a una demora en estas actividades por insuficiencia de fondos. Por otro lado, en Australia, el Grupo de Trabajo para Minas Abandonadas recalcó la importancia de la inversión privada, sea mediante la re utilización de minerales por las empresas mineras, el uso del terreno para otras actividades productivas, la instauración de tributos o por la celebración de acuerdo de financiamientos mixtos. Finalmente en Canadá, la instalación del Fondo "Restor-Action-Nunavik”, constituido por 30 compañías de exploración minera y el gobierto provincial de Quebec, llevó al cumplimiento del objetivo de remediación de 18 sitios contaminados de alta prioridad en el territorio provincial.

- Adicionalmente, la legislación comparada ha demostrado que la participación del privado en la gestión pública no debe ser únicamente a través de compromisos financieros. Los Grupos de Trabajo y las Comisiones enfocadas en la simplificación administrativa, instauradas en Australia, Francia y México, han llevado a la formulación de políticas públicas que priorizan la reducción de las trabas innecesarias para el mercado, así como a la revisión de procedimientos existentes. Los beneficios se han trasladado en la eliminación de trámites burocráticos innecesarios y al ahorro de tiempo, personal y costos monetarios vinculados al cumplimiento de trámites y servicios.

- A mediados del año 2018, el gobierno aprobó el uso de la modalidad de obras por impuesto para la remediación de los PAM. De acuerdo a lo analizado en la presente investigación, resulta ideal aplicar las OXI a la remediación de los PAM inventariados y es el mecanismo de inversión privada más adecuado. Para las empresas mineras, permite canalizar los gastos de responsabilidad social para la remediación de los sitios contaminados ubicados en la zona de influencia del proyecto, mejorando las condiciones de vida de la población. Para el Estado, las 
OxI permiten que la empresa asuma el riesgo y financiamiento del proyecto de restauración, para luego recuperar su inversión a través de deducciones tributarias.

- Además promover el uso de las OxI, el Estado debe fomentar la participación del sector privado mediante las modalidades de remediación voluntaria que recoge el RPAM. Para ello, es necesario que el aparato estatal priorice la sencillez en los procedimientos aplicables. Resulta vital que se reduzca la especialización de las entidades y direcciones vinculadas a la gestión de los PAM, concentrando en la DGAAM de todas las facultades con las que cuenta el MEM. Adicionalmente a ello, para el caso de los PAS que se encuentran bajo administración de AMSAC; es fundamental la implementación de una base de información compartida sobre el estado en el que se encuentra cada pasivo, la cual deberá ser permanentemente actualizada. De esta manera, no habría necesidad de un Decreto Supremo que libere al PAM del procedimiento previsto en el Decreto Supremo No 013-2008-EM, que exige la subasta pública del pasivo re aprovechable. Finalmente, instalar un comité revisor de la normativa vinculada a los PAM ofrecería una evaluación de los resultados de programas anteriores que luego influiría en las decisiones políticas, llevando a una mayor eficiencia en la gestión pública.

En aplicación del principio de subsidiariedad, recogido en el artículo $60^{\circ}$ de la Constitución Política del Perú, el Estado - por medio de AMSAC- debe encargarse de la remediación de los PAM únicamente cuando los privados no puedan o no estén interesados. Esto debe aplicarse incluso sobre los que hayan sido transferido a la empresa estatal para su remediación. Por lo tanto, el financiamiento de la remediación mediante recursos estatales se debe dar cuando ello sea indispensable.

- Para los casos en los que finalmente se utilicen ingresos estatales para la remediación de los PAM; la fuentes con las que cuenta el Estado no resultarían suficientes, por lo que debe incorporarse mecanismos financieros adicionales. Esto puede darse, por ejemplo, mediante la redistribución de un porcentaje de los ingresos provenientes del canon minero y de las multas ambientales. En el primer caso, no solo se asegura la calidad en el gasto del canon minero -toda vez que se dirigiría a la mejora de la calidad de vida de la población- sino que también habría 
una mayor rendición de cuentas en el gasto de estos ingresos, que la llevada a cabo por las autoridades locales, ya que AMSAC cuenta con experiencia en el manejo de presupuestos significativos. En el segundo caso, el uso de las multas que imponga el OEFA se encuentra justificado por el principio ambiental de prevención, el cual establece que siempre que no sea posible prevenir la degradación ambiental, corresponderá adoptar las medidas necesarias para la eventual reparación del daño. En ese sentido; resulta óptimo que el producto de las sanciones administrativas impuestas por daños ambientales se destinen a fines de restauración.

Finalmente, se proponen las siguientes modificaciones en la normativa vinculada al objeto de la presente investigación:

Tabla 7. Propuesta de mejoras al marco normativo vigente

\section{Ley $\mathbf{N}^{\circ} 28271$, Ley que regula los pasivos ambientales de la actividad minera y} Reglamento, aprobado por Decreto Supremo N 059-2005-EM.

- Establecer como una modalidad de remediación de PAM a las obras por impuesto, definiendo al MEM, a través de la DGAAM, como la entidad responsable de la evaluación de los proyectos propuestos por el administrado, en coordinación con Proinversión.

- Sustituir a la DGM en sus funciones en materia de PAM, concentrando en la DGAAM todas las facultades con las que cuenta el MEM en materia de gestión de PAM. En ese sentido, las funciones de elaboración y actualización del Inventario de PAM, y de celebración de convenios de remediación voluntaria (las cuales actualmente se encuentran bajo competencia de la DGM según el RPAM vigente), pasarían a ser competencia de la DGAAM.

- Establecer el uso de una base compartida entre DGM, DGAAM, INGEMMET, OEFA, OSINERGMIN y AMSAC la cual cuente con información actualizada sobre el estado en el que se encuentra cada pasivo a fin de absolver dudas sobre el estado de los PAM, bajo responsabilidad administrativa funcional ante la Contraloría General de la República del servidor o funcionario público responsable. 
- $\quad$ Eliminar el artículo 12-A del RPAM, el cual establece la necesidad de un decreto supremo refrendado por el Ministro de Energía y Minas que libere al PAM que se encuentra bajo administración de AMSAC del procedimiento previsto en el Decreto Supremo No 013-2008-EM, procedimiento que establece la necesidad de una subasta pública del pasivo re aprovechable.

- Facultar a la DGAAM para resolver conflictos de mejor derecho para ejecutar cualquiera de las modalidades de remediación voluntaria, en caso este sea alegado por dos o más personas o instituciones.

- Instituir un comité revisor de la normativa vinculada a la gestión de los PAM, en el cual participe el sector privado, a través de representantes de la empresa minera y de la Sociedad Nacional de Minería, Petróleo y Energía, y representantes de la Alta Dirección del MEM y de AMSAC.

Autorizar el uso por parte de AMSAC de las multas administrativas impuestas por OEFA, para las acciones de remediación de PAM.

Ley N$^{\circ}$ 27506, Ley de Canon y Reglamento, aprobado por Decreto Supremo $\mathbf{N}^{\circ}$ 005-2002-EF.

- Facultar la transferencia de recursos del canon minero a AMSAC, para la remediación de los PAM ubicados dentro de las áreas de influencia directa o indirecta de los proyectos mineros.

\section{La Ley No $^{\circ}$ 29325, Ley del Sistema Nacional de Evaluación y Fiscalización}

\section{Ambiental}

- Modificar el artículo $27^{\circ}$ de la Ley No 29325, el cual establece que constituyen recursos del OEFA los montos por concepto de multas que en el ejercicio de sus funciones, imponga dicha autoridad fiscalizadora; estableciendo la obligación de que OEFA destine un porcentaje de los recursos recaudadados por multas a la restauración del medio ambiente. Ello habilitará a que dichos ingresos puedan destinare a AMSAC para la remediación de los PAM. 


\section{REFERENCIAS}

Agencia de Promoción de la Inversión Privada- Perú. (2015). Obras por ImpuestoHistorias emblemáticas de desarrollo y progreso. Lima. ProInversión.

Andaluz Westreicher, C. (2016). Manual de Derecho Ambiental. Editorial Iustitia. (5ta ed). Lima.

Bailetti Frayssinet, G. (2008). Nuevas soluciones a viejos problemas. Análisis sobre la reciente modificación al régimen legal de pasivos ambientales mineros en el Perú. Revista de Derecho Administrativo, (8), 109-118. Recuperado de: http://revistas.pucp.edu.pe/index.php/derechoadministrativo/issue/view/1171

Boza, B. (2006). Canon minero: ¿Caja chica o palanca para el desarrollo? CAD, CIES. (1ra ed). Lima.

Castrilli, J. (2003). Enfoques potenciales de financiamiento para las Minas Huérfanas/Abandonadas en Canadá. Recuperado del sitio de internet de la Iniciativa NAOMI: $\quad$ http://www.abandoned-mines.org/wp/wpcontent/uploads/2015/06/PotentialFundingApproaches2003.pdf

Castrilli, J.F. (2005). Report on the legislative, regulatory and policy framework respecting collaboration, liability and funding measures in relation to orphaned and abandoned, contaminated, and operating mines in Canada. Recuperado del sitio de internet del National Orphaned/Abandoned Mines Initiative: http://www.abandoned-mines.org/publications-e.html

Comisión Europea. (2000) Libro Blanco sobre Responsabilidad Ambiental. Luxemburgo. Comunidades Europeas.

Conflictos sociales: ¿Cuánto pueden llegar a costar por semana a los grandes proyectos mineros? (17 de junio de 2016). Gestión. Recuperado de: 
https://gestion.pe/economia/conflictos-sociales-llegar-costar-semana-grandesproyectos-mineros-146579.

Cowan Minerals Ltd. (2006). Rehabilitating Abandoned Mines in Canada: A Toolkit of Funding Options. Recuperado del sitio de internet del National Orphaned/Abandoned Mines Initiative: http://www.abandoned$\underline{\text { mines.org/pdfs/ToolKitFundingReport.pdf }}$

Crozier, M. (1997). La transición del paradigma burocrático a una cultura de gestión pública. Revista del Centro Latinoamericano de Administración para el DesarrolloReforma y Democracia (7). P 7-18.

De la Vega, B. (2017). Beneficios del mecanismo Obras por Impuesto. Revista Desde Adentro. (166). p 35-37.

Díaz. J, Arana. M, Torres. J, Patrucco. S. (2016). Historia Ambiental del Perú: Siglos XVIII y XIX. Lima. MINAM.

Dineros del canon minero atrajeron la corrupción en las regiones del sur. (20 de abril de 2017). La República. Recuperado de: https://larepublica.pe/politica/867555dineros-del-canon-minero-atrajeron-la-corrupcion-en-las-regiones-del-sur

El basural de plata más codiciado del mundo está en el Perú. (04 de abril de 2016). El Comercio. Recuperado de: https://elcomercio.pe/economia/dia-1/basural-platacodiciado-mundo-peru-181928

Environmental Protection Agency. The Superfund Cleanup Program. Recuperado del sitio de de internet la la https://www.epa.gov/sites/production/files/documents/thesuperfundcleanupprogra $\underline{\text { m.pdf }}$

Herrera. E, Diez Canseco. J, Benites. H, Velásquez J, Rey. R. (2003) Privatización en el Sector Minero Informe Final. Recuperado del sitio de internet del Congreso de la 
República:

http://www4.congreso.gob.pe/historico/ciccor/infofinal/priv_centromin.pdf

Hogan. C, Tremblay. G. (2006). Abandones Mines in Canada. Kentucky. American Society of Mining and Reclamation

Humerto Alva, Alva. C. (2017). Ejecución de obras públicas mediante la modalidad Asociación Público-Privada (APP). Lima. Instituto Pacífico S.A.C.

Korea International Cooperation Agency (KOICA), Mine Reclamation Corporation (MIRECO). (2018). Informe Final de la Consultoría para la Mejora de la Institucionalidad para la Gestión de Pasivos Ambientales Mineros en el Perú. Lima.

Kresalja, Baldo. (2015). ¿Estado o Mercado? El principio de subsidiaridad en la Constitución peruana. Lima. Fondo editorial de la PUCP.

Landa, C. (2007). Principios rectores y derechos fundamentales del administrado en el marco de la Constitución económica de 1993. Revista de Derecho Administrativo. (3ra ed). Lima.

Maraví Sumar. M., Haman Vargas. D., Huapaya Nava. M., Mendoza Alegre. M., Ruiz Sánchez. A. (2012). Aspectos teóricos y prácticos de las asociaciones público privadas en Perú. Lima. ECB Ediciones S.A.C.

Maraví Sumar. M. (2000). La Simplificación Administrativa: Un Asunto Complejo. Themis. (40va ed). Lima. p 289-299.

MEM propondrá leyes que incentiven la remediación de pasivos ambientales por OxI. (29 de mayo de 2018). Gestión. Recuperado de: https://gestion.pe/economia/mempropondra-leyes-incentiven-remediacion-pasivos-ambientales-oxi-234748

Ministerial Council on Mineral and Pertroleum Resources/Minerals Council of Australia (MCMPR/MCA). (2010) Strategic Framework for Managing Abandoned Mines in 
the Minerals. Recuperado del sitio de internet del Departamento de Industria, Innovación $\quad$ y Ciencia del Gobierno Australiano: https://www.archive.industry.gov.au/resource/Mining/Documents/StrategicFrame workforManagingAbandonedMines.pdf

Ministerio de Enería y Minas. (17 de agosto de 2018). Minem impulsará electrificación rural y remediación de pasivos a través de mecanismo Obras por Impuestos. [Nota de prensa]. Recuperado de: https://www.gob.pe/institucion/minem/noticias/18022$\underline{\text { minem-impulsara-electrificacion-rural-y-remediacion-de-pasivos-a-traves-de- }}$ mecanismo-obras-por-impuestos

Oblasser. A. Chaparro. E. (2008). Estudio comparativo de la gestión de los pasivos ambientales mineros en Bolivia, Chile, Perú y Estados Unidos. División de Recursos Naturales e Infraestructura de la Comisión Económica para América Latina y el Caribe. Santiago de Chile. CEPAL.

Obras por Impuestos: Mineras lideran ejecución de proyectos con S/ 1,256 millones. (18 de julio de 2018). Gestión. Recuperado de: https://gestion.pe/economia/obrasimpuestos-mineras-lideran-ejecucion-proyectos-s-1-256-millones-238856

OECD. (2003). From Red Tape to Smart Tape: Administrative Simplification in OECD Countries. Recuperado del sitio de internet de la Organización para la Cooperación y el Desarrollo Económico: https://read.oecd-ilibrary.org/governance/from-redtape-to-smart-tape_9789264100688-en\#page1

Ramseur, J. Reisch, M. Mc Carthy, J. (2008). Superfund Taxes or General Revenues: Future Funding Issues for the Superfund Program. Recuperado del sitio de internet del Congressional Research Service: https://www.everycrsreport.com/files/20080204_RL31410_0836e5a178cb9592e7 b99f37adcfe5600d0b8871.pdf 
Resolución $N^{\circ}$ 13-2014-OEFA/TFA-SEM. (2014). Tribunal de Fiscalización Ambiental. Recuperado del sitio de internet del OEFA: https://www.oefa.gob.pe/tribunal-defiscalizacion-ambiental/resoluciones?node $=436$

Saade. M. (2014). Buenas practices que favorezcan una minería sustentable.. División de Desarrollo Económico de la Comisión Económica para América Latina y el Caribe. Santiago de Chile. CEPAL.

Salas Carreño, G. (2010). La embriaguez del canon minero. La política distrital en San Marcos a doce años de la presencia de Antamina. Revista Anthropologica de la PUCP. (28va ed). Lima.

Salinas Rivas, S. (2015). Obras por Impuesto: Cuellos de Botella y Propuestas de Mejora. Revista de Derecho \& Sociedad, $=(45)$, 273-287. Recuperado de: http://revistas.pucp.edu.pe/index.php/derechoysociedad/article/view/15220/15688

Secretaría de Economía de la Comisión Federal de Mejora Regulatoria (COFEMER). (2017). Informe Anual de Desempeño- COFEMER 2016-2017. Recuperado del sitio de internet de la Comisión Federal de Mejora Regulatoria: http://www.cofemer.gob.mx/docs-bin/dg/Informe_anual_2017.pdf

Servicio Nacional de Certificación Ambiental para las Inversiones Sostenibles. (2018). El ABC del SENACE. Recuperado del sitio de internet del SENACE: http://www.senace.gob.pe/wp-content/uploads/2018/05/ABCdelSenaceespanol.pdf

Sentencia del Expediente $N^{\circ}$ 0008-2003-AL/TC. (2003). Tribunal Constitucional. Recuperado de: http://www.tc.gob.pe/jurisprudencia/2003/00008-2003-AI.html

Sentencia del Expediente $N^{\circ}$ 2071-2002-AA/TC. (2003). Tribunal Constitucional. Recuperado de: http://www.tc.gob.pe/jurisprudencia/2003/02071-2002-AA.html

Sentencia del Pleno Jurisdiccional No 48-2004-PI-TC. (2005). Tribunal Constitucional. Recuperado de: http://tc.gob.pe/jurisprudencia/2005/00048-2004-AI.pdf 
Tenemos bolsa de S/70 millones para remediación ambiental (22 de enero de 2016). El Comercio. Recuperado de: https://elcomercio.pe/economia/dia-1/bolsa-s-70millones-remediacion-ambiental-275282

Unión de Gestión del País-Perú del Banco Mundial. (2005). Riqueza y Sostenibilidad: Dimensiones Sociales y Ambientales de la Minería en el Perú. Recuperado del sitio de internet del Banco Mundial:http://documentos.bancomundial.org/curated/es/410671468079729976/R esumen-ejecutivo

Unger. C, Lechner. A, Glenn. V, Edraki. M. and Mulligan, D. (2011). Mapping and prioritising rehabilitation of abandoned mines in Australia. Life of Mine Conference (AusIMM), Brisbane, Australia, 10-12 July 2012. Carlton North, VIC, Australia: The Australasian Institute of Mining and Metallurgy (AusIMM).

Unger, C. Van Krieken. A. (2011). Abandoned Mine Management in Australia. Australia. Australia. Recuperado del sitio de internet del AusIMM: https://ausimm.com/

Zegarra, JC. (2009). En O. Comité de Asuntos Tributarios. Cuadernos de Trabajo: IX Simposium de Tributación Mineroenergética (1ra ed). (p 15-19). Lima. Sociedad Nacional de Minería, Petróleo y Energía. 